\title{
Emerging Issues and Challenges in Integrating Solar with the Distribution System
}

May 2016

NREL/TP-5D00-65331

SAND2016-2524 R 


\section{On the Path to SunShot: Emerging Issues and Challenges in Integrating Solar with the Distribution System}

Bryan Palmintier ${ }^{1}$, Robert Broderick ${ }^{2}$, Barry Mather ${ }^{1}$, Michael Coddington ${ }^{1}$, Kyri Baker $^{1}$, Fei Ding ${ }^{1}$, Matthew Reno², Matthew Lave², and Ashwini Bharatkumar ${ }^{3}$

${ }^{1}$ National Renewable Energy Laboratory

2 Sandia National Laboratories

${ }^{3}$ Massachusetts Institute of Technology

NREL is a national laboratory of the U.S. Department of Energy, Office of Energy Efficiency and Renewable Energy, operated by the Alliance for Sustainable Energy, LLC.

Sandia National Laboratories is a multi-program laboratory managed and operated by Sandia Corporation, a wholly owned subsidiary of Lockheed Martin Corporation, for the U.S. Department of Energy's National Nuclear Security Administration under contract DE-AC04-94AL85000. 


\title{
NOTICE
}

This report was prepared as an account of work sponsored by an agency of the United States government. Neither the United States government nor any agency thereof, nor any of their employees, makes any warranty, express or implied, or assumes any legal liability or responsibility for the accuracy, completeness, or usefulness of any information, apparatus, product, or process disclosed, or represents that its use would not infringe privately owned rights. Reference herein to any specific commercial product, process, or service by trade name, trademark, manufacturer, or otherwise does not necessarily constitute or imply its endorsement, recommendation, or favoring by the United States government or any agency thereof. The views and opinions of authors expressed herein do not necessarily state or reflect those of the United States government or any agency thereof.

This report is available at no cost from the National Renewable Energy Laboratory (NREL) at www.nrel.gov/publications.

Available electronically at SciTech Connect http:/www.osti.gov/scitech Available for a processing fee to U.S. Department of Energy and its contractors, in paper, from:

\section{U.S. Department of Energy}

Office of Scientific and Technical Information

P.O. Box 62

Oak Ridge, TN 37831-0062

OSTI http://www.osti.gov

Phone: 865.576 .8401

Fax: 865.576.5728

Email: reports@osti.gov

Available for sale to the public, in paper, from:

\author{
U.S. Department of Commerce \\ National Technical Information Service \\ 5301 Shawnee Road \\ Alexandria, VA 22312 \\ NTIS http://www.ntis.gov \\ Phone: 800.553 .6847 or 703.605 .6000 \\ Fax: 703.605 .6900 \\ Email: orders@ntis.gov
}




\section{Preface}

The U.S. Department of Energy launched the SunShot Initiative in 2011 with the goal of making solar electricity cost-competitive with conventionally generated electricity by 2020 . At the time this meant reducing photovoltaic and concentrating solar power prices by approximately $75 \%$ relative to 2010 costs - across the residential, commercial, and utility-scale sectors. To examine the implications of this ambitious goal, the Department of Energy's Solar Energy Technologies Office (SETO) published the SunShot Vision Study in 2012. The study projected that achieving the SunShot price-reduction targets could result in solar meeting roughly $14 \%$ of U.S. electricity demand by 2030 and $27 \%$ by 2050 - while reducing fossil fuel use, cutting emissions of greenhouse gases and other pollutants, creating solar-related jobs, and lowering consumer electricity bills.

The SunShot Vision Study also acknowledged, however, that realizing the solar price and deployment targets would face a number of challenges. Both evolutionary and revolutionary technological changes would be required to hit the cost targets, as well as the capacity to manufacture these improved technologies at scale in the U.S. Additionally, operating the U.S. transmission and distribution grids with increasing quantities of solar energy would require advances in grid-integration technologies and techniques. Serious consideration would also have to be given to solar siting, regulation, and water use. Finally, substantial new financial resources and strategies would need to be directed toward solar deployment of this magnitude in a relatively short period of time. Still the study suggested that the resources required to overcome these challenges were well within the capabilities of the public and private sectors. SunShot-level price reductions, the study concluded, could accelerate the evolution toward a cleaner, more costeffective and more secure U.S. energy system.

That was the assessment in 2012. Today, at the halfway mark to the SunShot Initiative's 2020 target date, it is a good time to take stock: How much progress has been made? What have we learned? What barriers and opportunities must still be addressed to ensure that solar technologies achieve cost parity in 2020 and realize their full potential in the decades beyond?

To answer these questions, SETO launched the On the Path to SunShot series in early 2015 in collaboration with the National Renewable Energy Laboratory (NREL) and with contributions from Lawrence Berkeley National Laboratory (LBNL), Sandia National Laboratories (SNL), and Argonne National Laboratory (ANL). The series of technical reports focuses on the areas of grid integration, technology improvements, finance and policy evolution, and environment impacts and benefits. The resulting reports examine key topics that must be addressed to achieve the SunShot Initiative's price-reduction and deployment goals. The On the Path to SunShot series includes the following reports:

- Emerging Issues and Challenges with Integrating High Levels of Solar into the Electrical Generation and Transmission Systems (Denholm et al. 2016)

- Emerging Issues and Challenges with Integrating High Levels of Solar into the Distribution System (Palmintier, Broderick, et al. 2016)

- Emerging Opportunities and Challenges in Financing Solar (Feldman and Bolinger 2016) 
- Utility Regulatory and Business Model Reforms for Addressing the Financial Impacts of Distributed Solar on Utilities (Barbose et al. 2016)

- The Role of Advancements in Photovoltaic Efficiency, Reliability, and Costs (Woodhouse et al. 2016)

- Advancing Concentrating Solar Power Technology, Performance, and Dispatchability (Mehos et al. 2016)

- Emerging Opportunities and Challenges in U.S. Solar Manufacturing (Chung et al. 2016)

- The Environmental and Public Health Benefits of Achieving High Penetrations of Solar Energy in the United States (Wiser et al. 2016).

Solar technology, solar markets, and the solar industry have changed dramatically over the past five years. Cumulative U.S. solar deployment has increased more than tenfold, while solar's levelized cost of energy (LCOE) has dropped by as much as $65 \%$. New challenges and opportunities have emerged as solar has become much more affordable, and we have learned much as solar technologies have been deployed at increasing scale both in the U.S. and abroad. The reports included in this series, explore the remaining challenges to realizing widely available, cost-competitive solar in the United States. In conjunction with key stakeholders, SETO will use the results from the On the Path to SunShot series to aid the development of its solar price reduction and deployment strategies for the second half of the SunShot period and beyond. 


\section{Acknowledgments}

The authors thank the Solar Energy Technologies Office team for its support of this report and Robert Margolis of NREL for his management and oversight of the On the Path to SunShot report series. We are deeply indebted to Bruce Bugbee (NREL) for his expert assistance with statistical analysis. We also appreciate the knowledgeable input and helpful feedback provided by the following reviewers, which greatly improved this report: Frances Bell (SolarCity), Duncan Calloway (University of California at Berkeley), Kemal Celik (DOE), Ken Fong (Hawaiian Electric Companies), Bri-Mathias Hodge (NREL), Ben Kroposki (NREL), Rohan Ma (SolarCity), Tom McDermott (University of Pittsburgh), Dave Mooney (NREL), Robin Newmark (NREL), Jeff Smith (Electric Power Research Institute), David Sun (Alstom Grid, now GE Grid Solutions), Mary Werner (NREL), Brian Warshay (SolarCity), and Guohui Yuan (DOE). The authors also thank Jarrett Zuboy (consultant), Katie Wensuc (NREL), and Mike Meshek (NREL) for editorial assistance.

This work was funded by the Solar Energy Technologies Office of the U.S. Department of Energy (DOE) Office of Energy Efficiency and Renewable Energy (EERE). The contributions of the National Renewable Energy Laboratory (NREL) to this report were funded by the Solar Energy Technologies Office under Contract No. DE-AC36-08GO28308. The contributions of Sandia National Laboratories to the report were funded by the Solar Energy Technologies Office under Contract No. DE-AC04-94AL85000.

John Frenzl of NREL designed the covers for the On the Path to SunShot report series. 


\section{List of Acronyms}

$\begin{array}{ll}\text { AACEE } & \text { absolute area control error in energy } \\ \text { ACE } & \text { area control error } \\ \text { CES } & \text { community energy storage } \\ \text { DER } & \text { distributed energy resource } \\ \text { DERMS } & \text { distributed energy resource management system(s) } \\ \text { DGPV } & \text { distributed generation from photovoltaics } \\ \text { DMS } & \text { distribution management system(s) } \\ \text { DOE } & \text { U.S. Department of Energy } \\ \text { DPV } & \text { Distributed Photovoltaic (software analysis tool) } \\ \text { DRP } & \text { distribution resources plan } \\ \text { EPRI } & \text { Electric Power Research Institute } \\ \text { EV } & \text { electric vehicle } \\ \text { G2V } & \text { grid-to-vehicle } \\ \text { GTM } & \text { Greentech Media } \\ \text { IEEE } & \text { Institute of Electrical and Electronics Engineers } \\ \text { IGMS } & \text { Integrated Grid Modeling System } \\ \text { LMP+D } & \text { locational marginal price plus value of distributed resources } \\ \text { NEM } & \text { net energy metering } \\ \text { NREL } & \text { National Renewable Energy Laboratory } \\ \text { PG\&E } & \text { Pacific Gas \& Electric } \\ \text { PV } & \text { photovoltaic(s) } \\ \text { QSTS } & \text { quasi-static time series } \\ \text { SGIP } & \text { Small Generator Interconnection Procedure } \\ \text { VAR } & \text { volt-ampere reactive } \\ \text { X/R } & \text { ratio between reactance and resistance } \\ & \end{array}$




\section{Executive Summary}

From 2010 through the first half of 2015, the installed capacity of solar photovoltaics (PV) connected to the U.S. distribution system ${ }^{1}$ increased sixfold, from approximately $1.8 \mathrm{GW}$ to more than $11 \mathrm{GW}$. This accounts for over half of the approximate total U.S. solar installations of $20 \mathrm{GW}$. Distributed generation from PV (DGPV) is expected to comprise $50 \%-60 \%$ of total U.S. PV capacity through at least 2020. The rapid deployment of high penetrations of DGPV into the distribution system has both highlighted challenges and demonstrated many successful examples of integrating higher penetration levels than previously thought possible. In this report, we analyze challenges, solutions, and research needs in the context of DGPV deployment to date and the much higher levels of integration that are expected with the achievement of the U.S. Department of Energy's SunShot targets.

DGPV's unique characteristics present challenges and opportunities. The electrical output from DGPV is variable over short timescales (seconds to minutes) because of passing clouds, and it is variable over longer timescales (hours) because of the diurnal (night and day) nature of the sun. On one hand, this variability produces important and potentially challenging interactions with the distribution system — particularly with larger DGPV systems and higher penetrations - including managing the distribution voltage, potentially increasing wear and tear on electromechanical utility equipment, and complicating the configuration of circuit breakers and other protection systems. On the other hand, DGPV can provide benefits such as deferring system upgrades, managing voltage using advanced inverters (with or without batteries), and reducing distribution losses. DGPV systems in the United States have become increasingly diverse during the past 5 years, and they include small residential systems as well as multi-megawatt systems owned by utilities or third parties. During the next decade, it is likely that further diversification will boost community DGPV deployment, enhance grid resiliency via storage or microgrids, and increase utility ownership of DGPV located in residential, commercial, and community sites.

Achieving the levels of DGPV deployment envisioned by SunShot requires a much clearer and more accurate understanding of the technical limits of DGPV penetration on distribution feeders. Previous estimates of DGPV hosting capacities centered on the common interconnection rule-ofthumb assumption that DGPV penetrations higher than $15 \%$ require detailed impact studies; however, many engineering analyses have indicated that this assumption is often inaccurate. Recent analyses have greatly improved the accuracy of these estimates for individual distribution feeders, including the increased capacity limits enabled by emerging technologies - such as advanced inverters and storage - and modified operational strategies (Figure ES-1). ${ }^{2}$ However, these efforts also highlight the large diversity within the distribution system. Order of magnitude differences in DGPV hosting capacity are common within a feeder and across populations of feeders in a utility service area. This suggests that the path beyond traditional rules-of-thumb will

\footnotetext{
${ }^{1}$ Unless otherwise noted, installed distributed PV are estimated to include rooftop PV and ground-mounted systems $5 \mathrm{MW}$ and smaller.

${ }^{2}$ Hosting capacity estimates refer to the amount of DGPV that can be interconnected without changing the existing infrastructure or prematurely wearing out equipment. Up to this level, DGPV can be interconnected easily and could be subject to accelerated approval. It is feasible — and often practical and inexpensive - to install DGPV above this limit by allowing small changes in system operations, adjusting controller set points, or upgrading or installing additional equipment. The changes necessary to exceed the current hosting capacity require more extensive analysis.
} 
require some form of location-specific analysis. For example, precomputed hosting capacities are beginning to be used, often on a trial basis, in California, Hawaii, and other regions to expedite DGPV interconnection requests and installations. Additional research and development are needed to streamline these computations; accelerate their adoption by utilities; and especially account for emerging technologies including advanced inverter functions, storage, and other distributed energy resources (DERs).

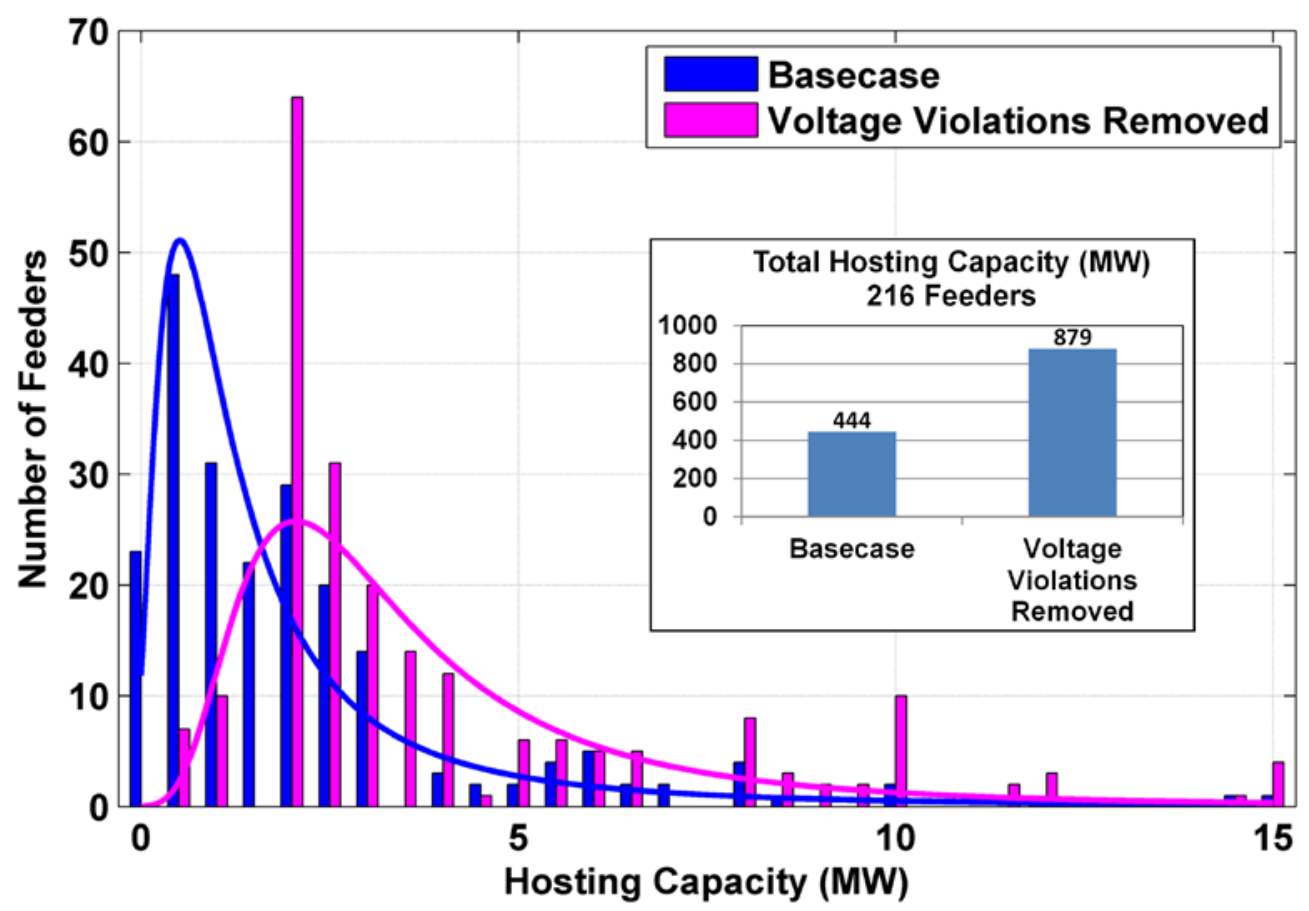

Figure ES-1. Hosting capacity increase for $\mathbf{2 1 6}$ feeders assuming that all voltage violations are mitigated by advanced inverter functions

Image from Reno and Broderick 2016

We build on recent work on local hosting capacity to statically estimate the minimum DGPV hosting capacity for the contiguous United States. Even with traditional inverters we estimate that distribution system can support about $170 \mathrm{GW}$ of $\mathrm{DGPV}^{3}$ without any new hardware and with no changes in operations. However, this assumes that DGPV is located according to feederlevel hosting capacity, which would likely require revised interconnection processes and new incentives or other policies to encourage such integration patterns. As seen Figure ES-1, if advanced inverter functions can successfully manage voltage challenges, the hosting capacity can be roughly doubled, increasing the distribution-level nationwide hosting capacity to approximately $350 \mathrm{GW}$. The distribution hosting capacity could be further increased at relatively low cost by carefully siting DGPV systems within distribution feeders; making minor changes to distribution operations; coordinating DGPV operations through distribution management systems (DMSs) or distributed control approaches; and/or through cooperation with other DERs.

${ }^{3} 170 \mathrm{GW}$ is a median estimate of minimum hosting capacity; the $90 \%$ credible range is $98-430 \mathrm{GW}$ 
Although these technical estimates do not consider resource availability, economic viability, or transmission-level constraints; they do suggest that the distribution system could continue to support a majority of PV integration in 2050 under all of the NREL Standard Scenarios (Sullivan et al. 2015) which range from 142-559 GW of total solar capacity.

A critical step toward integrating 100's of GW of DGPV is further improving the DGPV interconnection processes, associated standards and codes, and compensation mechanisms so that they embrace the contributions of DGPV to system-wide operations. When the SunShot Initiative commenced in 2011, utility interconnection requirements were largely based on outdated practices from the early 2000s. DGPV was expected to trip off-line during minor grid disturbances, and it was barred from contributing to voltage and frequency support. Today, changes are underway to revise these practices, including new support methods for voltage and frequency disturbance ride-through and active voltage control. Yet considerable effort is still required to fully develop and implement revised technical standards and codes (particularly for advanced inverters), establish effective tariffs, and implement proper utility systems integrations of DGPV.

Until recently, utilities and PV stakeholders have focused only on the deployment and integration of DGPV. Looking forward, DGPV will be increasingly integrated with energy storage and other complementary technologies. Together these technologies can provide a wide range of value streams, including reducing customer peak charges, improving reliability, and increasing power system resiliency. In addition to electric storage, complementary "virtual storage" can aid in managing household and building energy loads, using thermal and other indirect energy storage, and supporting electric vehicle charging methods to enable greater levels of DGPV (McGranaghan et al. 2008). Thus, there is a near-term need to expand and improve existing DGPV-focused tools and analyses to include storage and to develop approaches for siting, sizing, and controlling storage in conjunction with DGPV. In the future, DGPV could form the foundation of an integrated suite of distributed energy resources that interact to improve overall grid operations. This will include tightly controlled resources incorporated into microgrids as well as loosely controlled federations of resources acting alone, through energy management systems, or under aggregator control. Further research is needed on advanced interconnection methodologies, distribution modeling, cost-effective strategies to mitigate impacts, designing and operating distribution systems, and using advanced technologies such as smart inverters.

The past 5 years of DGPV deployment have demonstrated that adopting hundreds of gigawatts of DGPV will require unprecedented coordination of the historically separate distribution and transmission systems. Considerable analyses will be necessary even for established distributiontransmission system concepts such as DGPV's ability to relieve congestion and reduce system losses by generating closer to loads. In addition, several more direct techno-economic interactions will become increasingly critical, including (1) minimizing system operating costs and reserve deployments via increased DGPV visibility; (2) providing frequency response, transient stability, and synthesized inertia from DGPV in the event of large-scale system disturbances; (3) developing communications and control architectures that incorporate DGPV into system-wide operations; and (4) potentially increasing reactive power requirements due to the large-scale deployment of advanced inverter functions, which can also benefit the transmission system by providing voltage regulation (Figure ES-2). Moving toward a fully integrated distribution-transmission system that supports the SunShot targets of DGPV 
deployment will require significantly improved analysis tools, technologies (such as advanced inverters), and operating strategies.

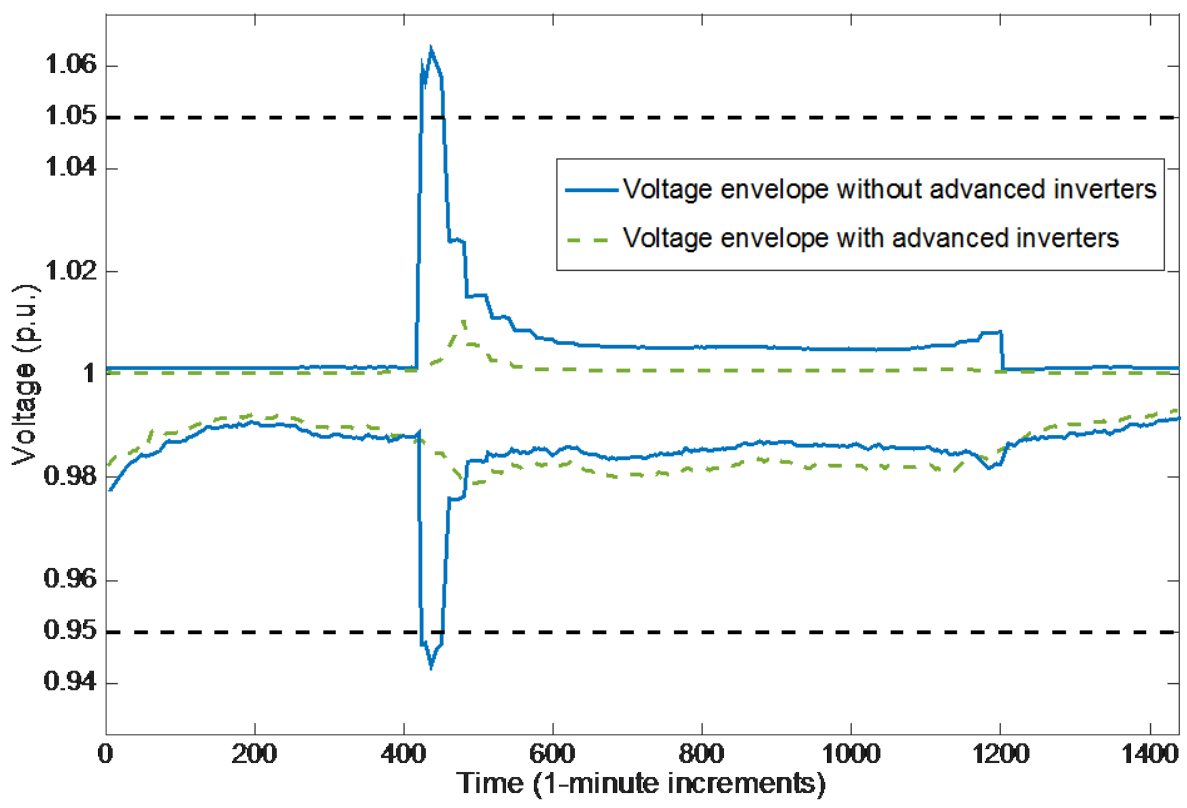

Figure ES-2. Transmission-level bus voltage magnitudes with and without advanced inverter functionality

Image from Palmintier, Hale, et al. 2016 


\section{Table of Contents}

Executive Summary ................................................................................................ viii

1 The Changing Distributed Solar Landscape .................................................. 1

1.1 Most Solar Is Connected to the Distribution System …………........................................... 1

1.2 System Sizes Are Increasing ………………………………………………………....

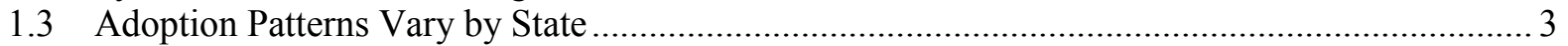

1.4 Ownership Models Are Being Diversified............................................................................. 3

1.5 Interest in Complementary Technologies Is Increasing ............................................................ 5

1.6 Research Needs on the Distributed Solar Landscape ............................................................. 5

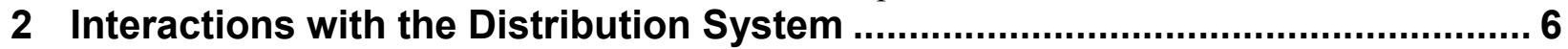

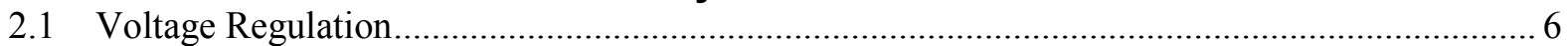

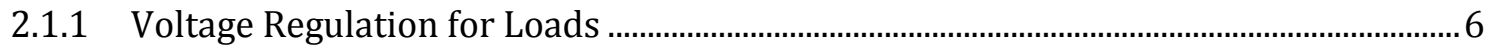

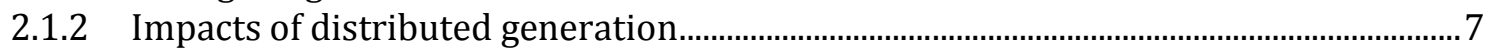

2.1.3 Advanced Inverters for Voltage Support..................................................................................

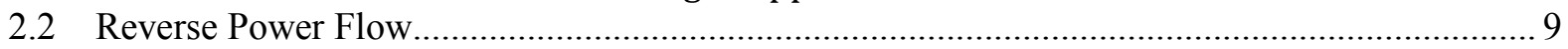

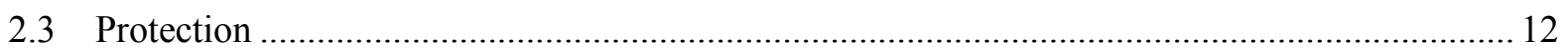

2.4 Equipment Wear and Tear........................................................................................ 13

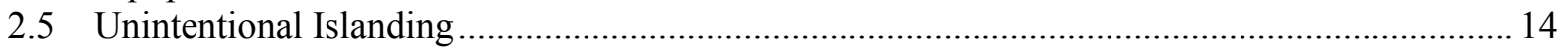

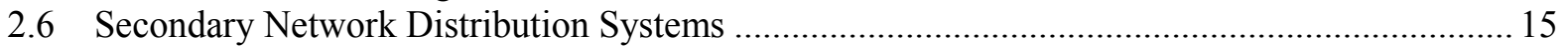

2.7 Cloud-Driven Photovoltaic Variability ............................................................................ 15

2.8 Challenges to System Reconfiguration …………………................................................... 17

2.9 Promises of Improved Distribution Planning ......................................................................... 17

2.10 Research Needs on Solar-Distribution Interactions …………….......................................... 17

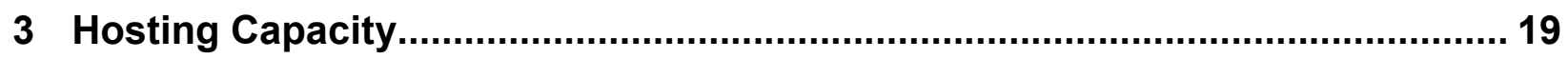

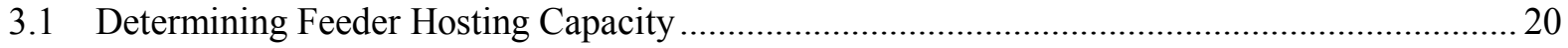

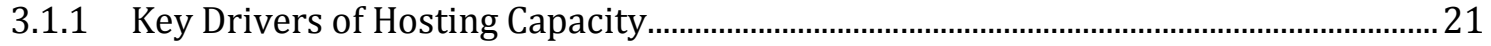

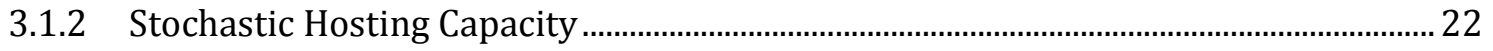

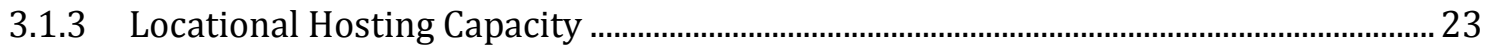

3.1.4 Other Hosting Capacity Methods …………………………………………………………....25

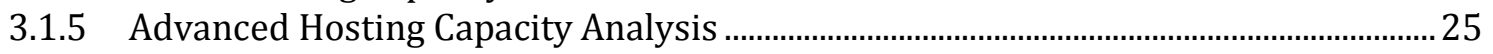

3.2 Opportunities for Increasing Hosting Capacity …………....................................................2 26

3.2.1 Carefully Siting Distributed Generation from Photovoltaics...........................................2 27

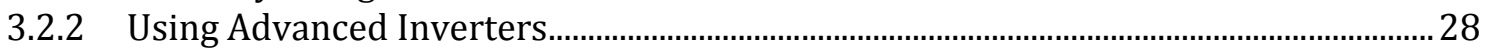

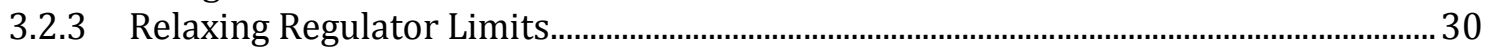

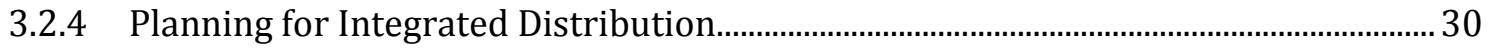

3.3 Prior Utility-Wide Hosting Capacity Studies ............................................................................ 31

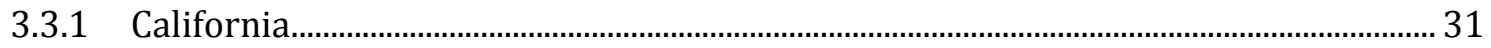

3.3.2 Tennessee Valley Authority/Electric Power Research Institute ......................................32

3.4 Statistical Estimates of Nationwide Hosting Capacity ……………………………………….......... 33

3.5 Research Needs on Distribution Hosting Capacity .................................................................... 34

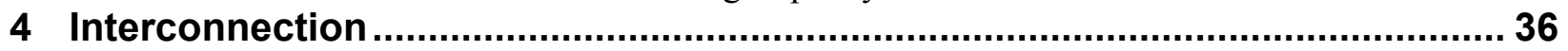

4.1 The Interconnection Process …………………………….................................................... 36

4.2 Key Codes and Standards................................................................................................... 38

4.2.1 Institute of Electrical and Electronics Engineers Standard 1547.................................. 39

4.2.2 Underwriters Laboratories Standard 1741 ................................................................... 40

4.2.3 American National Standards Institute Standard C84.1-2011 ........................................ 40

4.2.4 National Electrical Code/National Fire Protection Association Standard 70 .............40

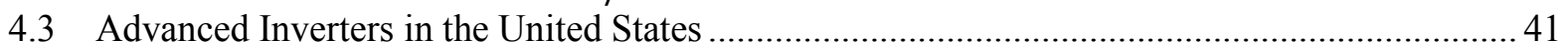

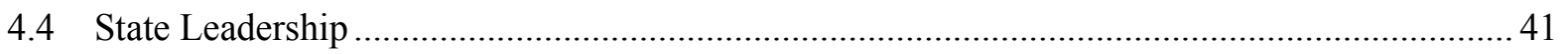




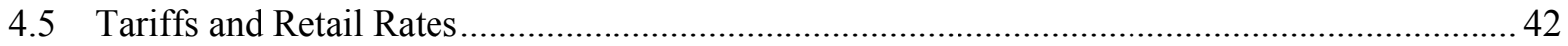

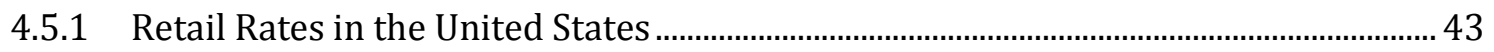

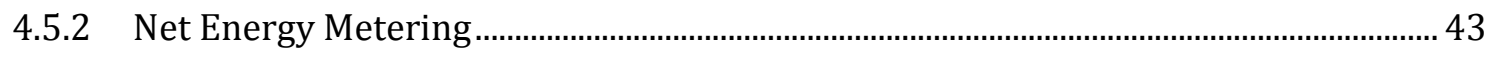

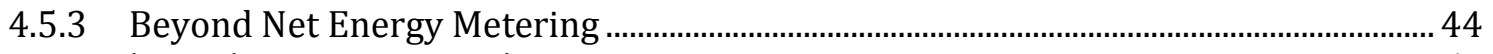

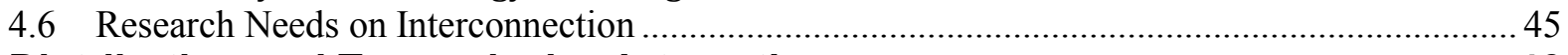

5 Distribution and Transmission Interactions ............................................... 46

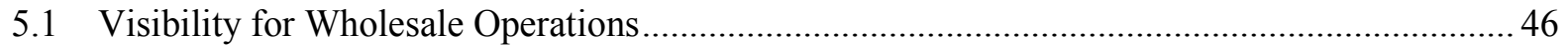

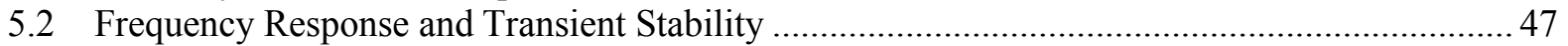

5.3 Reactive Power and Voltage Control with Advanced Inverters................................................ 49

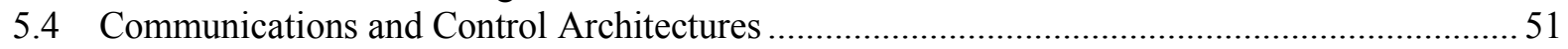

5.5 Research Needs on Transmission-Distribution Interactions …................................................ 52

6 Storage and Complementary Technologies .............................................. 53

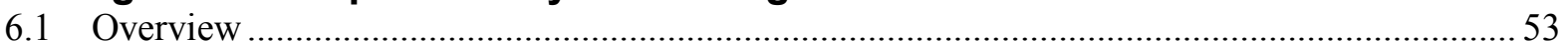

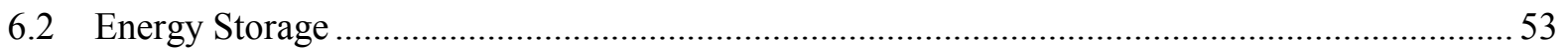

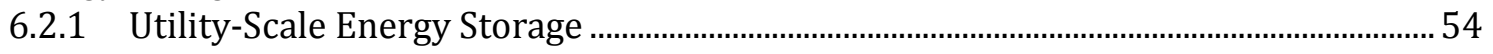

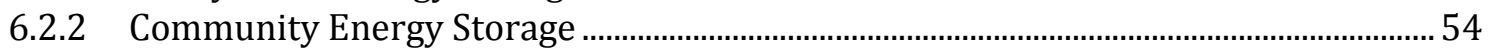

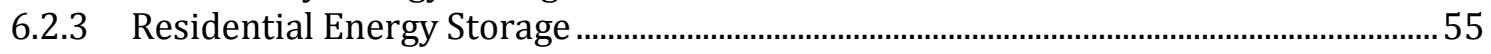

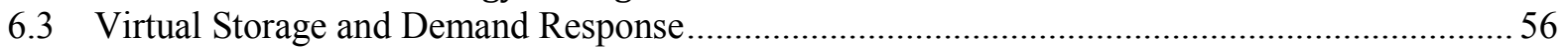

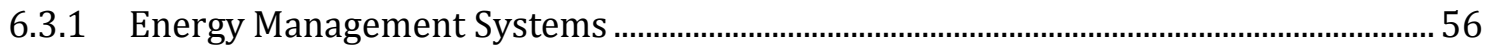

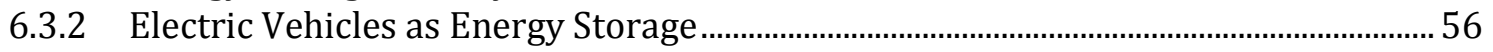

6.4 Feeder Hosting Capacity with Energy Storage ................................................................. 57

6.5 Research Needs on Complementary Technologies …......................................................... 57

7 Conclusions and Research Priorities ......................................................... 58

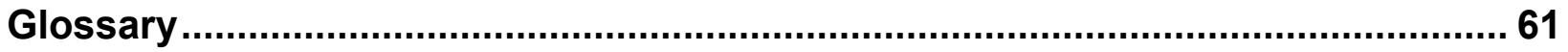

References ..................................................................................................... 64

Appendix A: Additional Literature Review ................................................... 78

Appendix B: Additional Details on Statistical Estimates for Nationwide Hosting

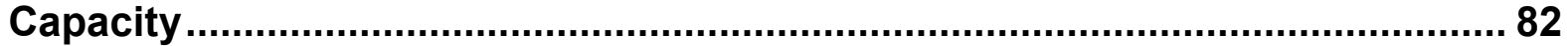




\section{List of Figures}

Figure ES-1. Hosting capacity increase for 216 feeders assuming that all voltage violations are mitigated by advanced inverter functions viii

Figure ES-2. Transmission-level bus voltage magnitudes with and without advanced inverter functionality $\mathrm{x}$

Figure 1. U.S. PV adoption by sector from 2008-2014 with projection to 2020 including the December

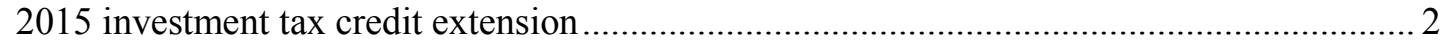

Figure 2. Median PV system capacity over time ..................................................................... 3

Figure 3. Residential, third-party PV penetrations and installations by ownership type .......................... 4

Figure 4. Representative voltage drop across a distribution feeder as a function of the distance from the

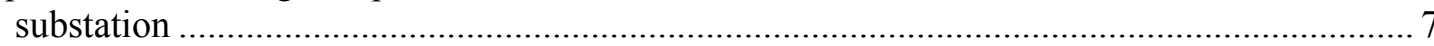

Figure 5. Simplified voltage impacts of DGPV and mitigation using a voltage regulator ......................... 8

Figure 6. Simplified depiction of the ability of advanced inverters to absorb reactive power and help mitigate challenges to voltage rise on the feeder .............................................................. 9

Figure 7. The voltage and reactive power flow at the point of interconnection from a 5-MW PV system before and during the fixed power factor PV mitigation field demonstration ....................... 11

Figure 8. Example of relay desensitization due to DGPV integration .................................................. 12

Figure 9. Example of impacts on fault current observed by equipment due to DGPV ........................... 13

Figure 10. Power through voltage regulator (top), voltage regulator tap position (middle), and cumulative number of tap changes (bottom) for a test feeder with no PV (black) or with $3 \mathrm{MW}$ of PV based on solar variability in Oahu, Hawaii (red) ................................................................. 14

Figure 11. Average weekly tap-change operations and solar variability (based on simulations throughout 1 year) for 10 locational samples plus a base case with no PV ............................................ 14

Figure 12. Zones showing areas of low and high solar variability .................................................... 16

Figure 13. Comparison of the relative variability of a single house with $4 \mathrm{~kW}$ of PV (red) and the sum of 467 houses spread throughout $0.4 \mathrm{~km}^{2}$ totaling $1.82 \mathrm{MW}$ of PV (black) as recorded on July

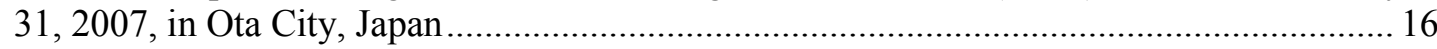

Figure 14. Stochastic scenario results for hosting capacity for overvoltage on a single feeder showing the

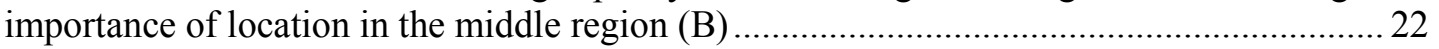

Figure 15. Locational PV hosting capacity for each bus and type of violation that limited the locational PV hosting capacity for the $12.47-\mathrm{kV}$ publicly available distribution system EPRI Circuit

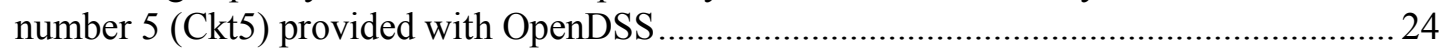

Figure 16. PV hosting capacity of three test feeders with various voltage control modes ........................ 28 Figure 17. Hosting capacity increase for 216 feeders assuming that all voltage violations are mitigated by

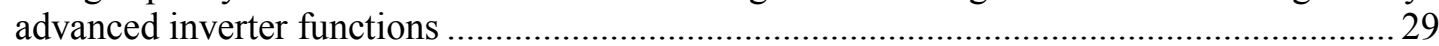

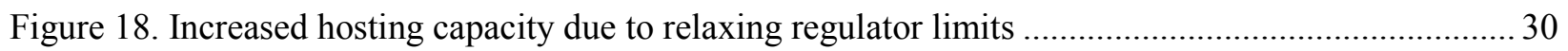

Figure 19. Steps for integrated distribution planning................................................................... 31

Figure 20. Study from EPRI and the Tennessee Valley Authority on hosting capacity at the substation

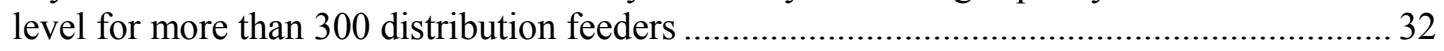

Figure 21. DGPV hosting capacity limiting element for PG\&E's service territory ................................ 33

Figure 22. General interconnection process used by U.S. utilities ...................................................... 36

Figure 23. Example of the SGIP fast-track screening process often employed by U.S. utilities ................ 37

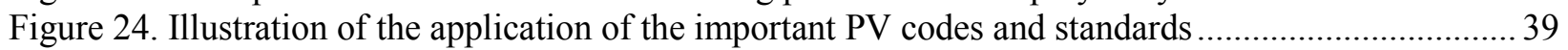

Figure 25. Distributed generation trip resulting in a less severe frequency nadir..................................... 48

Figure 26. Histograms of transmission load bus reactive power demand (positive) and supply with and without advanced inverter volt/VAR functionality ............................................................ 50

Figure 27. Transmission-level bus voltage magnitudes with and without advanced inverter functionality 51

Figure 28. Estimate of PG\&E utility-wide DGPV hosting capacity as a function of line section derating showing that feeder-level hosting capacity limits dominate until the sum of line section hosting capacities are derated more than $60 \%$ 
Figure 29. Histogram describing the distribution of aggregated hosting capacity estimates scaled to a national level.

\section{List of Tables}

Table 1. Major Utility Concerns Related to DGPV 6 Table 2. Comparison Among Levels of DGPV Visibility/Forecast for a Test System Loosely Based on the Sacramento Municipal Utility District..... 


\section{The Changing Distributed Solar Landscape}

Most photovoltaics (PV) in the United States are connected to the distribution system, and this trend is expected to continue. However, during the past 5 years, system sizes, configurations, and ownership models have considerably diversified. Previously, distributed generation from photovoltaics (DGPV) primarily included smaller residential rooftop systems. Today, the DGPV market has expanded to include utility-scale solar (1-10+ MW capacity), utility-owned plants, and widespread third-party ownership. During the next decade, this diversification is poised to continue: there is growing interest in shared solar ownership by community members; utility ownership of residential, commercial, and community solar; and in using solar as a part of multitechnology solutions to enhance power system resiliency by coupling solar with storage or using it in more diverse microgrids.

\subsection{Most Solar Is Connected to the Distribution System}

From 2010 through the first half of 2015, the installed capacity of solar photovoltaics (PV) connected to the U.S. distribution system ${ }^{4}$ increased sixfold, from approximately $1.8 \mathrm{GW}^{5}$ (Darghouth and Wiser 2011) to more than $11 \mathrm{GW}^{6}$ (Barbose and Darghouth 2015; GTM Research and SEIA 2015). Despite strong growth in large, transmission-connected PV systems, at the end of 2014 DGPV represented over half (at least $61 \%^{7}$ ) of the total PV capacity. Distributed generation from PV (DGPV) is expected to comprise $50 \%-60 \%$ of total U.S. PV capacity through at least $2020 .{ }^{8}$ Concentrating solar power is all but nonexistent at the distribution level. Figure 1 shows a representation of these trends, which reflect the recent extension of the federal investment tax credit. As shown, utility solar includes both transmissionconnected PV and DGPV sold directly to the utility. We estimate that in 2014 at least $25 \%$ of utility solar in these data was connected at the distribution level. ${ }^{9}$ The 2016 spike is due to a rush

\footnotetext{
${ }^{4}$ Unless otherwise noted, installed distributed PV includes rooftop PV and ground-mounted systems $5 \mathrm{MW}$ and smaller.

${ }^{5}$ DGPV in 2010 included all behind-the-meter solar and "utility" solar that was 5MW and smaller (Darghouth and Wiser 2011). These numbers were not reported directly; instead, they were scaled up from the reduced sample sizes based on reported percent coverage. Specifically, (Darghouth and Wiser 2011) included 79\% of 1,400 MW of behind-the-meter PV and $76 \%$ of $285 \mathrm{MW}$ of total utility PV, of which $11 \%$ was $5 \mathrm{MW}$ and smaller. This gives $1,400 / 79 \%+11 \% * 285 / 76 \%=1,800 \mathrm{MW}$.

${ }^{6} 11 \mathrm{GW}$ includes $9,800 \mathrm{MW}$ of DGPV by the end 2014 plus more than 1,300 MW of additional DGPV that was added during the first half of 2015 (GTM Research and SEIA 2015). The 9,800MW end of 2014 estimate was taken as the sum of the total residential and nonresidential PV from (Barbose and Darghouth 2015). These numbers were not reported directly; instead, they were scaled up from the reduced sample sizes based on the reported percent coverage. Specifically, the sample in (Barbose and Darghouth 2015) included $81 \%$ of $6,100 \mathrm{MW}$ installed through 2013 and $62 \%$ of $1,500 \mathrm{MW}$ added in 2014 , which yields $6,100 / 81 \%+1,500 / 62 \%=9,800 \mathrm{MW}$.

${ }^{7}$ This is based on 6,200 MW of ground-mounted PV that is larger than $5 \mathrm{MW}$ taken as non-distributed as reported in (Bolinger and Seel 2015), compared to an estimated 9,800 MW of DGPV as computed above.

${ }^{8}$ The 2020 estimates begin by assuming all residential and non-residential PV is distribution connected (accounting for $48 \%$ of projected cumulative installations) and then adjusting based on 2014 estimates of greater than $25 \%$ of utility solar as distribution connected (described below). This gives an estimate of $61 \%$ of PV at the distribution level in 2020.

${ }^{9}$ The 2014 distribution-connected solar is based on 9,800 MW distributed and 6,200 MW non-distributed described above (16,000 MW total), scaled to the GTM 2014 statistics of 18,400 MW to give 7,130 MW scaled nondistributed by our definition. Of this total, $9,750 \mathrm{MW}$ are defined as utility by GTM, giving 7,130/9,750 $=73 \%$ of
} 
of installations before the investment tax credit was set to expire. It has since been extended, and many planned projects are expected to continue; this resulted in higher expected installations for 2016 followed by fewer installations through 2018. This rapid increase in DGPV has simultaneously highlighted challenges and demonstrated many successful examples of integrating higher penetration levels than previously thought possible.

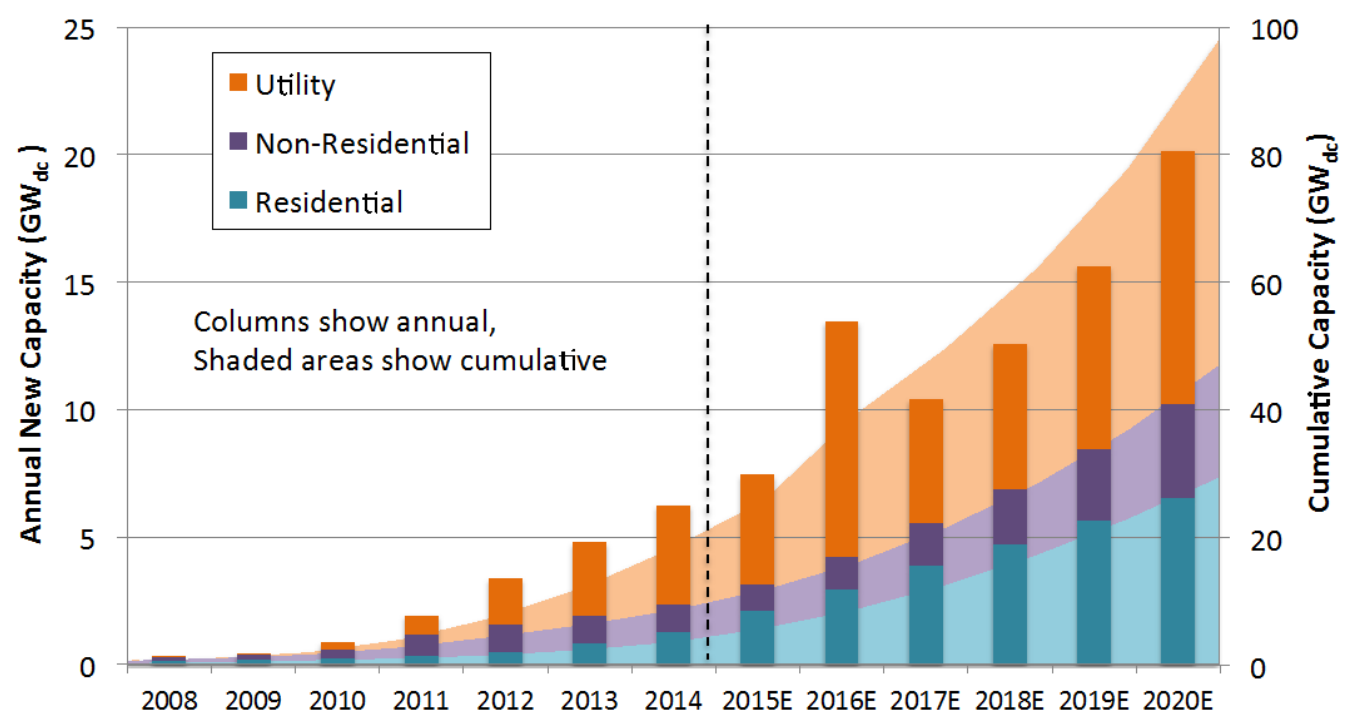

Figure 1. U.S. PV adoption by sector from 2008-2014 with projection to 2020 including the December 2015 investment tax credit extension

Data from the following sources: 2010-2020 additions based on GTM Research data with projections for Omnibus extensions as of 12/16/2015; pre-2010 data adapted from Barbose, Weaver, and Darghouth (2014); Look and feel inspired by Bolinger and Seel (2015).

The GTM data use a different definition for utility solar. An estimated $25+\%$ of utility solar in this figure is $\leq 5 \mathrm{MW}$, and hence it is likely that it would be connected at the distribution level along with all of the residential and non-residential systems.

\subsection{System Sizes Are Increasing}

Today, the PV market is divided nearly equally into utility-scale PV, which includes both distribution- and transmission-connected systems, and small-scale DGPV. As shown in Figure 2, the median capacity of residential and larger nonresidential DGPV systems has grown significantly since 2000 (Barbose and Darghouth 2015).

utility solar by GTM's definition as larger than $5 \mathrm{MW}$ ground-mounted solar leaving $(9,750-7,130) / 9,750=27 \%$ of utility solar defined as distributed in this report. 

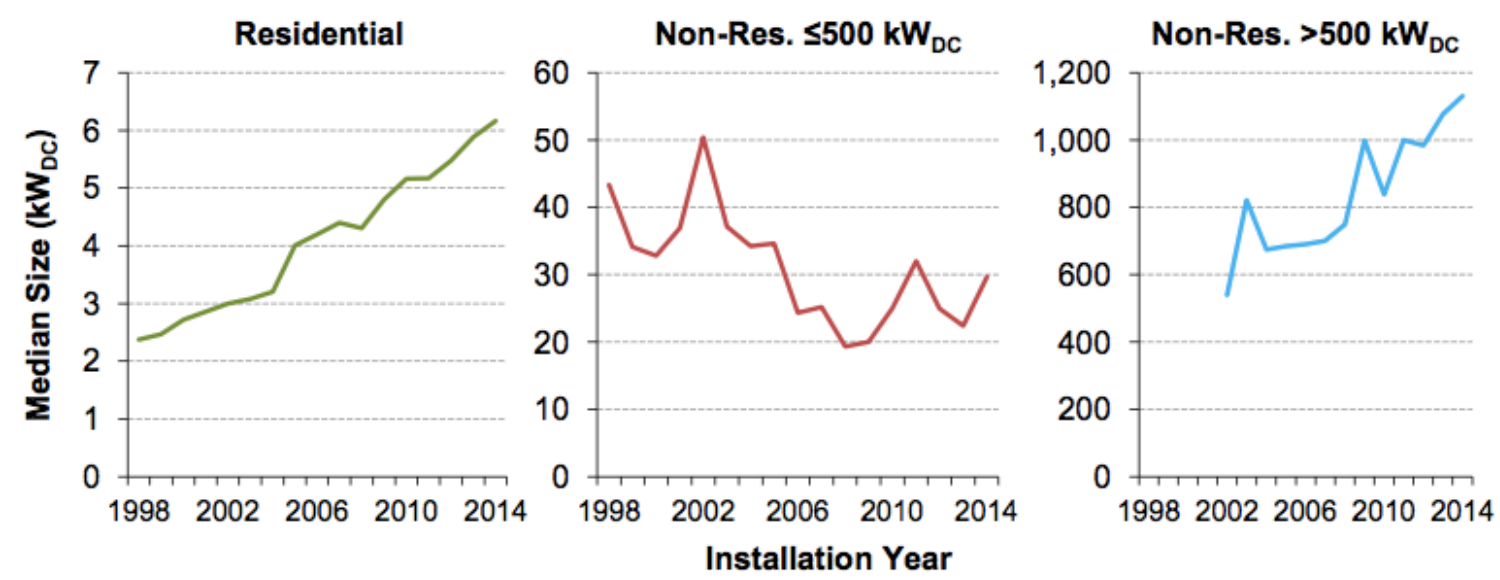

Figure 2. Median PV system capacity over time

Image courtesy of Barbose and Darghouth 2015

\subsection{Adoption Patterns Vary by State}

System scales vary considerably throughout the United States primarily because of differences in state incentives and electricity rates. California and Arizona currently lead in installed PV capacity and have experienced rapid growth in the integration of both residential and utility-scale systems. Yet Hawaii (ranked seventh in the United States for installed solar capacity) and New York (ranked ninth with nearly $400 \mathrm{MW}$ ) have instead experienced growth primarily driven by residential solar, which comprises more than $80 \%$ of the total installed PV capacity in each state. In contrast, in North Carolina (ranked fourth in total installed capacity) more than $98 \%$ of PV capacity is utility scale that is in the range of $500 \mathrm{~kW}$ to $5 \mathrm{MW}$. Nevada (ranked fifth with nearly 800 MW installed) has a similar share of utility-scale PV capacity. Yet PV penetration in New Jersey has been driven by commercial installations (Barbose and Darghouth 2015; Kimbis and Kann 2013; Kimbis and Kann 2015; GTM Research and SEIA 2015). The adoption of DGPV can be locally concentrated within each of these regions, which results in pockets that have very high penetration levels - often above $100 \%$ capacity, exceeding the local peak demand (e.g., Mather and Neal 2012; Narang et al. 2015; Palmintier, Ponder, and Gantz 2015). These high penetration levels drive the near-term need for research in improved integration strategies and serve as examples for future, more widespread, high penetrations of DGPV.

\subsection{Ownership Models Are Being Diversified}

There has been tremendous interest and growth in nontraditional ownership of PV systems particularly at the distribution level. In addition to the longstanding practices of customer-owned systems for residential PV and independent power producer ownership for utility-scale, distribution-connected PV, there has been recent growth in the following areas:

- Third-party ownership. In third-party ownership, PV systems are installed and owned by third-party companies such as SolarCity, Vivint Solar, and Sunrun. These companies have been very successful in attracting residential customers with an offer of low-cost energy that has no upfront expenditures. In exchange, customers typically agree to purchase that PV energy for an average term of 20 years. Greentech Media (GTM) Research has shown that $72 \%$ of U.S. residential solar installed in 2014 was third-party 
owned, up from 42\% in 2011 (Munsell 2015b). Interestingly, the trend is expected to reverse during the next 5 years owing to declining system costs and increases in other direct financing mechanisms (Figure 3).

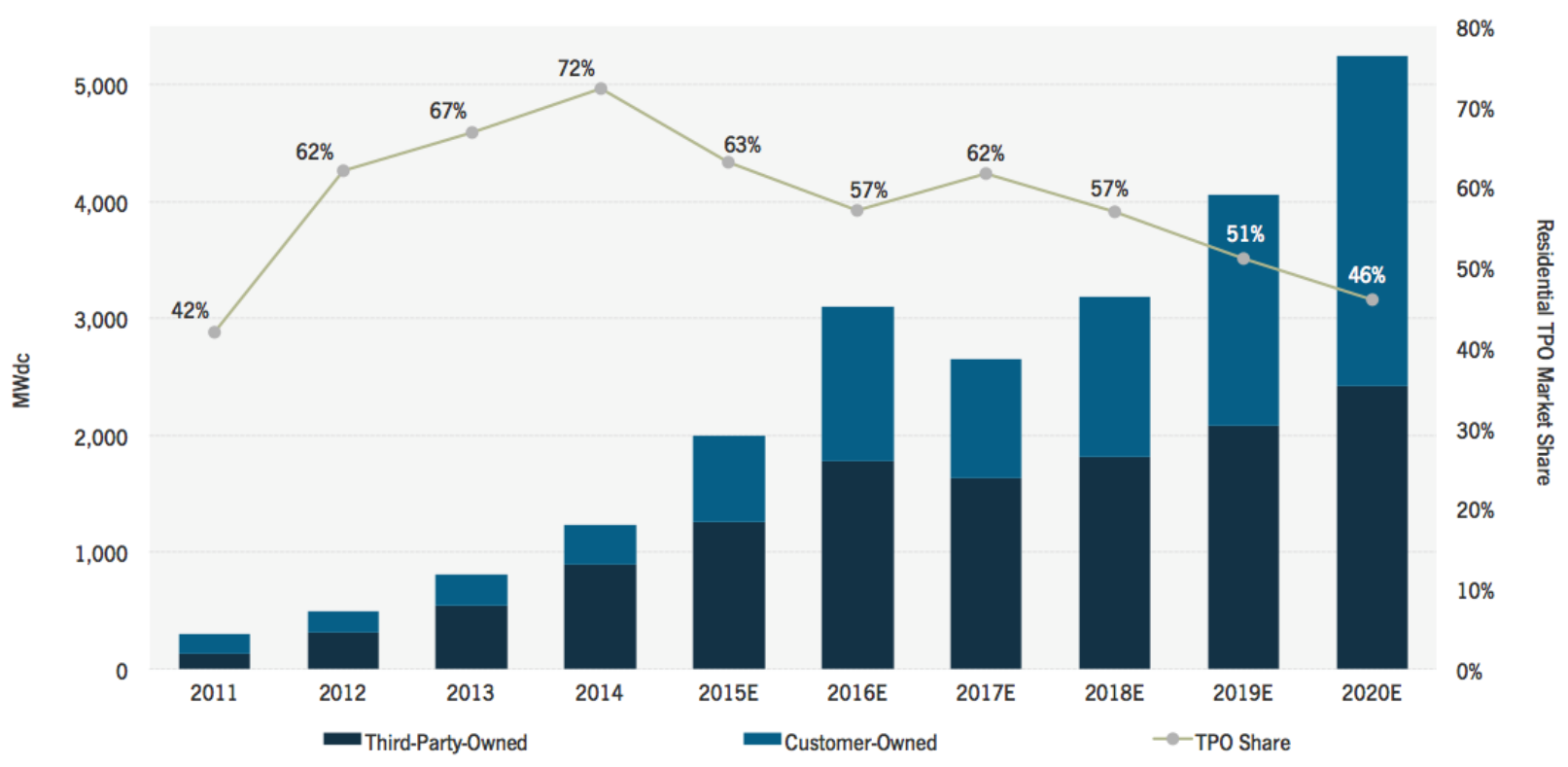

Figure 3. Residential, third-party PV penetrations and installations by ownership type

Image courtesy of Litvak 2015

- Utility ownership. In utility ownership, utilities either purchase and own utility-scale PV systems or sign long-term power-purchase agreements to purchase energy from a third party. Such arrangements are especially popular in states where utilities may seek larger PV projects to meet requirements for renewable portfolio standards. In addition, utilities have recently shown interest in owning residential-scale PV for research purposes and as an alternative to third-party ownership (“APS-Solar Partner Program” 2015).

- Community ownership. In community ownership, multiple customers share the benefits from owning and operating a single PV system. This approach could double the number of customers who have access to PV by allowing participation from those who have challenges to individual ownership (e.g., tenants) or building constraints (e.g., high-rise residences, businesses, or poor roof orientation). Recent reports show that there is potential for tremendous growth in community solar (Munsell 2015a) and an estimate that community solar could comprise one-third to one-half of all distributed solar by 2020 (Feldman et al. 2015). ${ }^{10}$

These models can shift cash flows from upfront capital to periodic payments while potentially also shifting the operations, maintenance, and other responsibilities among parties. Such shifts could have important implications on the relationships among utilities, providers, and customers

\footnotetext{
${ }^{10}$ Additional information about these and other business model trends can be found in Barbose et al. (2016), which is part of the On the Path to SunShot series.
} 
because advanced, inverter-enabled, remote communications and grid services support raise questions about who is in charge of these matters and what compensation is provided.

\subsection{Interest in Complementary Technologies Is Increasing}

Recent natural disasters, such as Hurricane Sandy in 2012, have increased the interest in using PV systems with complementary technologies to enhance power system resiliency. Many PV manufacturers now include direct plug-in capability for use when the electric grid is unavailable (e.g., SMA's Secure Power Supply). Interest has also been increasing in complementing PV with the use of battery storage to support loads during outages of both short and long durations. As the prices of battery systems continue to fall, pairing PV with moderately-sized storage systems (such as the Tesla Powerwall) would allow PV owners enough energy to power critical loads including refrigerators, cell phone chargers, lighting, and perhaps a furnace motor during emergencies. Batteries are already being used to comply with specialized interconnection requirements such as ramp-rate limits and non-export requirements in Hawaii.

\subsection{Research Needs on the Distributed Solar Landscape}

Additional trend data would be helpful to improve both techno-economic analyses and industry analyses for DGPV, specifically:

- Public tracking via regular state-of-the-industry reporting of which PV systems are connected to the distribution system compared to those connected to the transmission system

- Enhanced tracking via regular state-of-the-industry reporting of PV ownership models that include those owned by customers, third parties, communities, and multiple categories of those owned by utilities, including direct utility use, community programs, and PV sited in residential areas.

- Tracking the adoption of integrated PV with storage systems at a range of scales, including residential, commercial, distribution-utility, and transmission-utility. 


\section{Interactions with the Distribution System}

Unlike power from conventional generation such as coal-powered plants or nuclear power plants that is provided through transmission networks, PV power output is variable during short timescales (seconds to minutes) because of clouds passing overhead and diurnally because of the day and night. This variability produces a number of important and challenging interactions with the distribution system such as managing distribution voltage, potentially increasing wear and tear on existing electromechanical utility equipment, and configuring circuit breakers and other protection systems. These issues generally become more challenging with larger PV systems and higher levels of DGPV. They must be weighed against potential positive impacts, including deferring system upgrades when PV provides power during peak-demand times, using advanced inverters (with or without batteries) to help manage voltage levels, and reducing distribution losses (Denholm et al. 2014). This section introduces these interactions and highlights the current understanding and concerns from utilities.

In a 2015 report by the National Renewable Energy Laboratory (NREL) and the Electric Power Research Institute (EPRI), 21 utilities outlined a significant number of concerns about the impacts of integrating DGPV (EPRI 2015b). These are not universal because each utility is different and the employees have individual perspectives, but the goal is to prevent concerns from becoming problems. Table 1 shows the most common concerns and the number of utilities that reported each concern as significant. These concerns are explored in more detail below.

Table 1. Major Utility Concerns Related to DGPV

\begin{tabular}{ll}
\hline Concern & $\begin{array}{l}\text { Number of Utilities } \\
\text { (Out of 21) }\end{array}$ \\
\hline Voltage regulation & 16 \\
Reverse power flow & 11 \\
Protection coordination & 10 \\
Increased duty on line regulators & 8 \\
Unintentional islanding & 8 \\
Secondary networks & 6 \\
Variability due to clouds & 5 \\
Capacitor switching & 4 \\
\hline
\end{tabular}

Data source: Coddington and Smith 2014

\subsection{Voltage Regulation}

\subsubsection{Voltage Regulation for Loads}

Utilities are required to maintain the voltage of the customer's service entrance within a narrow operating range, typically within $\pm 5 \%$ of the nominal value (ANSI 2011). To comply, historically distribution systems have been designed to overcome voltage drops as current flows through resistive lines. As shown in Figure 4, this is normally achieved by maintaining a high voltage at the substation and using regulating transformers and/or switched capacitor banks to compensate for line voltage drops along the length of the circuit. 


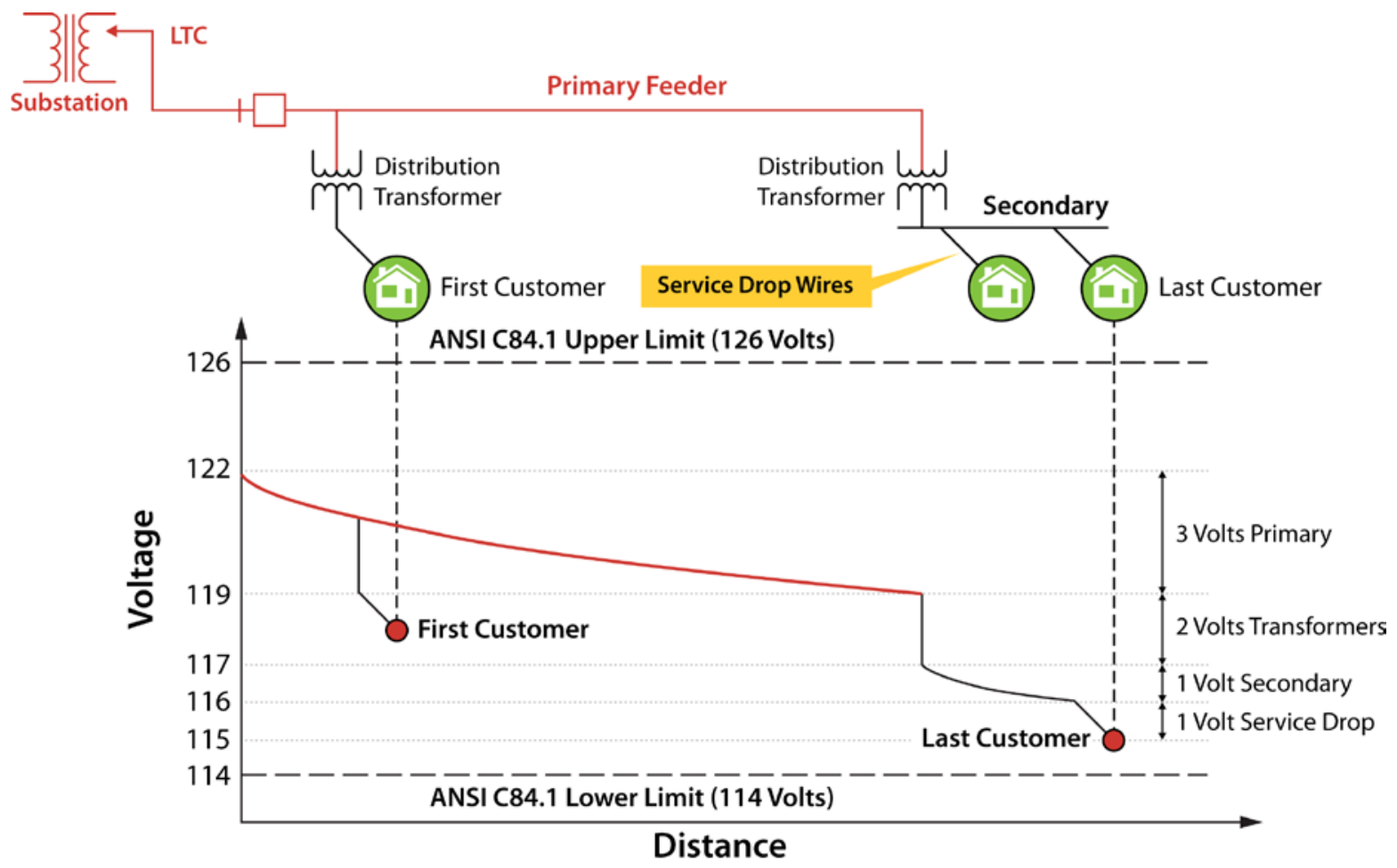

Figure 4. Representative voltage drop across a distribution feeder as a function of the distance from the substation

\subsubsection{Impacts of distributed generation}

Distributed generation of any kind, including DGPV, raises the voltage locally, potentially beyond the acceptable range; see Figure 5(a). And it may require the addition of voltageregulating equipment; see Figure 5(b). The amount of voltage rise depends on the feeder characteristics, including voltage rating, wire size, whether the lines are overhead or underground, etc.; the location of the PV; and the loading pattern. In addition, the local voltage and hence the action of the voltage-regulating equipment change with variations in insolation.

These voltage impacts are exacerbated in the United States because most PV inverters currently inject only pure real power. As described in Section 2.1.3, the voltage impacts can be reduced or eliminated using advanced inverters that also absorb or inject reactive power. Such technologies could reduce voltage impacts or displace the need for other voltage-regulating equipment. 


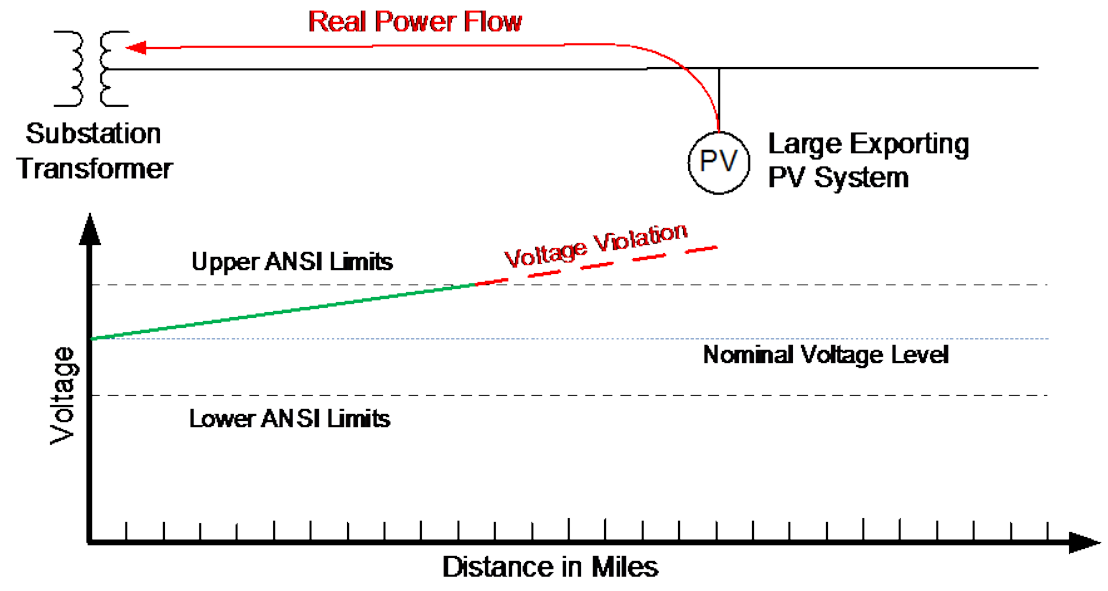

(a) Voltage rise resulting from reverse power flow from DGPV

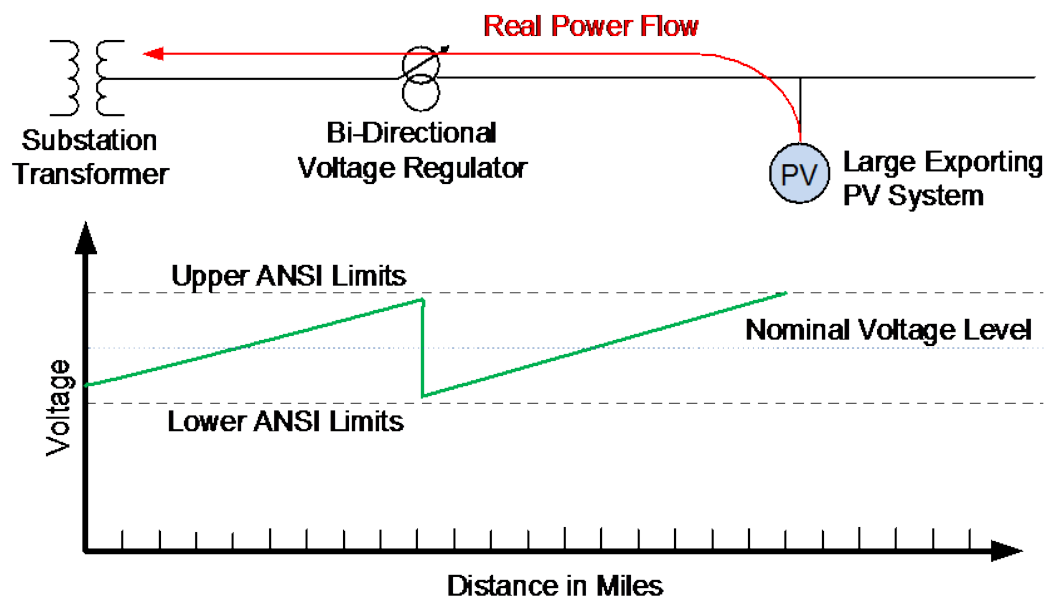

(b) DGPV overvoltage corrected using a voltage regulator

Figure 5. Simplified voltage impacts of DGPV and mitigation using a voltage regulator

\subsubsection{Advanced Inverters for Voltage Support}

The power electronics inside modern PV inverters can be used to correct the potential voltage challenges of distributed generation by shifting the phase angle of their sinusoidal current output to absorb (or inject) reactive power. This can offset the undesirable voltage rise caused by the power injection, and it can even help regulate voltage when the sun is not shining (Figure 6). 


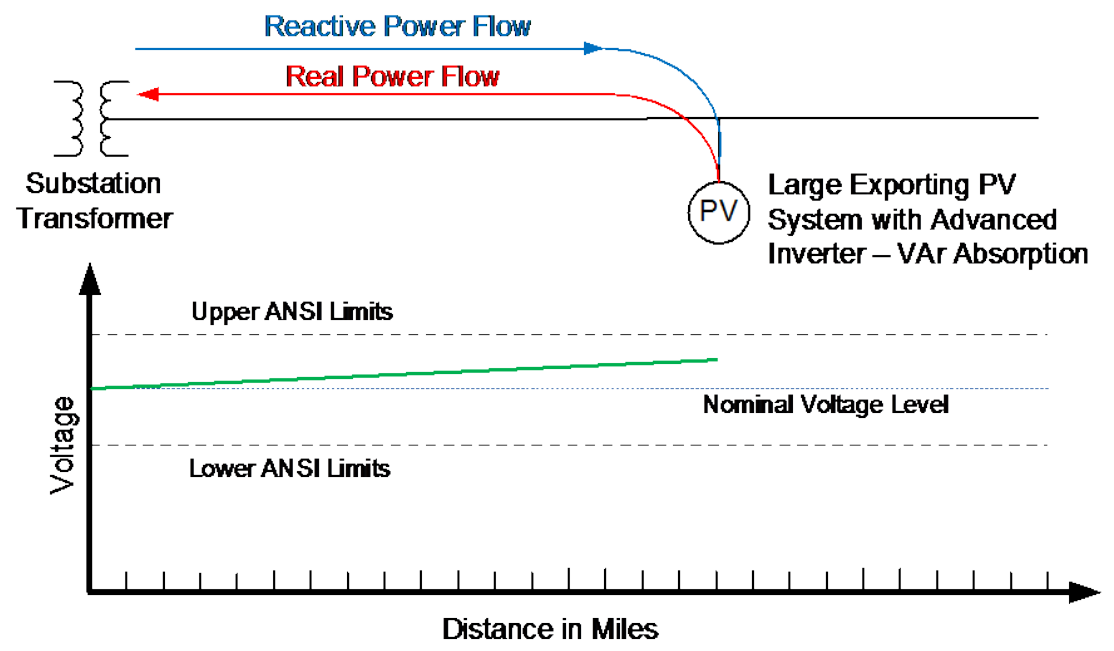

Figure 6. Simplified depiction of the ability of advanced inverters to absorb reactive power and help mitigate challenges to voltage rise on the feeder

Previous studies have shown that advanced inverters can mitigate voltage-related issues and that 25\%-100+\% more PV can be accommodated using advanced reactive power controls such as volt/volt-ampere reactive (VAR) and constant power factor (e.g., Braun et al. 2011; Seuss et al. 2015; Coddington et al. 2012). In addition to helping with local voltage regulation, advanced inverters can provide capabilities that can benefit the larger power system, including external controllability, real power curtailment in response to excess generation, ${ }^{11}$ voltage and frequency ride-through, and so on. (See the sidebar below on "Southern California Edison's HighPenetration Photovoltaic Project" for a description of how advanced inverter functions were used to successfully integrate high penetrations [1-5 MW] of DGPV with minimal impact on distribution voltage.)

\subsection{Reverse Power Flow}

Historically, the distribution system was designed to deliver power in one direction: from central generation to loads. With the widespread deployment of DGPV, power can flow in reverse from the DGPV toward the substation, where it either supplies power to load in neighboring feeders or back out onto the transmission system. Because DGPV output varies, the magnitude of this reverse power flow will also vary, potentially switching between forward and reverse with passing clouds. Moreover, somewhat lower DGPV production can cause reverse power flow along only a portion of a feeder when DGPV output is high enough to serve some upstream loads after supplying all downstream loads. Fundamentally there is no problem with this bidirectional flow because wires and fixed-ratio transformers work well in both directions, and they can accommodate roughly as much reverse power as their forward ratings before they are overloaded.

\footnotetext{
${ }^{11}$ This is often referred to as frequency-watt control because an increase in grid frequency is the first measurable change of excess generation compared to load.
} 
However, reverse power flow can create control and protection problems if settings are not properly configured. In particular, tap-changing transformers used as voltage regulators can encounter control problems with reverse power flows. These devices electromechanically adjust the transformer turns ratio to raise or lower the secondary (downstream) voltage. Reverse power flows can trick improperly configured controllers into incorrect operations that lead to voltage problems. Some older units may ignore flow direction and sense the magnitude of the reverse power flow from the DGPV as a highly loaded condition. This causes the regulator to increase voltage, which is the exact opposite behavior required to mitigate DGPV voltage rise. Even with directional current measurements, many situations require different control settings for reverse power flows, such as cogeneration or reverse power modes (Jauch 2005).

In addition, many tap-changing transformers that are used for voltage regulation use recirculation schemes to avoid arcing and other challenges when changing voltage ratios under load. These schemes can limit the reverse power rating for tap-changing transformers to less than their forward rating (Cipcigan and Taylor 2007). However, many successful field deployments have successfully operated high penetrations of DGPV with large substation reverse power flows, which suggests these concerns may be overstated for U.S. systems (Mather and Gebeheyu 2015; Palmintier, Ponder, and Gantz 2015).

A final concern about reverse power flow is about the distribution-transmission interface. In much of the United States, separate companies or separate utility business units have responsibility for the distribution and transmission systems. A DGPV system that feeds power from the distribution system into the transmission system may require interconnection approval from multiple parties, and the existing inherent differences between the distribution and transmission markets are often a considerable barrier for interconnection. Additional research is required to define market exchanges and to develop guidelines for wheeling power produced by the distribution system at the bulk level to support very high penetrations of DGPV. 


\section{Southern California Edison's High-Penetration Photovoltaic Project}

The impetus for this project was the approval of Southern California Edison's request to the California Public Utilities Commission to install 500 MW of utility-scale rooftop PV within their distribution system footprint. Starting in 2009, this resulted in a number of distribution circuits that installed very high penetrations of PV in predominantly rooftop systems placed on the flat roofs of large industrial warehouses. These systems were typically sized between $1 \mathrm{MW}$ and $5 \mathrm{MW}$. NREL partnered with Southern California Edison to study the distributionsystem impacts of PV integration on these high-penetration circuits and to develop, test, and demonstrate the mitigation of these impacts using advanced PV inverter functionality.

A study methodology validated using high-resolution impact data collected from the distribution circuits was developed for use in PV impact assessments on future PV interconnection requests. Further, a mitigation strategy using fixed power factor operation of the PV systems was developed for each circuit. The mitigation studies showed that an inductive power factor of 0.95 was sufficient to counteract the voltage rise seen at the PV systems' points of interconnection due to real power injection. All three circuits regularly showed that the PV systems were backfeeding the entire circuit - completely reversing the real power flow on the portion of the distribution circuit between the substation and the PV systems' points of interconnection. Figure 7 shows the results of a field demonstration showing the efficacy of using a fixed power factor operation for the circuit, which has a 5MW PV system interconnected about 7 miles from the substation on a very lightly loaded circuit. The figure shows the PV system's voltage and reactive power flows at the point of interconnection for the day immediately before the field demonstration began and a day during the demonstration. The voltage rise at the point of interconnection was effectively eliminated using an inductive 0.95 fixed power factor operation, allowing the voltage profile and utility-owned voltage-regulating equipment of the circuit to return to a pre-PV integration state of operation. Additional reactive power flowing on the circuit was provided via existing capacitors already in place for substation/sub-transmission voltage regulation.
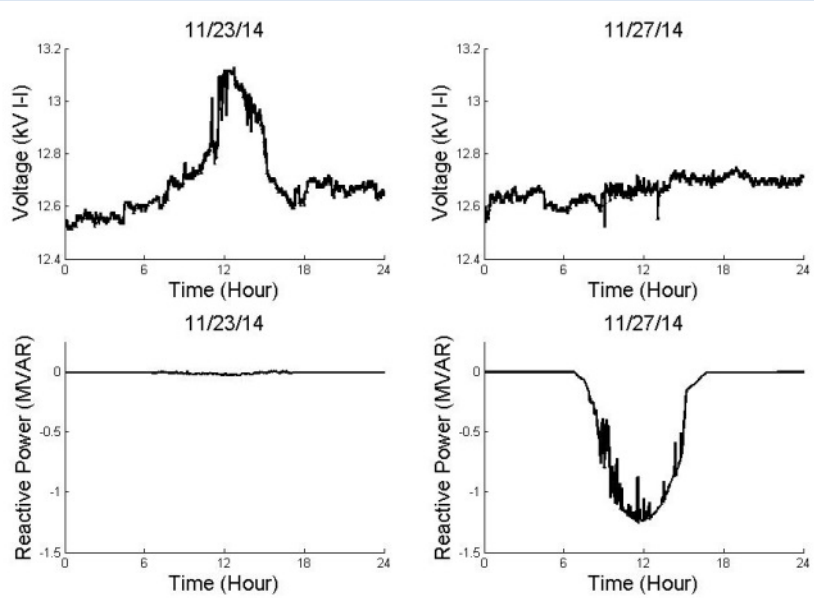

Figure 7. The voltage and reactive power flow at the point of interconnection from a 5-MW PV system before (left) and during (right) the fixed power factor PV mitigation field demonstration. Image from Mather and Gebeheyu 2015 


\subsection{Protection}

The protection system is designed to stop power flow during a fault such as a line to ground short. Distribution protection equipment generally relies on detecting an increase in current flowing during a fault to isolate the problem while allowing the rest of the system to maintain operations. Routine changes in operating conditions within the distribution system complicate detecting and locating faults, particularly high-impedance faults. The addition of any distributed generation, including DGPV, can create further challenges in detecting and locating faults because distributed generation can increase or decrease the fault current flows through the multiple protection devices on a distribution system that potentially confuse current measurements and cause them to operate in a less than optimal way.

One such problem is relay desensitization (Figure 8), wherein current from PV decreases the fault current that would otherwise be observed by existing protection devices such as substation breakers, reclosers, and fuses. This can cause the protection to operate more slowly or not at all during the fault and potentially damage utility and customer equipment.

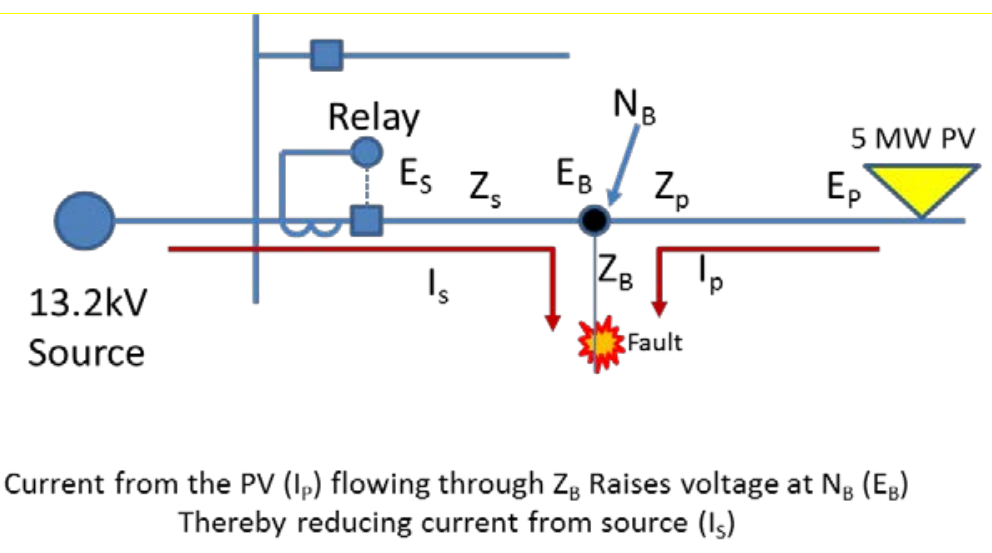

Figure 8. Example of relay desensitization due to DGPV integration

Image from Seguin et al. 2015

The additional fault current from DGPV can also increase the fault current experienced on all or portions of a circuit. Figure 9 shows a fault on an adjacent circuit (connected to the same substation bus as the circuit with PV) fed by an increased amount of fault current due to the DGPV. This requires the protection equipment on the adjacent circuit to be rated to operate below the higher fault current. Moreover, the current flowing through the protection on the DGPV's feeder could be high enough to trip and incorrectly de-energize the DGPV's feeder even though it does not have a fault.

Protection coordination can be another challenge with DGPV. Protection coordination attempts to balance the reaction times of multiple protection devices to respond appropriately to faults at various locations on the distribution system. For example, if a fault occurs on an extremity of the circuit, it is likely that the protection devices located nearer the extremity would have been designed to operate (i.e., clear the fault) by first disconnecting the extremity instead of tripping the substation breaker and causing an outage of the entire circuit. With DGPV, there is a potential need to adapt the existing settings of circuit breakers, fuse ratings, and other fault- 
protection systems on the distribution system to accommodate the changing currents. These adaptations are relatively inexpensive to implement. Typically, no new equipment is needed; instead, new set points are determined through routine modeling, and a minimal amount of time from the utility crew is required to implement the set points in the field. Additionally, the variable nature of DGPV complicates protection coordination because the protection scheme must work under varying output (and load) levels and with some or all DGPV sources offline. However, DGPV systems typically have much lower levels of sustained fault current contributions than traditional, rotating-machine-based distributed generation (Keller and Kroposki 2010), and this greatly reduces the overall protection-related challenges with DGPV. Further, the fault behavior of DGPV is somewhat programmable and controllable, which allows it to be adapted to the specific protection scheme used by a utility. Still, additional analysis and design work may be required for high penetrations of DGPV.

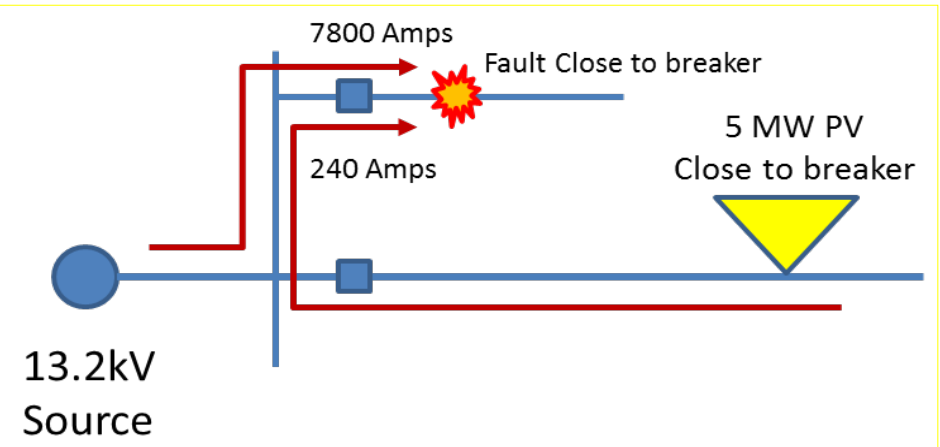

Figure 9. Example of impacts on fault current observed by equipment due to DGPV

Image from Seguin et al. 2015

\subsection{Equipment Wear and Tear}

In addition to the challenges in regulating voltage at the customer level as described in Section 2.1, DGPV can also impact the wear and tear on existing utility-owned equipment used to help regulate these voltages - namely load tap-changing transformers located at the substation, tapchanging line regulators, and capacitors. Though these devices may already operate dozens of times per day (Harlow 1996; Jauch 2005), with high penetrations of DGPV increased power flow variation can cause increased wear and tear on these electromechanical actuators and potentially require their premature replacement. (See the sidebar below on "Impact of Solar Variability on Operations.") In other situations, particularly with advanced inverters (see Section 2.1.3), the DGPV could potentially reduce the number of actuations and extend the life of this equipment.

The presence of voltage regulators and/or switched capacitors is generally an indication of a circuit with relatively higher impedance and/or the presence of voltage-sensitive customers on the circuit. Thus, circuits that have these types of equipment are generally more challenging cases of DGPV integration because of the characteristics of the circuit more than the specific use of the voltage regulators and/or switched capacitors. 


\section{Impact of Solar Variability on Operations}

Figure 10 shows an example simulation of the impact that solar variability can have on voltage regulator operations by comparing a base case that has no $\mathrm{PV}$ to a simulated case that has 3 MW of central PV (31\% of peak load) using solar profiles for Oahu, Hawaii. The solar variability in Oahu is much larger than the load variability so the PV case causes many more tap operations than the case that has no PV. Figure 11 extends this analysis to simulate $3 \mathrm{MW}$ central PV plants using various locational solar profiles. It shows that the number of tap operations per week varies considerably based on the locational solar variability: the difference is nearly a factor of three from highest (Oahu) to lowest (Livermore).
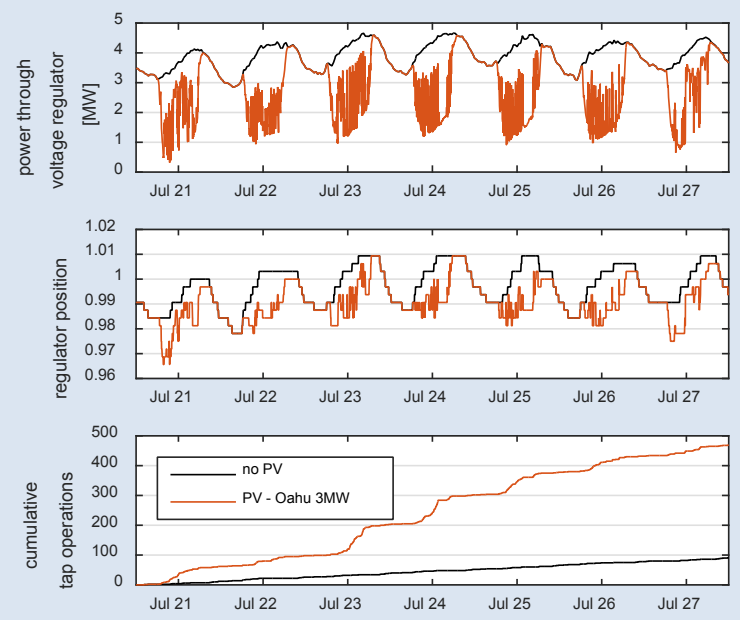

Figure 10. Power through voltage regulator (top), voltage regulator tap position (middle), and cumulative number of tap changes (bottom) for a test feeder with no PV (black) or with 3 MW of PV based on solar variability in Oahu, Hawaii (red).

Adapted from Lave, Reno, and Broderick 2015

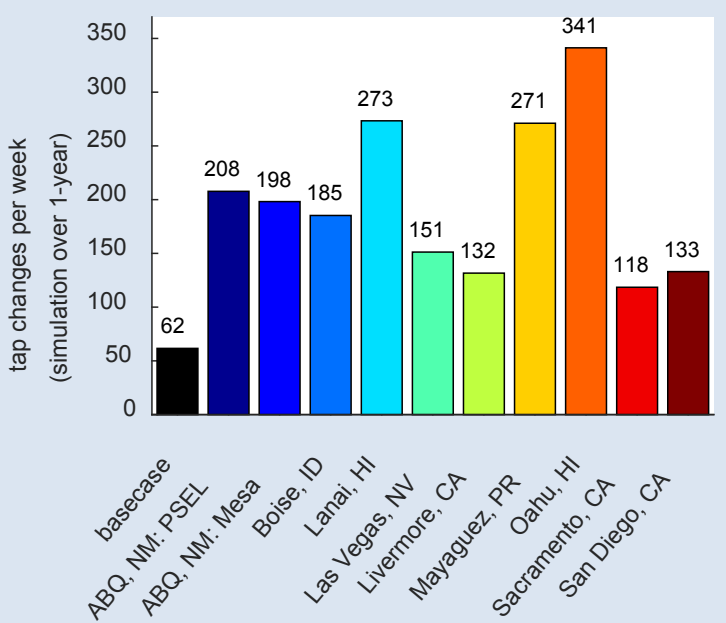

Figure 11. Average weekly tap-change operations and solar variability (based on simulations throughout 1 year) for 10 locational samples plus a base case with no PV.

Adapted from Lave, Reno, and Broderick 2015

\subsection{Unintentional Islanding}

Unintentional islanding refers to the potential for a portion of the distribution system to continue to run even when the larger power system is disconnected by a protection device. Although this might sound like a desirable state, ${ }^{12}$ an unintentional island could result in equipment damage and safety concerns. To prevent these problems, grid-connected PV inverters have anti-islanding features and must be certified to detect and drop offline within 2 seconds after an island forms (IEEE 1547 2003). Yet, even with certification, because of the complexities of distribution systems, there is concern that the ability of PV systems to detect islanded conditions may not be sufficient. The placement of DGPV and traditional, rotating-machine-based distributed generation may slow island detection times or defeat detection altogether resulting in two risks:

\footnotetext{
${ }^{12}$ The intentional creation of a self-sufficient island, or microgrid, requires careful design, planning, and more sophisticated control architectures. DGPV can contribute to microgrid architectures, but typically such systems are used only for high-reliability cases when the potentially high cost is justified.
} 
potential equipment damage due to operation outside the bounds of normal utility-controlled conditions (e.g., voltage bounds, frequency/phase synchronization with the grid) and a potential safety risk to utility crews working on the circuit. In practice, traditional anti-islanding schemes (Ropp et al. 2000) have worked very well in the field; however, ride-through requirements that are necessary to integrate large quantities of PV successfully into bulk operations may be incompatible with these anti-islanding approaches.

\subsection{Secondary Network Distribution Systems}

Although most distribution networks are operated radially_-with a non-looping, treelike structure of customers connected to only one point - many dense, urban areas employ secondary networks wherein customers are connected to a large, meshed, low-voltage network that is fed by multiple points. Historically, connecting PV to these systems has been strongly limited because of strict limits placed on the reverse power flow for each customer. During the past 5 years, installing PV onto secondary networks has become much more acceptable partially as a result of best-practice and case-study research (Coddington et al. 2009).

Networks incorporate special protective devices, called "network protectors," at each network transformer that disconnect when electric power (both real and reactive power) flows back toward the utility. These devices are part of the design to provide much higher service reliability to urban customers, compared to suburban and rural customers. However, network protectors can hinder PV interconnection because routine excess power generation from DGPV may cause reverse-current flow through the network protector and thus cause the device to open unnecessarily. Because of this and related challenges, many utilities with networks do not allow their customers to interconnect a PV system (or any generating system). The NREL report, cited in the Institute of Electrical and Electronics Engineers (IEEE) Standard 1547.6, offers several design options for increasing the number of PV systems on secondary networks. More recently, a combination of advanced inverters and utility-grade relays has demonstrated the ability to create a low-cost, locally controlled system that allows higher levels of PV to be installed on networks with very low risk of backfeeding into the network protector (Coddington et al. 2009).

\subsection{Cloud-Driven Photovoltaic Variability}

Cloud patterns are the major driver for solar irradiance variability and hence PV production variability (Mills et al. 2011). Without clouds, the underlying solar profile varies smoothly, slowly, and predictably because of the movement of the sun through the sky. The amount of cloud-caused variability depends on the local climate. Some locations have many small clouds and/or fast wind speeds that lead to large numbers of short fluctuations between clear and cloudy. Other locations have consistent (clear or cloudy) weather patterns that last for entire days so they have relatively low variability. A map of zones displaying areas that have high and low solar variability is shown in Figure 12. 

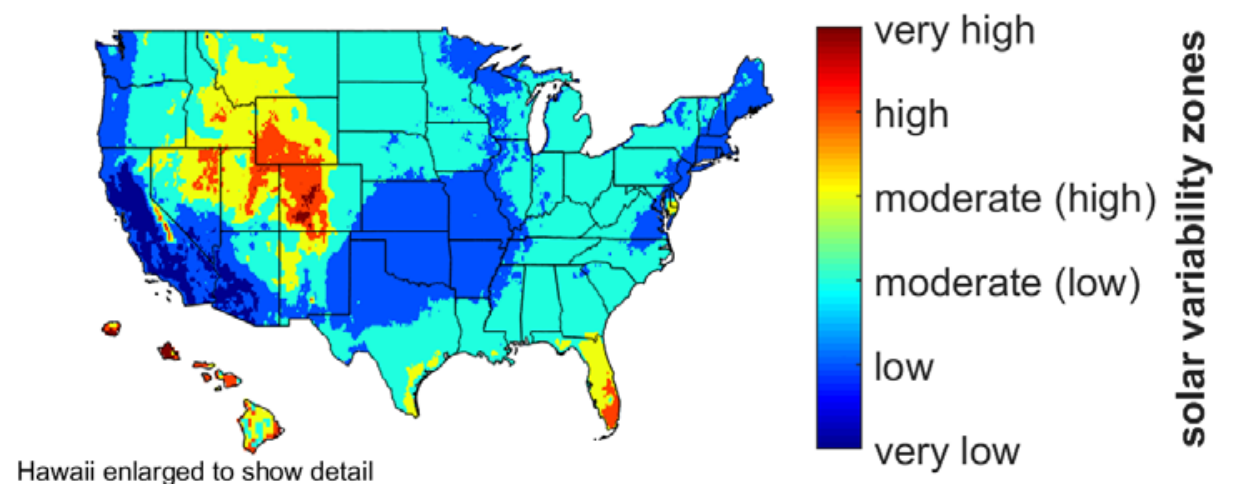

Figure 12. Zones showing areas of low and high solar variability

Image from Broderick et al. 2015

For large PV plants or for distributed PV spread throughout a potentially multi-mile extent of a distribution feeder, the spatial diversity of PV modules can considerably reduce the overall variability. When aggregated, some of the modules may be covered by clouds while others experience clear skies. The amount of variability smoothing due to spatial diversity depends on the arrangement of PV modules, the daily cloud speed, and the timescale considered. Figure 13 shows how the variability of 467 aggregated houses is much less than the variability of a single house. This example is from a PV test neighborhood that has very dense PV ( $80 \%$ of houses); in most neighborhoods, PV will be significantly less dense, and the smoothing will be even greater.

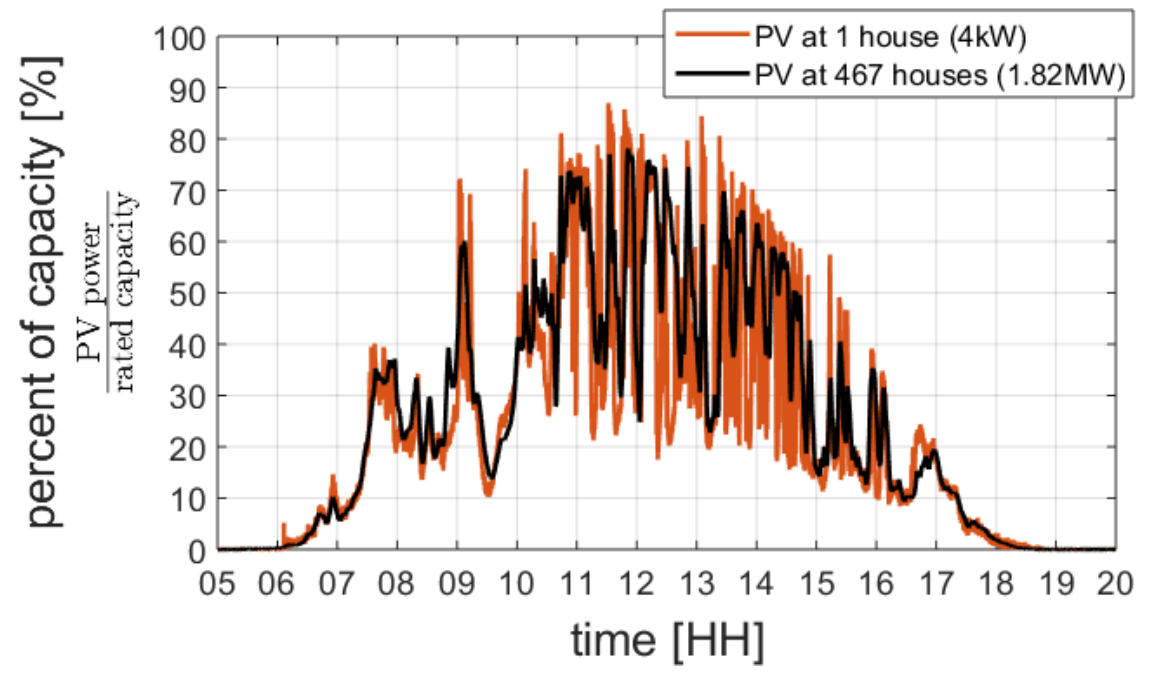

Figure 13. Comparison of the relative variability of a single house with $4 \mathrm{~kW}$ of PV (red) and the sum of 467 houses spread throughout $0.4 \mathrm{~km}^{2}$ totaling $1.82 \mathrm{MW}$ of PV (black) as recorded on July 31, 2007, in Ota City, Japan

Image adapted from Lave et al. 2011 
The main effect of short-timescale PV variability on distribution feeders is that it causes voltage fluctuations. These voltage fluctuations are typically much larger than the fluctuations caused by load so they can, for example, lead to a significant increase in voltage regulating, tap-changing operations (see sidebar above on "Impact of Solar Variability on Operations"). Accounting for local cloud patterns and spatial smoothing is essential to accurately determine and manage the impact of $\mathrm{PV}$ on distribution grid operations.

\subsection{Challenges to System Reconfiguration}

In all but the most remote distribution circuits, utilities often install switches or otherwise provide for limited reconfiguration to connect adjacent distribution circuits. Reconfiguration is a valuable tool that utilities use to manage changes in circuit loading and circuit outages (both planned and unplanned). Integrating distributed generation, including PV, on certain circuits or certain portions of a circuit can complicate the switch sequencing, control configurations, and protection settings needed to ensure reliable operation during reconfiguration. At a minimum, considering reconfiguration makes PV interconnection studies more complex and time consuming.

\subsection{Promises of Improved Distribution Planning}

As PV penetration levels increase on any particular distribution feeder, that feeder's ability to accommodate additional, new PV without upgrades or setting changes is reduced (EPRI 2015b). Once the low- or no-cost hosting-capacity limit is reached for a circuit, the cost of integrating future PV systems on that grid will naturally increase. Thus, regulators and utilities are paying increasing attention to how to best plan for high penetrations of PV, including whether a utility should continue its reactive approaches to integrating new PV systems and mitigation techniques or whether it should preplan (via electrical distribution planning) for greater amounts of PV. Contributing to these discussions, in 2013 the Interstate Renewable Energy Council published a paper on "Integrated Distribution Planning: A Path to Sustaining Growth" (Lindl et al. 2013), and in 2015 SolarCity published a report about how utilities could include PV and other distributed energy resources (DERs) in their long-term planning (SolarCity 2015). Such forwardlooking planning could go a long way toward easing the interconnection of SunShot levels of DGPV penetration by preplanning voltage regulation, protection, and other schemes to work with varying quantities of DGPV and other DERs. A key complicating factor is that the penetration levels and patterns of DGPV and other DERs are uncertain.

\subsection{Research Needs on Solar-Distribution Interactions}

Critical near-term research needs center on improving the understanding of the interactions among multiple advanced inverters and existing utility equipment.

- To ensure reliable operations among a wide range of deployment scenarios, it is important to determine whether or not advanced inverters with active volt/VAR control would interact poorly with each other and/or with traditional utility regulating equipment and potentially cause isolations or other undesired effects. Initial simulations and lab tests have been done in this area (Paradis, Katiraei, and Mather 2013; Chakraborty, Hoke, and Lundstrom 2015), but additional work is required. 
- To address system protection with high penetrations of DGPV, further research could help ease utility concerns by either working with utilities to develop a best-practices handbook and/or developing new automated protection coordination technologies to handle varying DGPV outputs, installation patterns, and feeder reconfigurations. This is an area of increasing concern, but it is not yet well understood outside of specialized groups.

- To address anti-islanding concerns, developing and testing new schemes that work well with ride-through requirements and at higher penetrations will be critical to ensure the successful and widespread deployment of DGPV. Alternately, inexpensive and reliable means to implement a direct transfer trip or other communications-controlled trip of DGPV offline through a utility signal would be useful.

Looking farther ahead toward very high penetrations of DGPV, there is a need for new research in the following areas:

- A key need for solar value studies, rate design, and distribution-level markets is to develop methods for cost-based service exchanges between PV and the grid. These studies should explore how distribution grid operators might identify, transact, execute, and price PV to provide voltage-management and other services.

- Planning tools and techniques are needed to better prepare for uncertainty in the adoption patterns, sizes, and advanced features of high penetrations of DGPV.

- At very high penetrations, new controls are needed to operate grids with large amounts of nonsynchronous generation. 


\section{Hosting Capacity}

A key question for achieving the hundreds of gigawatts of solar envisioned by the SunShot Initiative beyond 2020 is whether technical limitations will restrict a greater than tenfold increase in interconnection of distributed solar. In the past few years, there have been major strides in directly estimating such potential limits based on engineering analysis rather than the dated - and often very inaccurate - rule-of-thumb of $15 \%$ of peak load. ${ }^{13}$

Such analysis has come to be known as determining the "hosting capacity" of a distribution feeder or system. These hosting capacity estimates refer to the quantity of PV that can be interconnected without imposing any changes to the existing infrastructure and without prematurely wearing out equipment, such as that used for voltage control. Up until this level, PV can be easily interconnected and could be subject to accelerated approval. It is feasible - and often practical and inexpensive - to install more PV than this limit either by allowing some small changes in system operations, adjusting controller set points, or upgrading or installing additional equipment. The changes required to go beyond the hosting capacity require more extensive analysis.

This section discusses lessons learned regarding hosting capacity during the last few years and then presents new results to estimate that the minimum DGPV hosting capacity for the contiguous United States is approximately $170 \mathrm{GW}$ without imposing any changes to the distribution system. This assumes that DGPV is located according to feeder-level hosting capacity, which would likely require revised interconnection processes and new incentives or other policies to encourage such integration patterns. The results show that using advanced inverters to help manage voltage ${ }^{14}$ can roughly double hosting capacity, resulting in a nationwide distribution hosting capacity estimate of about $350 \mathrm{GW}$. Careful location of DGPV systems within distribution feeders; making minor changes to distribution operations; coordinating DGPV operations through distribution management systems (DMSs) or distributed control approaches; and/or through cooperation with other DERs could allow considerably higher penetrations of DGPV at little to no cost.

Looking forward, hosting capacity could be precomputed for distribution systems as a way to screen the amount and location of DGPV that can be integrated without further analysis. Early efforts in this area are already underway in California, Hawaii, and other regions, but additional research and development effort is needed to incorporate advanced inverters, storage, and other complementary technologies; encourage widespread adoption; and further streamline computations.

\footnotetext{
${ }^{13}$ California Rule 21 and the Federal Energy Regulatory Commission's SGIP are used by most states as models for developing their interconnection procedures. Both share the $15 \%$ rule of thumb. Under most applicable interconnection screening procedures, penetration levels on a switched circuit segment higher than $15 \%$ of peak load trigger the need for supplemental studies. The $15 \%$ rule derives from a threshold of DGPV not exceeding load with an estimate that minimum load is typically about $30 \%$ of peak with a $50 \%$ safety margin (Coddington et al. 2012). ${ }^{14}$ Advanced inverters can manage voltage either through constant off-nominal power factors or via active volt/VAR control as described further in Section 2.1.3.
} 


\section{Capacity versus Energy Penetration}

Depending on the context, many metrics and variations are used to measure PV penetration. At the bulk transmission level, penetration level is often referred to in energy terms. In contrast, distribution-oriented discussions typically use capacity-based metrics. The distinction is critical because daily solar cycles and other variability make capacity-based metrics roughly three to four times larger than those based on energy.

Capacity penetration is often defined as the ratio of the total kilowatt nameplate capacity of PV systems to the kilowatt peak load on that circuit. Capacity penetration, including the " $15 \%$ penetration rule," has been used to screen PV system applications. With very high levels of renewables, there will be periods and regions that have capacity penetrations that are significantly more than $100 \%$.

Energy penetration measures the percent of annual energy use supplied by renewable energy sources. It is typically used by states for renewable portfolio standards, climate impact assessments, and transmission-scale comparisons.

\subsection{Determining Feeder Hosting Capacity}

The concept of hosting capacity is used to study how much PV can be placed on a feeder before negative effects on normal distribution system operation and power quality occur. Hosting capacity is typically expressed as the megawatt value of PV spread across any locations on the feeder that causes the first violation of operating constraints. Though the specific criteria and thresholds for these violations - and hence the precise definition of hosting capacity — are subject to on-going debate; the criteria used by EPRI's Distributed Photovoltaic (DPV) tool (EPRI 2012a) provides a comprehensive list of possible violations to evaluate:

1. Primary system overvoltage/undervoltage

2. Primary system voltage deviation

3. Regulator voltage deviation

4. Secondary system voltage deviation

5. Secondary system overvoltage/undervoltage

6. Sympathetic breaker tripping

7. Breaker reduction of reach

8. Breaker/fuse coordination

9. Element fault current

10. Thermal overload.

The DGPV penetration level resulting in the first violation of any of these concerns for any combination of load and PV population is treated as the hosting capacity for that feeder. Not surprisingly, these criteria mirror the utility and technical concerns described in Section 2: 


\subsubsection{Key Drivers of Hosting Capacity}

The distribution system is extremely diverse in its design and implementation. It varies not only in form - from compact urban feeders to extensive, sparsely loaded rural feeders - but also in design principles, owing to variations among the more than 3,000 distribution utilities in the country, and even among different distribution engineers within each utility. There are a number of characteristics that vary with this diversity and can strongly influence the hosting capacity on a feeder. Some of the most important characteristics that determine hosting capacity are: voltage, short-circuit fault current, impedance $\mathrm{X} / \mathrm{R}$ ratio, number and location of voltage regulators, control settings for utility equipment, and the particular PV/load placement on the circuit.

\section{Using Statistics to Identify the Key Drivers of Hosting Capacity}

To identify the key drivers of hosting capacity statistically, we used hosting capacity results for 16 California feeders from the EPRI/California Solar Initiative/NREL/Sandia project on "Alternatives to the 15\% Rule" (EPRI 2015) along with 8 other feeders from outside of California. We fit multivariate regression models to the data and selected the most promising based on a combination of adjusted R-squared and Akaike Information Criteria (Akaike 1973). The most promising model explains $75 \%\left(\mathrm{R}^{2}\right)$ of the observed feeder-to-feeder variation within this small sample using:

- Feeder primary voltage $\left(\mathrm{p}=7 \times 10^{-7}\right)$

- Feeder maximum load in megawatts $\left(\mathrm{p}=4 \times 10^{-5}\right)$

- Farthest customer distance from substation in miles $\left(p=4 \times 10^{-6}\right)$

- Load-weighted average of primary X/R $\left(\mathrm{p}=3 \times 10^{-4}\right)$

- Sum of regulator and capacitor counts, $\log$ transformed $\left(\mathrm{p}=3 \times 10^{-4}\right)$

- Total reactive power rating of capacitors $\left(\mathrm{p}=1 \times 10^{-5}\right)$.

The low p-values for the variable-wise t-tests above indicate the presence of significant statistical relationships - in this case, the variables are indicators of hosting capacity for the sampled feeders - unlikely to arise from random chance. P-values represent the probability of a false positive, i.e., the chance that an element of the model is actually not important for the data. Likewise, the F-statistics $\left(\mathrm{p}=2 \times 10^{-14}\right)$ strongly suggest the presence of statistically significant relationships among this set of parameters and per-feeder hosting capacity. These promising statistics are based on a fairly small sample size, and there is considerable diversity among feeders in the field; thus, some feeders will have actual hosting capacities quite different than those predicted by this (or any other) model. Further research-likely adapted to utility-specific practices - is required to understand the potential and limitations of using statistical methods for hosting capacity.

Of the parameters, the circuit electrical characteristics captured in the primary $\mathrm{X} / \mathrm{R}$ ratio deserve special mention. Analysis showed that some measure of capturing customer source impedance either directly $(Z)$ or as the ratio between reactance and resistance $(X / R)$ was critical to producing the best regression models. Without one of these electrical characteristics, the ability to explain hosting capacity variability $\left(\mathrm{R}^{2}\right)$ dropped by one-third. 


\subsubsection{Stochastic Hosting Capacity}

Since the early 2010s, stochastic approaches that evaluate a large number of stochastic placements of PV have been developed somewhat independently by a number of researchers (Dubey, Santoso, and Maitra 2015; Advanced Power and Energy Program - University of California, Irvine 2013). Many of these approaches use only a limited number of scenarios for PV size and location, and they evaluate only a limited set of the constraints described in Section 3.1.1. In contrast, the DPV tool developed by EPRI (Smith et al. 2012; Rylander and Smith 2012) provided the first comprehensive estimates of hosting capacity. It uses stochastic PV deployment that evaluates thousands of scenarios of size and location for small-scale PV. To do so, it randomly selects a PV size for each customer and increases penetration until all customer locations have been deployed with PV. Multiple stochastic residential deployment series are tested to explore a wide range of spatial and sizing scenarios. The DPV tool also handles largescale PV deployment using a different method that evaluates a select number of three-phase primary line locations (typically five) as probable points of interconnection. At each penetration level, one 500-kW PV system is interconnected at a randomly selected location behind a $480-\mathrm{V}$, three-phase step-up transformer. The PV penetration level is increased until $10 \mathrm{MW}$ of PV have been deployed (20 MW for feeders above $15 \mathrm{kV}$ ). Similar comprehensive tools have also been developed by others (Cohen and Callaway 2015; D. Nguyen and Kleissl 2015; Reno and Coogan 2013; Dubey, Santoso, and Maitra 2015).

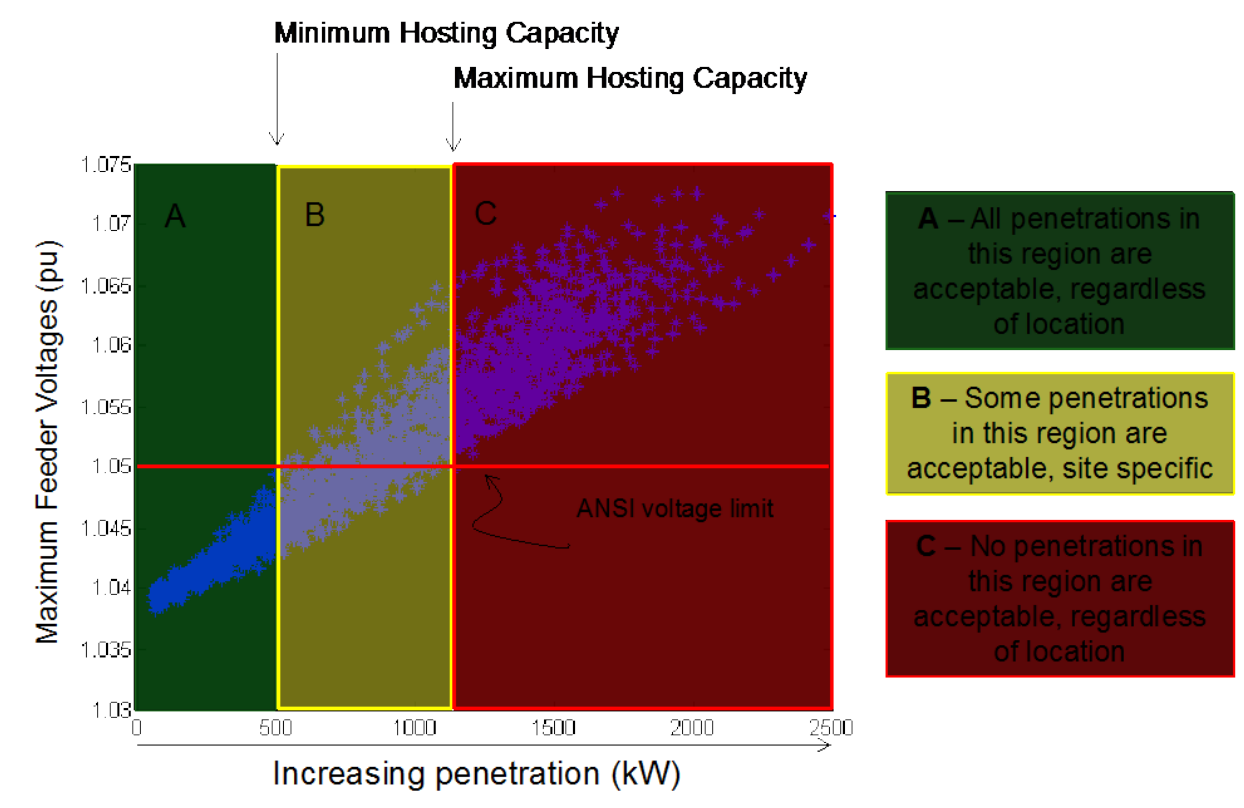

Figure 14. Stochastic scenario results for hosting capacity for overvoltage on a single feeder showing the importance of location in the middle region (B)

Image courtesy of EPRI 2012b 


\subsubsection{Locational Hosting Capacity}

One of the key outcomes of feeder hosting capacity research is the observation that - up to a certain, feeder-specific point or minimum hosting capacity - solar can be integrated anywhere on a distribution feeder (region A in Figure 14) without operational challenges. Above the minimum hosting capacity is a region where the locations of DGPV are critical: some combinations of location are okay, but others are not (region B in Figure 14). Finally, above the "maximum" hosting capacity, there are challenges independent of where the DGPV systems are located on the feeder (region $\mathrm{C}$ in Figure 14). As described below, even this is not a hard upper limit, but it indicates a point where something must change, such as using advanced inverters, adjusting control settings, accepting additional equipment operations, or upgrading equipment.

Locational hosting capacity builds on this insight to map the hosting capacity patterns across a feeder explicitly. It uses a systematic PV deployment strategy to determine the hosting capacity on each three-phase bus on a feeder for all PV system sizes ranging typically from $100 \mathrm{~kW}$ to 10 MW in 100-kW steps for 12-kV class feeders (Reno and Broderick 2015). This in-depth analysis will typically involve more than 40,000 PV scenarios. In contrast to traditional hosting capacity, which provides a single value for the largest amount of PV that can be placed anywhere on the feeder (minimum hosting capacity), locational hosting capacity analysis finds the maximum amount of PV that can be placed at each location on the feeder. The advantage of determining locational hosting capacity is the ability to generate detailed hosting capacity maps for the entire feeder backbone that capture how hosting capacity varies at each bus or circuit segment and identify what causes the hosting capacity limitation at each bus or circuit segment (Figure 15). Future efforts will extend this approach down to single-phase laterals and the secondary system. 


\section{Evaluating Pacific Gas \& Electric's Distribution Circuits}

An early case study by the University of California at Irvine and Pacific Gas and Electric (PG\&E) was undertaken to determine the hosting capacity of feeders (Advanced Power and Energy Program - University of California, Irvine 2013). It focused on evaluating the effects of high penetrations of $\mathrm{PV}$ generation on a residential feeder and a commercial distribution feeder. The impact of high penetrations of PV generation on feeder voltage, voltageregulating equipment, substation power factor, and line loss was evaluated. Three-phase balanced models for both circuits were developed and validated using measured data. PV location along the feeder was varied to include radial distribution (existing PV), beginning, middle, and end of the feeder. A normalized seasonal average PV curve along with varying $\mathrm{PV}$ penetration levels was simulated. Overall, 160 scenarios were simulated for the commercial feeder, and 54 scenarios were evaluated for the residential feeder.

Results indicate that voltage issues were observed only on the residential feeder. All PV penetration scenarios caused voltage issues when the PV was located at the end of the feeder. Voltage issues were also observed for scenarios with PV located at the beginning of the feeder and with PV penetration greater than $40 \%$. In addition, an increase in yearly tap position changes for the substation load tap changer was observed on both feeders with increasing PV penetration. PV penetration had a minimal impact on capacitor switching on the commercial feeder. Capacitor switching attributed to the addition of PV occurred in only 2 out of the 160 scenarios simulated on the commercial feeder. Not surprisingly, as the PV penetration increased - resulting in lower net real power demand - the substation power factor decreased. The authors suggest that advanced capacitor switching controls would easily solve the issue. Finally, the results also show that line losses decrease with increased PV penetration until PV generation-induced reverse power flow dominates. The minimum loss penetration is typically higher for scenarios with PV located at the beginning of the feeder than those at the end.

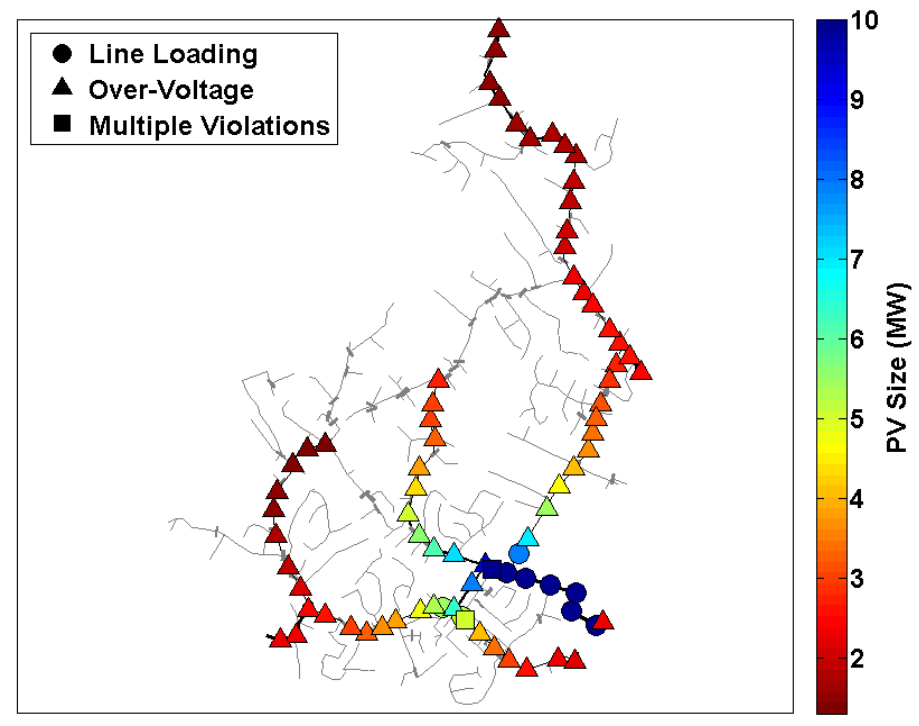

Figure 15. Locational PV hosting capacity for each bus and type of violation that limited the locational PV hosting capacity for the $12.47-\mathrm{kV}$ publicly available distribution system EPRI Circuit number 5 (Ckt5) provided with OpenDSS

Image from Reno and Broderick 2015 


\subsubsection{Other Hosting Capacity Methods}

Expanding on the previous hosting capacity efforts mentioned above, EPRI has developed a modified method that requires the analysis of fewer PV-deployment scenarios than the original Monte Carlo method (Rylander, Smith, and Sunderman 2015). The likelihood of PV placements across a distribution circuit is not a flat distribution function in this method; rather, the distributions encourage higher densities of PV at the beginning, middle, and end of the circuit. This method shows promise for decreasing the computational burden for determining the hosting capacity of distribution circuits.

Commercial distribution system analysis software vendors have also developed hosting capacity toolsets. One example is Electrical Distribution Design's DEW analysis package, which includes a hosting capacity method (Steffel, Acharya-Menon, and Bank 2015). The current state of this tool appears to be generally equivalent to the state of EPRI's DPV hosting capacity method described above.

Additionally, the three main investor-owned utilities in California (Pacific Gas \& Electric [PG\&E], Southern California Edison, and San Diego Gas \& Electric) have developed methods to determine the integration capacity analysis as part of their mandated distribution resources plans (DRPs) (Pacific Gas and Electric 2015; Southern California Edison 2015; San Diego Gas and Electric 2015). Although the three methods differ somewhat, they all attempt to determine the hosting capacity of the distribution circuits in their service territories, either by studying each circuit or using a subset of circuits to represent the largest portion of the service territory, for various technologies deployed at the distribution scale. The technologies include DGPV, DGPV with energy storage, electric vehicles, and traditional DG. The resolutions at which the integration capacity analysis calculations were completed also differed among the utilities. Integration capacity analysis hosting capacity numbers were calculated for line sections of the distribution circuit in some cases and for the entire distribution circuit in others.

\subsubsection{Advanced Hosting Capacity Analysis}

Existing methods to calculate hosting capacity typically focus on modeling a limited number of peak periods, usually the daytime peak and minimum load condition on the feeder and the corresponding peak solar condition. In some cases, a limited amount of time-series analysis will be performed at high time resolution, typically 1 second, for 1 highly variable day. The challenge of running only peak periods or a peak variability day is to know how to extrapolate these results accurately to the full year of operations. Knowing the voltage regulator tap operations caused by solar and load variability is essential to determine the actual impact of DGPV on these crucial and expensive pieces of utility equipment. Paired with accurate load and generation time-series data or models, a quasi-static time-series analysis (QSTS) can accurately measure these effects. QSTS analyzes the power system by solving a series of steady-state power-flow solutions with a fast enough time step to capture control actions with moderately slow, generally multi-second, response times. QSTS with time steps of 1-60 seconds is sufficient to capture the response of typical distribution equipment, including voltage regulators (Paradis, Katiraei, and Mather 2013), and can be simulated for periods from hours to years. 
Broderick et al. (2013) demonstrated how time-series analysis capability is essential for fully analyzing the impacts of PV integration by using QSTS with four high DGPV feeders in Georgia and Utah. In many cases the highest voltage found on a feeder during a study week did not occur at the time of highest PV penetration, highlighting the importance of QSTS's ability to capture interactions of DGPV with the voltage-regulation equipment at other times. QSTS also enables quantifying impacts over time, such as the duration of a voltage deviation or the total number of load tap-changing operations.

QSTS is not commonly performed in PV interconnection studies today because of the data needs and computational burden. The current state-of-the-art of existing power-analysis software tools is limited, the computational times are too long, and data requirements for high-resolution data are difficult to meet for most utilities. Some commercial vendors have recently implemented basic QSTS functionality into their software packages, but typical implementations do not analyze sufficient time periods with fast enough time steps to accurately capture key impacts of DGPV on operations over time. The QSTS functionality of existing tools needs further improvements to achieve faster computation times with more accurate data to represent load and solar variability. Ongoing research seeks to address these issues during the next 3 years by achieving yearlong, high-resolution time-series solutions that can be run in less than 5 minutes to support utility decision-support systems within an acceptable error.

\subsection{Opportunities for Increasing Hosting Capacity}

In addition to advancing the state-of-the-art for determining DGPV hosting capacity as described by the progression of hosting capacity analyses above, there are opportunities to increase DGPV hosting capacity by siting DGPV carefully, adopting technological capabilities (advanced inverters, communications), relaxing the operational changes considered used as limits to DGPV penetration, and using integrated distribution planning. Several of these opportunities are described below. 


\section{Alternatives to California's $15 \%$ Rule}

Beginning in 2012, EPRI, NREL, and Sandia National Laboratories undertook a comprehensive distribution modeling-based project to develop advanced PV interconnection screens for California. Funded by the California Solar Initiative and the U.S. Department of Energy (DOE) and working closely with Southern California Edison, PG\&E, and San Diego Gas \& Electric, the project first completed a review of PV screening practices used in-house at utilities in California and throughout the United States where substantial PV is being interconnected at the distribution level (Coddington and Smith 2014). Concurrently, 21 distribution circuits were selected for inclusion in the study. These circuits were chosen from among the roughly 10,000 distribution circuits found in California using a clustering analysis - an attempt at grouping circuits by metadata characteristics to allow the development of a taxonomy of California's distribution circuits (Broderick and Williams 2013). Models of these circuits were developed and validated using utility-available data from supervisory control and data acquisition systems. Then, using the validated models, the hosting capacity was determined for random deployments of DGPV to be used as a baseline hosting capacity (Rylander, Smith, Broderick, and Mather 2015a). Analysis was completed for residential DGPV and utility-scale DGPV deployment scenarios for each circuit. Various prototype screens were then tested, effectively modifying the PV deployment within the circuit model, for improving fast-track DGPV interconnections along the lines of California's Rule 21, which institutes a $15 \%$ distributed generation penetration limit for fast-track DGPV interconnections (Rylander, Smith, Broderick, and Mather 2015b).

The study's results can be used to inform future revisions of California's Rule 21 . Specifically, the presence of line voltage regulators on the circuit was verified as a likely indication of a circuit with lower PV hosting capacity. This is due to the use of voltage regulators on circuits that are typically longer (i.e., higher impedance) than circuits without a regulator, and it is due to the use of maximum PV hosting capacity metrics that limited PVinduced voltage deviations on the circuit to a level that would not impact (i.e., operate) voltage regulators on the circuit. Allowing voltage regulators to operate during hosting capacity analysis could increase the hosting capacity of these circuits. Additionally, relatively easily computed equations, called shorthand equations, were developed that calculated the hosting capacity of a circuit directly using circuit-impedance characteristics and metadata. Analyzing a set of six circuits, reserved at the beginning of the study for validation purposes, showed that the shorthand equations accurately predicted a circuit's DGPV hosting capacity. The relationship of the developed screens and shorthand equations to California's DRPs was discussed in the project's final report (Rylander, Smith, Broderick, Reno, et al. 2015).

\subsubsection{Carefully Siting Distributed Generation from Photovoltaics}

The concept that some locations on a feeder can accommodate more DGPV than othersintroduced in Figure 14 and Section 3.1.3 - suggests that careful DGPV siting offers a technically easy way to increase the no-changes-required hosting capacity of the existing distribution system. Moreover, it is generally easier to accommodate more spatially distributed DGPV than to accommodate DGPV concentrated in a single region. 


\subsubsection{Using Advanced Inverters}

Research has shown that PV inverters can effectively regulate the voltage at their point of common connection (von Appen et al. 2014a; Smith et al. 2011). The hosting capacity is often limited by voltage violations, and the application of advanced inverters can help overcome the voltage violations and thus improve the hosting capacity (Seuss et al. 2015). Traditional hosting capacity makes conservative assumptions about system operations and assumes unity power factor output from inverters, resulting in the most difficult challenges in voltage rise. Advanced inverter functions - including constant power factor setting, volt/VAR control, and volt/watt control — can be used to adjust the amount of reactive power (VAR) and real power (watts), and hence power factor, to help overcome voltage challenges and improve hosting capacity.

To explore these interactions further, we studied 18 utility distribution feeders and found that the application of advanced inverters can help increase the hosting capacity by about 1.5-3 times. Figure 16 shows the hosting capacities of three of the 18 feeders we studied before and after the application of advanced inverters control. It shows how the results vary considerably among feeder configurations. For the base case, all PV inverters operate at unity power factor, injecting only pure real power in to the grid. The green bar denotes the result after changing the power factors of all $\mathrm{PV}$ inverters to 0.98 absorbing, absorbing reactive power to mitigate voltage rise. The yellow bars show the results of using advanced volt/VAR control for all PV inverters such that the reactive power outputs from PV inverters are automatically adjusted based on the voltage results. The setting points of the volt/VAR curve used are given as:

$$
Q=[100 \%, 0 \%, 0 \%, 100 \%] \text { and } V=[0.95 p u, 1 p u, 1 p u, 1.05 p u]
$$

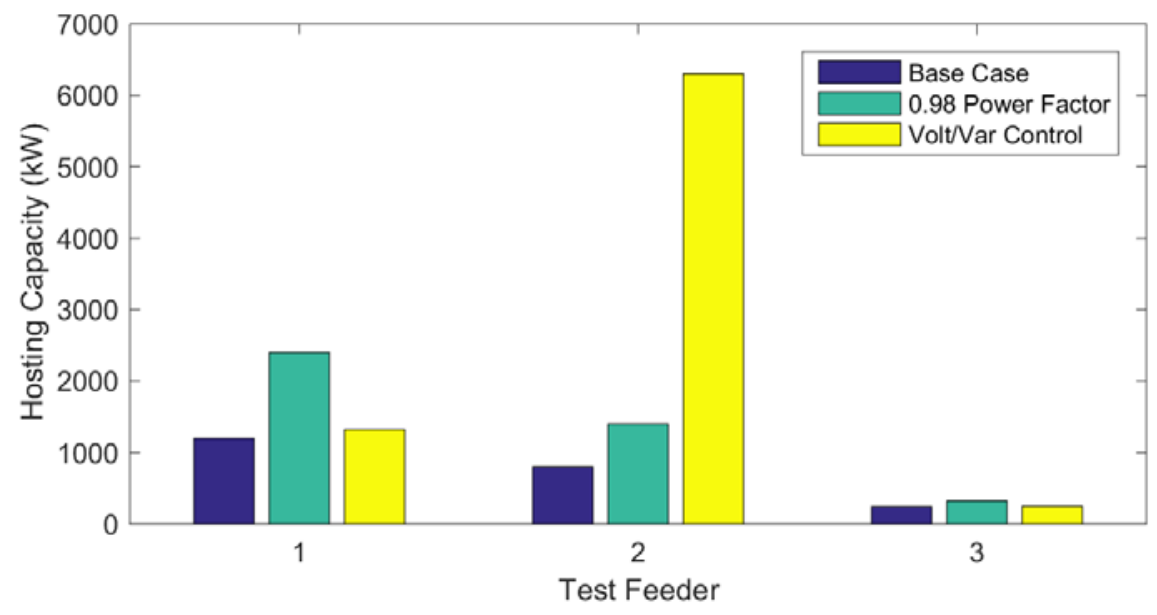

Figure 16. PV hosting capacity of three test feeders with various voltage control modes

Feeder-3 has line regulators, and the line regulators are locked to the initial tap position when PV is connected during analysis. After changing the unified power factor from unity to 0.98 absorbing, the hosting capacity of feeder-1 is increased from $1,200 \mathrm{~kW}$ to $2,400 \mathrm{~kW}$, and the hosting capacity of feeder- 2 is increased from $800 \mathrm{~kW}$ to $1,400 \mathrm{~kW}$. The hosting capacity of feeder-3 remains the same. After applying the volt/VAR control, the hosting capacities of feeder1 and feeder- 2 are increased to $1,320 \mathrm{~kW}$ and $6,300 \mathrm{~kW}$, respectively. This result shows that both 
constant power factor and volt/VAR control can improve hosting capacity, but the performance is highly dependent on feeder characteristics.

The hosting capacity of feeder-3 remains very low because voltage violations occur even at low PV penetrations, for two reasons: (1) the feeder with line regulators is generally long and weak, and thus it is more likely to use a wide swath of the allowable voltage range along the circuit; and (2) the line regulator is locked to the initial position, so the voltage cannot be adjusted automatically after integrating PV, which limits potential voltage deviation as well as (possibly unnecessarily) the DGPV hosting capacity by enforcing that the circuit's voltage profile must closely match the original "no DGPV" profile.

Figure 17 shows similar results for the average hosting capacity increase for 216 feeders, ${ }^{15}$ assuming all voltage violations are mitigated by advanced inverter functions.

In both analyses, the improvements for different feeders can be quite different. To provide the most helpful support from advanced inverters, the optimal constant power factor setting, volt/VAR optimization, and volt/watt optimization must be investigated through modeling. An important area for future research is improving the understanding of which types of controls and settings to use as a function of feeder and deployment configuration.

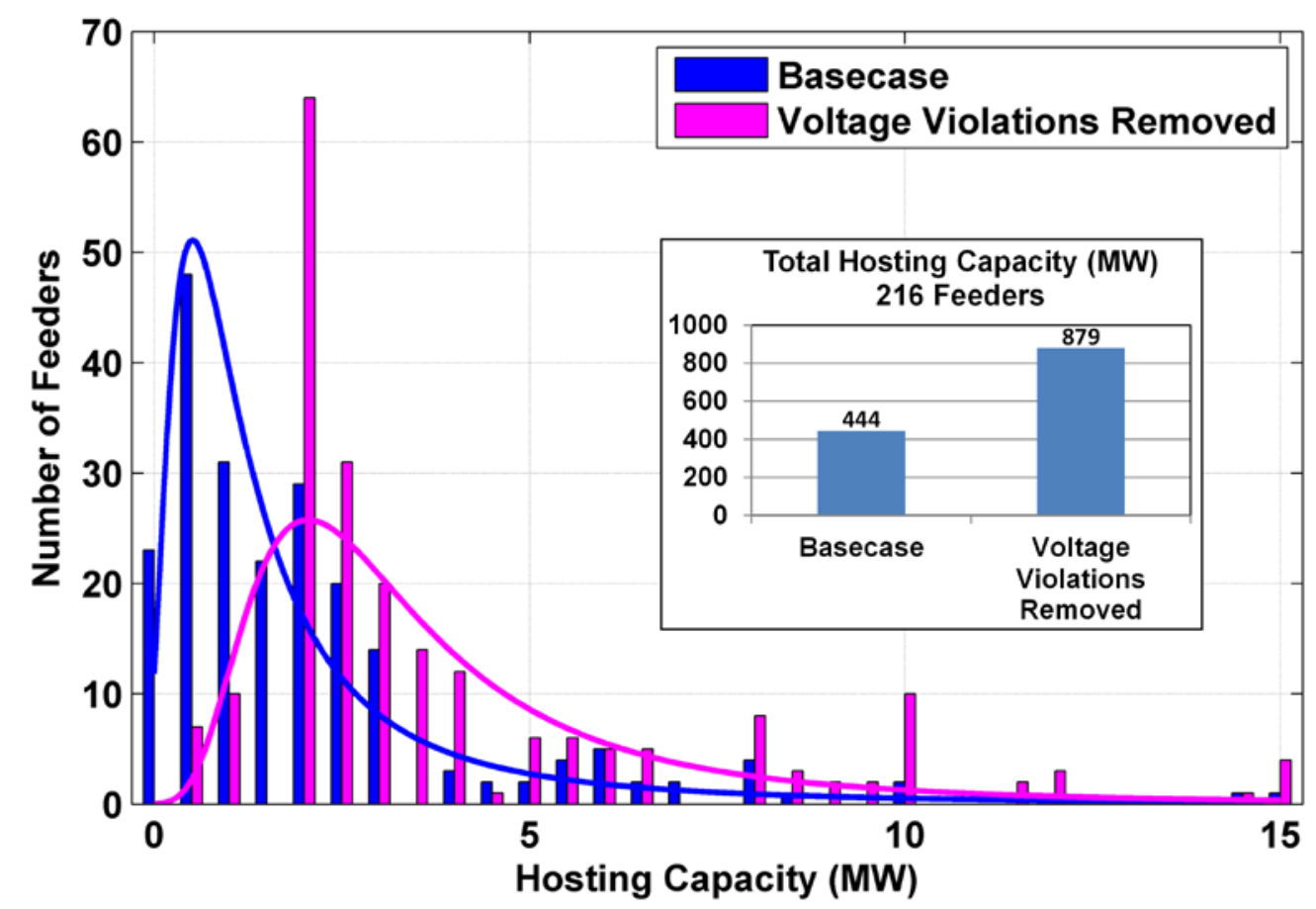

Figure 17. Hosting capacity increase for $\mathbf{2 1 6}$ feeders assuming that all voltage violations are mitigated by advanced inverter functions

Image from Reno and Broderick 2016

\footnotetext{
${ }^{15}$ This set of 216 feeders was synthesized from a smaller set of a few dozen feeders by varying control settings and other parameters to force a diversity of conditions.
} 


\subsubsection{Relaxing Regulator Limits}

During traditional PV hosting capacity studies (e.g., using EPRI's DPV tool), all regulators and capacitor switches are locked at their initial states because it is assumed that all regulating equipment has slower response times than the speed of cloud transients. If such short-time-scale transients are expected to be less common due to the distributed nature of a specific DGPV deployment scenario (i.e., many small systems instead of large utility-scale systems), automatic tap changing at each regulator could improve the voltage profile and thus increase the potential DGPV hosting capacity.

Among the three feeders analyzed in Section 3.2.2, feeder-3 has a voltage regulator, and we analyzed it to demonstrate the impact of allowing the regulator to operate to help manage voltage. Figure 18 shows the hosting capacity of feeder-3 after relaxing the constraints on voltage regulator movement, compared to the initial result (i.e., locked voltage regulators). After relaxing the regulator's movements, the hosting capacity increased roughly $50 \%$ to $360 \mathrm{~kW}$.

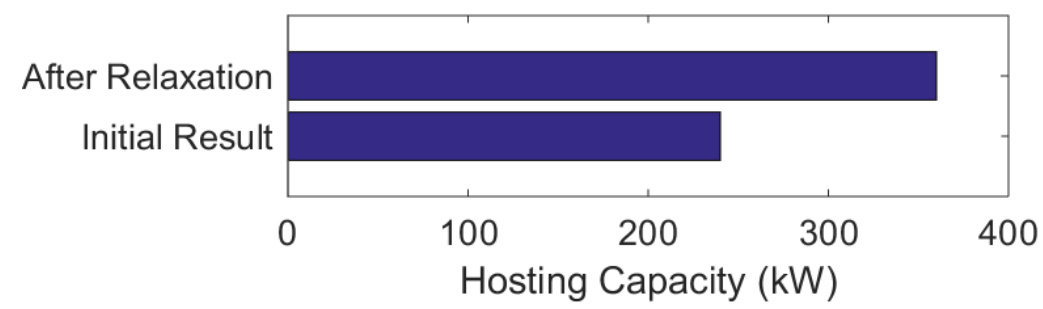

Figure 18. Increased hosting capacity due to relaxing regulator limits

\subsubsection{Planning for Integrated Distribution}

Integrated distribution planning is a proactive approach for accommodating high penetrations of distributed generation resources (Lindl et al. 2013). It leverages existing distribution system planning tools to estimate the hosting capacity of distribution circuits in advance of a particular interconnection request. This is also now becoming common when utilities are required to file distributed resource plans (Carson and Davis 2014). However, integrated distribution planning goes beyond hosting capacity analysis by also anticipating DER growth and then identifying any potential infrastructure upgrades needed to accommodate that growth. This approach may benefit utilities and developers through more efficient planning, improved interconnection timelines, and reduced interconnection costs.

The typical utility interconnection process today is still largely reactive, waiting for an application to interconnect a generator before potential impacts to safety, reliability, and power quality may be assessed. The reactive nature of this approach means that the hosting capacity of a distribution circuit (the ability to accommodate new distributed generation without upgrading the circuit) is determined after an interconnection request is received, if it is determined at all. To facilitate interconnection of high penetrations of distributed generation, some utilities (e.g. State of Hawaii Public Utilities Commission 2013) are beginning to consider approaches to integrated distribution planning by proactively studying distribution circuits and determining their hosting capacities in advance. 
When fully implemented, integrated distribution planning combines DER growth forecasts with hosting capacity analysis and upgrade planning in the multi-step process shown in Figure 19. The results of this proactive study can speed subsequent interconnection requests by estimating in advance the level of distributed generation that can be accommodated without impacts. Where anticipated growth exceeds a distribution circuit's hosting capacity, the utility can plan in advance what additional infrastructure that may be necessary to accommodate the anticipated growth. As DERs are deployed on a circuit, additional - perhaps regularly scheduled - hosting capacity studies could be completed to inform future interconnections.

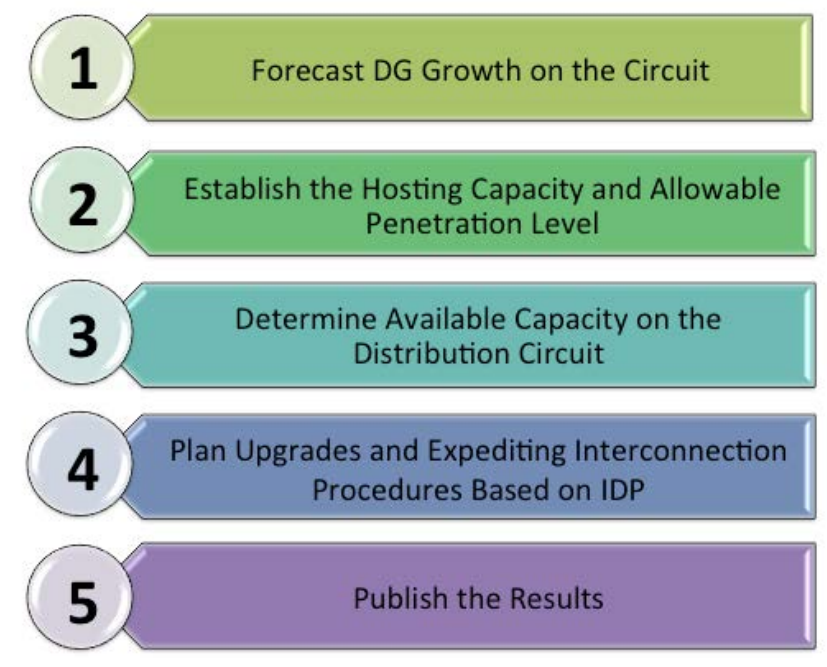

Figure 19. Steps for integrated distribution planning Image courtesy of Lindl et al. 2013

\subsection{Prior Utility-Wide Hosting Capacity Studies}

Part of the integrated distribution planning process is beginning to be adopted by multiple utilities where hosting capacity analysis is conducted in advance to help speed interconnection request processing both utility wide (e.g., for PG\&E, Southern California Edison, and San Diego Gas \& Electric) and on a trial basis (such as for Hawaiian Electric Company and Commonwealth Edison). Such analysis is further enabled by the recent availability of hosting capacity analysis integrated into commercial distribution planning tools (EPRI 2015a).

\subsubsection{California}

As required by the California Public Utilities Commission, the investor-owned utilities operating in California (Southern California Edison, PG\&E, and San Diego Gas \& Electric) filed distribution resource plans (DRPs) on July 1, 2015 (California Investor-Owned Utilities 2015). These DRPs aim to identify optimal locations for the deployment of various DERs and to identify the additional grid investments needed to integrate DERs in a safe, reliable, and costeffective manner. As a part of the DRPs, the investor-owned utilities were required to develop publicly available integration capacity analyses of their service territories to increase the transparency of DER interconnection practices and to inform those requesting DER interconnection of areas where interconnection would be more or less beneficial and costly to the existing electrical power system. This type of analysis could also be useful for determining 
utility-wide hosting capacity and identifying the most common barrier to higher DGPV penetrations. (See the sidebar below on "Determining the Scale of Integration Challenges from DRP Data." See also the Appendix B for DRP-derived, utility-wide estimates of DGPV hosting capacity.)

\subsubsection{Tennessee Valley Authority/Electric Power Research Institute}

EPRI began a project in 2014 with the Tennessee Valley Authority and the 155 individual local power companies that Tennessee Valley Authority serves to understand how higher penetrations of distributed generation would impact their distribution systems and planning efforts. EPRI applied a new streamlined hosting capacity methodology to more than 300 distribution feeders to create detailed hosting capacity maps for use in system-wide distribution planning (Figure 20). The streamlined methodology has reduced the time to analyze a feeder from weeks down to less than 10 minutes. The new methodology can be used with existing software and planning tools to determine ways to reinforce distribution systems that face increased deployment of DER such as rooftop solar and energy storage. EPRI is also working with utilities and the developers of utility planning tools - such as CYME, Milsoft, and Synergi- to support the use of its methodology with existing utility databases and software.

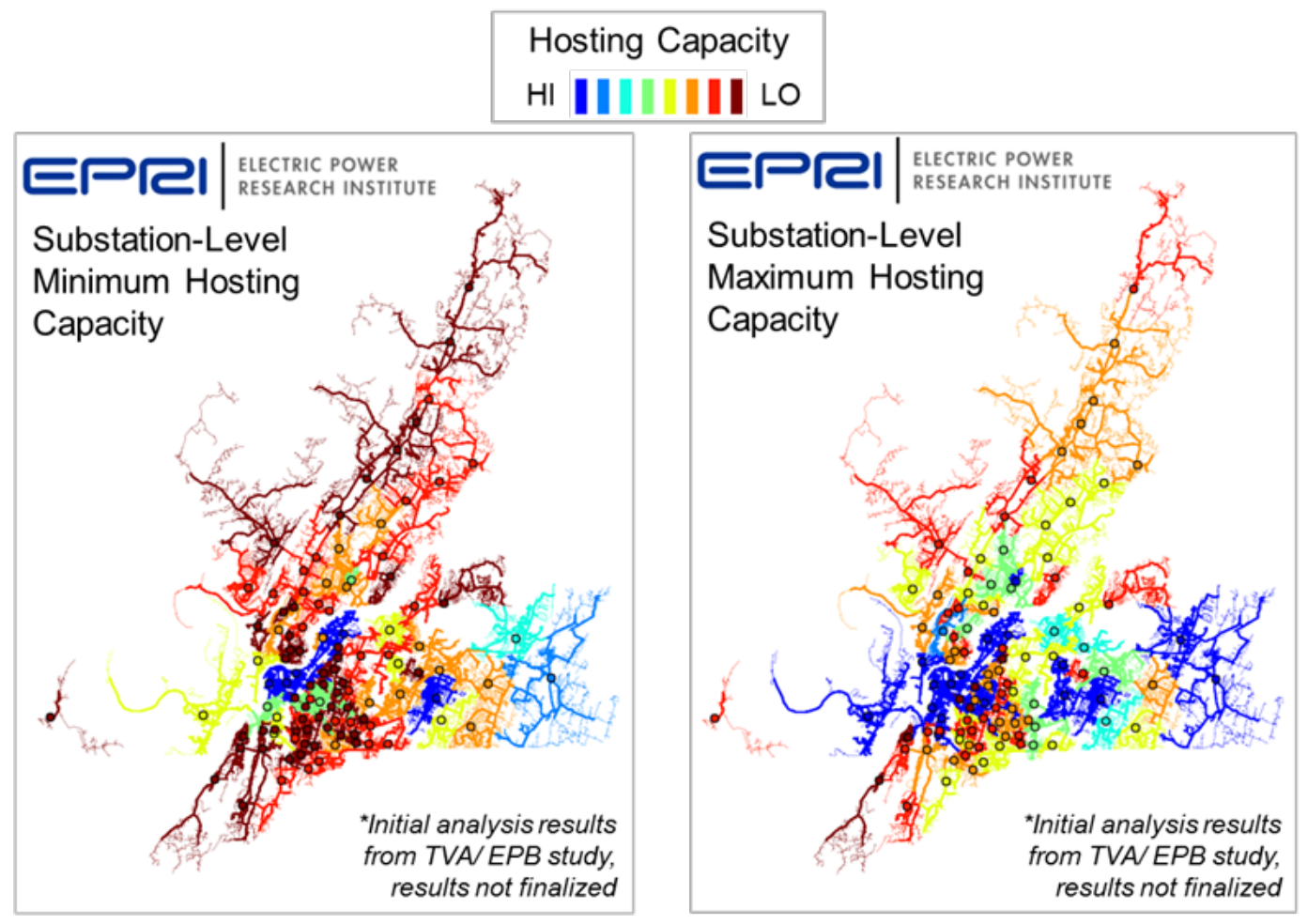

Figure 20. Study from EPRI and the Tennessee Valley Authority on hosting capacity at the substation level for more than $\mathbf{3 0 0}$ distribution feeders

Images courtesy of EPRI Rylander 2015 


\section{Determining the Scale of Integration Challenges from DRP Data}

We used the publicly available data sets from California's DRP integration capacity analyses to examine what scale of spatial interaction is most limiting for DGPV. PG\&E's results include the most detailed information about the estimated DGPV hosting capacity for their distribution system (Pacific Gas and Electric 2015) at three different scales: circuit line section (i.e., a portion of a distribution system divided by protection devices), complete feeder, and substation transformer bank (typically a single substation transformer serves multiple feeders). To clarify the interactions of these limits, we evaluated which of these scales most severely limited hosting capacity. A complication of this analysis is that the linesection hosting capacities are not cumulative but rather represent the maximum amount of DGPV that could be installed on that line section when all other line sections had no DGPV installed. To overcome this, we varied the amount to "derate" the sum of the line sections and compared this result to limits at the feeder and substation bank levels. Figure 21 shows how even with severe derating (70\%) of the line segments, DGPV hosting capacity is most oftenfor about $70 \%-80 \%$ of circuits - limited by the feeder-level DGPV impacts. Less than $20 \%$ of the feeders are limited by the substation transformer bank. However, as DGPV penetration grows, feeder-to-feeder interactions are expected to grow, suggesting an important area for future research in multi-feeder combined hosting and interconnection analysis.

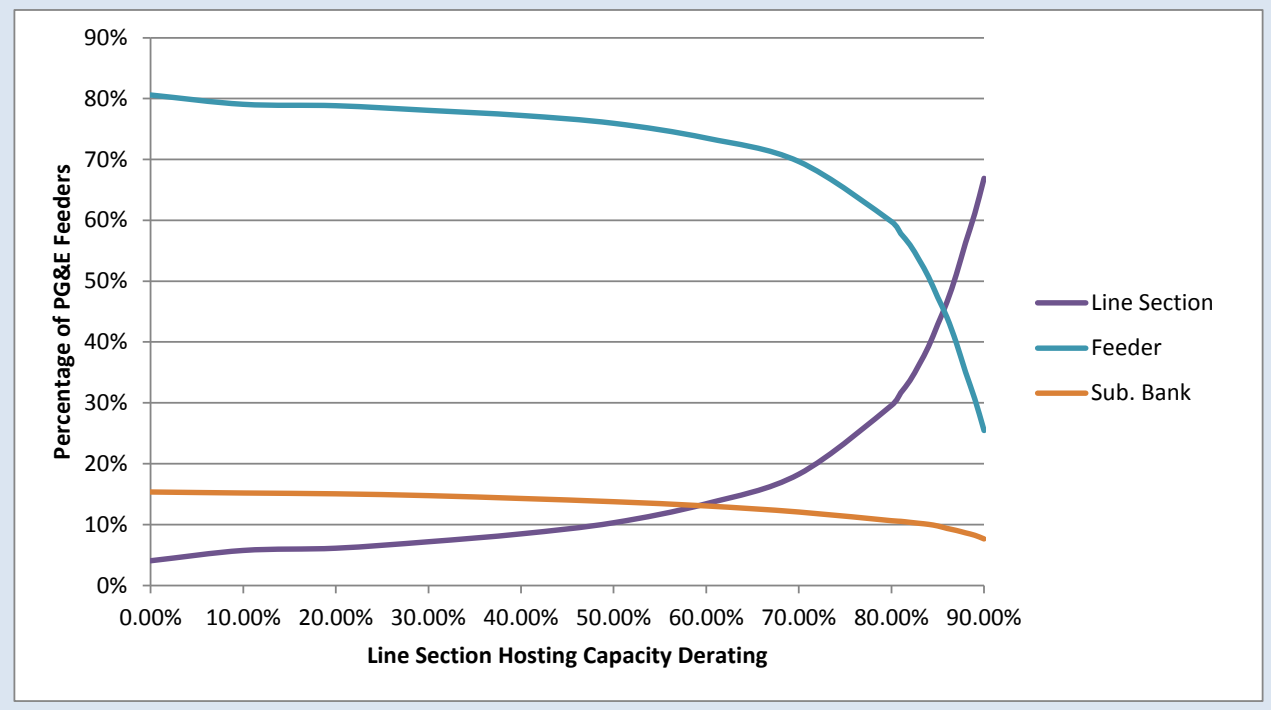

Figure 21. DGPV hosting capacity limiting element for PG\&E's service territory

\subsection{Statistical Estimates of Nationwide Hosting Capacity}

Building off detailed, individual-feeder hosting capacity analysis, we employed statistical techniques to develop a rough estimate of the total amount of solar that can technically be integrated into the U.S. distribution system with little or no change in operations or cost ${ }^{16}$. Specifically, as described further in the appendix, individual-feeder hosting capacity results for

${ }^{16}$ A detailed, expanded description of this analysis is forthcoming. 
16 feeders from the "Alternatives to the 15\% Rule" project (EPRI 2015b) plus eight additional feeders analyzed by NREL from outside of California were used to develop a multivariate regression model to estimate feeder-by-feeder hosting capacity as a function of available descriptive metadata. Then, the best model was used to estimate system-wide hosting capacity using state-level feeder metadata. Finally, this value was scaled to a nationwide estimate based on the ratio of state to national peak loads. The aggregate estimates were then cross-referenced against sums for 3,000 feeders based on DRP data for PG\&E, and they were found to match closely.

This approach estimates that the U.S. distribution system can accommodate at least $170 \mathrm{GW}^{17}$ of DGPV using traditional inverters with little or no change to distribution system operations. As described above, using advanced inverters to help manage local voltage impacts would roughly double this estimate (see Section 3.2) to around $350 \mathrm{GW}$ of DGPV. This estimate assumes DGPV is distributed among feeders based on their minimum hosting capacity. In practice, customer demographics, land/roof availability, and other factors are key determinants for DGPV siting and often may not match these locations. However, if locational hosting capacity were used to optimize placement of DGPV's location within each feeder, it would be possible to reach the typically much higher maximum hosting capacity, enabling even higher amounts of DGPV to connect.

Although these technical estimates do not consider resource availability, economic viability, or transmission-level constraints; they do suggest that the distribution system could continue to support a majority of PV integration in 2050 under all of the NREL Standard Scenarios (Sullivan et al. 2015) which range from 142-559 GW of total solar capacity.. Still, these estimates are likely conservative because they are based on the strict no-changes threshold used with traditional hosting capacity approaches. They also do not include the potential for simple changes to distribution operations that may have low to moderate costs and would enable even larger integration of DGPV. Likewise, increased adoption of storage and/or other complementary technologies would greatly increase all of these hosting capacity estimates. Additional description of the techniques used for this analysis can be found in the appendix.

\subsection{Research Needs on Distribution Hosting Capacity}

Although, our nationwide estimates suggest that the distribution system, as whole, can accommodate high levels of DGPV with few changes, these levels are only possible if PV were sited optimally for hosting capacity. Hence, local hosting capacity estimates are still critical to identifying these preferred locations. Further, DGPV adoption may be driven by other factors toward other more challenging locations. In these contexts, understanding hosting capacity with advanced inverters and other technologies will be critical to achieving very high penetrations of DGPV. And, despite the considerable recent strides made in understanding and deploying hosting capacity estimates, there remain outstanding research directions for enabling these techniques to efficiently achieve their full potential:

- With the advent of DRPs and similar efforts, the tools and methods used to determine hosting capacity must be improved so - as DGPV is integrated - they can be used

${ }^{17} 170 \mathrm{GW}$ is a median estimate of minimum hosting capacity; the $90 \%$ credible range is $98-430 \mathrm{GW}$ 
regularly to update the remaining hosting capacity available for specific circuits. Such improvements include reducing the time required to complete a study, integrating the interchange of data between tools and data sources, and increasing the fidelity of input data sets for distribution-connected load and generation.

- Further development of locational or line-segment-based hosting capacity is needed to investigate utilities' ability to encourage DGPV at optimal locations within their distribution systems. Such work could also inform utility incentives - or full market development - for additional grid services that DGPV could provide.

- An improved understanding of how feeder characteristics and advanced inverter features impact hosting capacity would help utilities by providing a more accurate, alternative prescreen that could enable rapid screening for feeders and utilities where more widespread precomputed hosting capacity was not in place.

- Developing more advanced, automated assessment of feeder-level upgrades that may considerably increase DGPV hosting capacity could provide many PV impact-mitigation options for future PV interconnections. Additionally, developing a way to compare the costs of various upgrade choices quickly and accurately could be invaluable for utilities and developers alike.

- Going beyond hosting capacity to also develop techniques to simultaneously determine the corresponding optimal settings - power factor or volt/VAR (watt) curve for advanced inverters - would enable utilities to rapidly interconnect the maximum amount of PV today that leverage such advanced features.

- DGPV unintentional islanding during utility outages remains a concern for many utilities, yet current hosting capacity estimates use fairly crude assessments for islanding. This suggests the need for developing a more sophisticated multi-distributed generation islanding screen/assessment that accounts for various mixes of distributed generation types, the presence of active controls (from advanced inverters), and the amount of distributed generation on a circuit.

- As greater amounts of relevant data become available, those data can be incorporated into DGPV interconnection/hosting capacity studies to improve results. For instance, hosting capacity computations could be made more accurate by incorporating customer demographics, roof space availability, orientation, and tree cover into residential and commercial rooftop solar adoption scenarios.

Additionally, the initial nationwide estimates presented in this report are simply the first step in what could grow into a key new research area. Specific next steps include:

- Refining the nationwide estimate using the results from a larger data set of feeder-level hosting capacities, potentially developing regional estimates, and extending this analysis to more rigorously account for advanced inverters and other technologies; and

- Expanding beyond line segment and feeder-level hosting capacity to integrate operational limits that might be imposed by the substation or transmission systems. 


\section{Interconnection}

Transitioning to a SunShot future with hundreds of gigawatts of solar will require further streamlining of the still time-consuming interconnection process and evolving associated interconnection standards to embrace DGPV systems as key contributors to system-wide operations. When the SunShot Initiative began in 2011, DGPV interconnection processes were largely based on early 2000s practices that already needed updates (Fox et al. 2012), DGPV was expected to trip off-line during grid disturbances (IEEE 1547 2003), and most smaller DGPV participated in net energy metering (NEM) tariffs. Today, there is growing acceptance that revisions to interconnection procedures, standards, and tariffs may be needed to most effectively integrate high penetration DGPV. Yet, even as these changes begin, there is still considerable effort required to further streamline processes, agree on technical standards — particularly for advanced inverters - and provide effective rates for DGPV.

\subsection{The Interconnection Process}

The United States has 3,250 utilities and nearly as many different interconnection processes. However, many utilities follow a general process that starts with an interconnection application and ends when permission to operate has been obtained. Figure 22 provides a summary of this process based on a survey of 21 utilities in the United States (Coddington and Smith 2014).

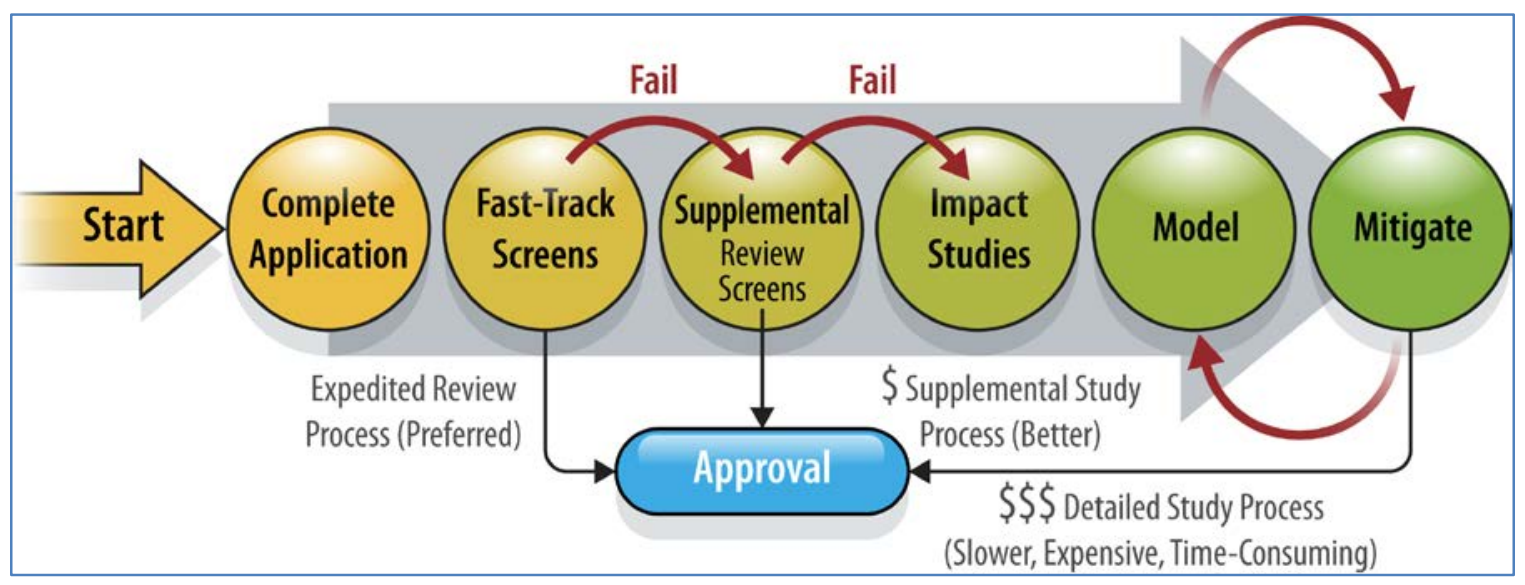

Figure 22. General interconnection process used by U.S. utilities

The interconnection process begins when a PV developer completes an interconnection application. Once they receive the application, most utilities apply a set of technical screens (also known as "fast-track screens") generally based on the Federal Energy Regulatory Commission's Small Generator Interconnection Procedures (SGIP) (Figure 23). ${ }^{18}$ These allow a utility specialist to review a PV application and grant fast-track approval if it passes the screens. If these screens fail, the application may still be rapidly approved based on utility-adaptable supplemental screens, or it may require more time-consuming and expensive in-depth impact studies. Detailed impact studies may conclude that the proposed interconnected system may or

\footnotetext{
${ }^{18}$ The SGIP outlines the formal process utilities and interconnecting customers must follow when evaluating a request for parallel operation of a generating facility with the electric power system. The SGIP applies to new facilities and facility expansions with generation outputs of $20 \mathrm{MW}$ or less.
} 
may not require mitigation strategies. Mitigation strategies may be no-cost or low-cost changes to the system design and operation, or they may require DER equipment changes or utility system upgrades.

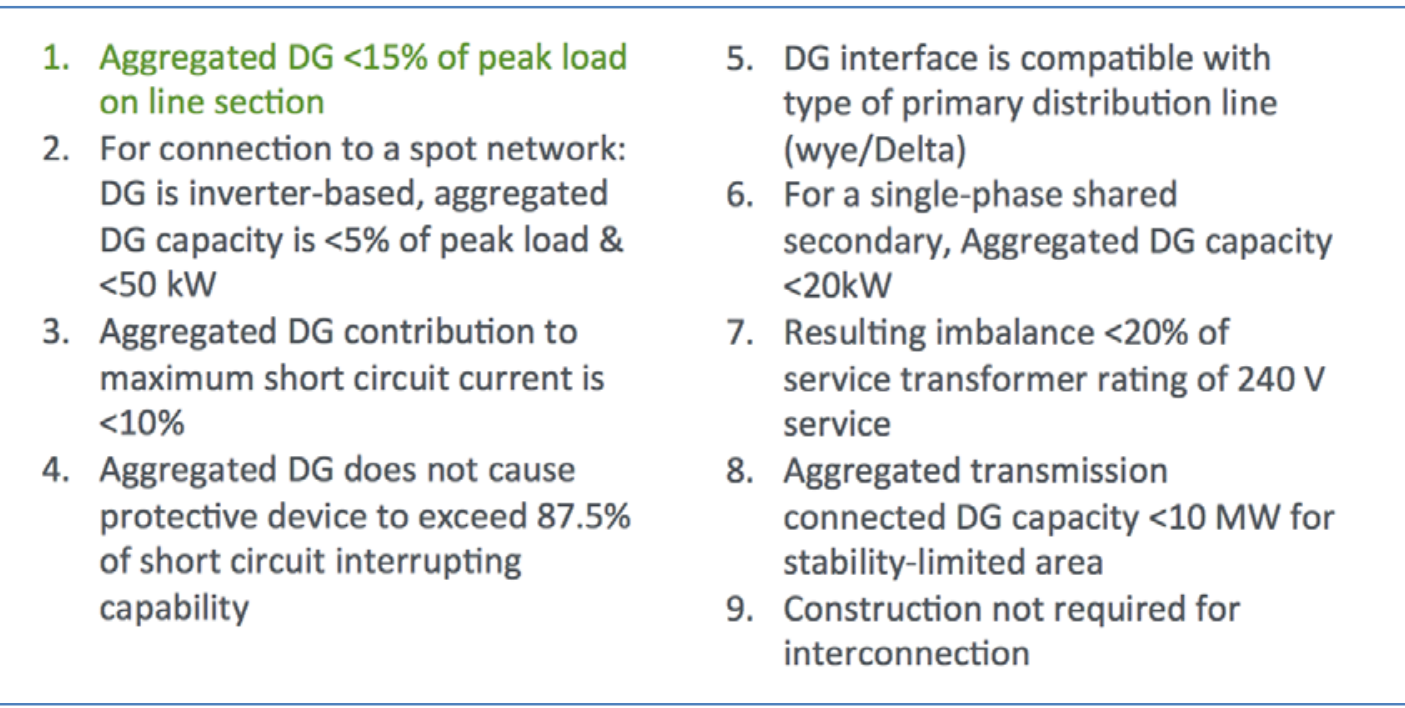

Figure 23. Example of the SGIP fast-track screening process often employed by U.S. utilities Image from FERC 2013

In 2013, the Federal Energy Regulatory Commission made some revisions (2013) to help expand the number of systems that could be approved quickly as a result of industry inputs and reports by NREL (Coddington et al. 2012) and the Interstate Renewable Energy Council (Fox et al. 2012). These revisions enabled larger (up to $5 \mathrm{MW}$ ) generators to participate in fast-track screens and provided developers with a pre-application report to help determine the viability of interconnection. More importantly, updates provided for the supplemental review screens that may allow some PV systems to be approved even if they fail the fast-track screens, including flexibility with the $15 \%$ penetration rule.

If a PV interconnection application fails both types of screens, or if a PV system is too large based on the SGIP limits (larger than 0.5-5 MW depending on feeder voltage and DGPV location), the application will go through a detailed impact study. A detailed impact study is complex and time consuming, and it requires a utility engineer to use modeling software by inserting the proposed PV system into a feeder. If there are problems (such as high voltage, protection miscoordination, etc.), the engineer will seek to mitigate that problem in the software and arrive at a solution. The solutions used by the various utilities can be quite different, and prices can be significantly different from one strategy to another. Finally, if a PV developer agrees to pay for the mitigation strategies, construction can begin, and the permission to operate can finally be achieved. (See the sidebar below on "When Fast Screens Fail: A Closer Look at In-Depth Impact Studies.”) 


\section{When Fast Screens Fail: A Closer Look at In-Depth Impact Studies}

An analysis of 100 completed PV SGIP studies was performed by Sena, Quiroz, and Broderick (2014) to identify the most common impacts for large DGPV system interconnections and the costs to mitigate adverse system impacts. The data for the study came from nine U.S. utilities for PV facility sizes ranging from 1-20 MW. Generating facilities entered the study process by failing fast-track screens and other requirements.

It was observed that the interconnection topologies were strongly correlated to the incidence of adverse impacts. Generally, adverse system impacts for large DGPV were more probable if the generating facility interconnected through an existing distribution circuit. Adverse system impacts were found in $68 \%$ of generating facilities interconnecting through existing distribution circuits. Adverse system impacts were less probable if the facility required the construction of a new distribution circuit. Adverse system impacts were found in only $14 \%$ of facilities interconnecting through newly constructed distribution circuits. Building new distribution circuits to interconnect generating facilities essentially limits the amount of existing equipment outside of the substation exposed to possible adverse system impacts.

The two most interesting general results from the study are that (1) $44 \%$ of generation facilities that entered the SGIP detailed impact study process had no adverse impact on the electric power system, and (2) protection impacts were the most common adverse system impact ( $43 \%$ of the studies). The fact that $44 \%$ of the requests that went into the study process identified no negative impacts suggests that more efficient screening methods are needed to avoid this high rate of false positives and time-consuming studies that ultimately find no adverse impacts. Most protection impacts were associated with transfer-trip requirements to protect against generation facility islanding. Mitigation costs for protection ranged from $9 \%$ to $69 \%$ of total interconnection costs. When mitigation was required, $50 \%$ of the SGIP studies identified total connection costs of less than $\$ 690,000$ and less than $\$ 133,000$ per megawatt.

\subsection{Key Codes and Standards}

Independent of the path taken through the interconnection process, distributed generation including DGPV is subject to a number of technical codes and standards that seek to ensure the safe, cost-effective, and reliable interconnection of DGPV. Many of these are presently under significant revision and will likely require DGPV to participate more actively in grid operations. Examples of grid-support functions include frequency ride-through and frequency-watt control, voltage ride-through, and active voltage control. These updates build upon a combination of recent research (see the in-depth literature review in the appendix) and international examples, such as the German grid standards (Braun et al. 2011), that offer key insights into higher DGPV penetrations despite important differences in grid configuration. (See the sidebar below on "North American versus European Distribution Systems.") 


\section{North American versus European Distribution Systems}

It is important to understand critical differences in distribution system design when comparing PV interconnection in North America to that in most European countries. The North American standard is for single-phase, 120/240-volt service to each residential and small commercial customer, whereas most European customers receive three-phase, 400/230-volt service. With the need for only a single phase to most loads, the North American system makes extensive use of single-phase "laterals" at medium voltage $(4-30+\mathrm{kV})$ that may radiate considerable distances from the "trunk" three-phase medium voltage backbone. As a result, the trunk and substations in North America are unbalanced phase-to-phase, whereas those in Europe are balanced. Transformer size for residential and small commercial customers also varies greatly. In North America, 25 or $50 \mathrm{kVA}$ transformers typically provide service to only 1-10 customers, whereas European transformers are generally 500 or $1,000 \mathrm{kVA}$ and serve dozens or hundreds of customers through an extensive low voltage $(400 / 230 \mathrm{~V})$ radial network. These and other differences impact the distribution system's ability to accommodate DGPV. In general, the larger, three-phase European systems with more homes per transformer are able to more readily accommodate high levels of DGPV.

Dozens of interrelated codes and standards are behind successful electric system and DGPV design and integration. Figure 24 illustrates how some of the most important cover a range of perspectives. Specifically, the IEEE 1547 family of standards applies at the point of common coupling, the National Electrical Safety Code covers a larger area on the utility side, and the National Electrical Code and Underwriters Laboratories Standard 1741 apply to the customer side of the meter.

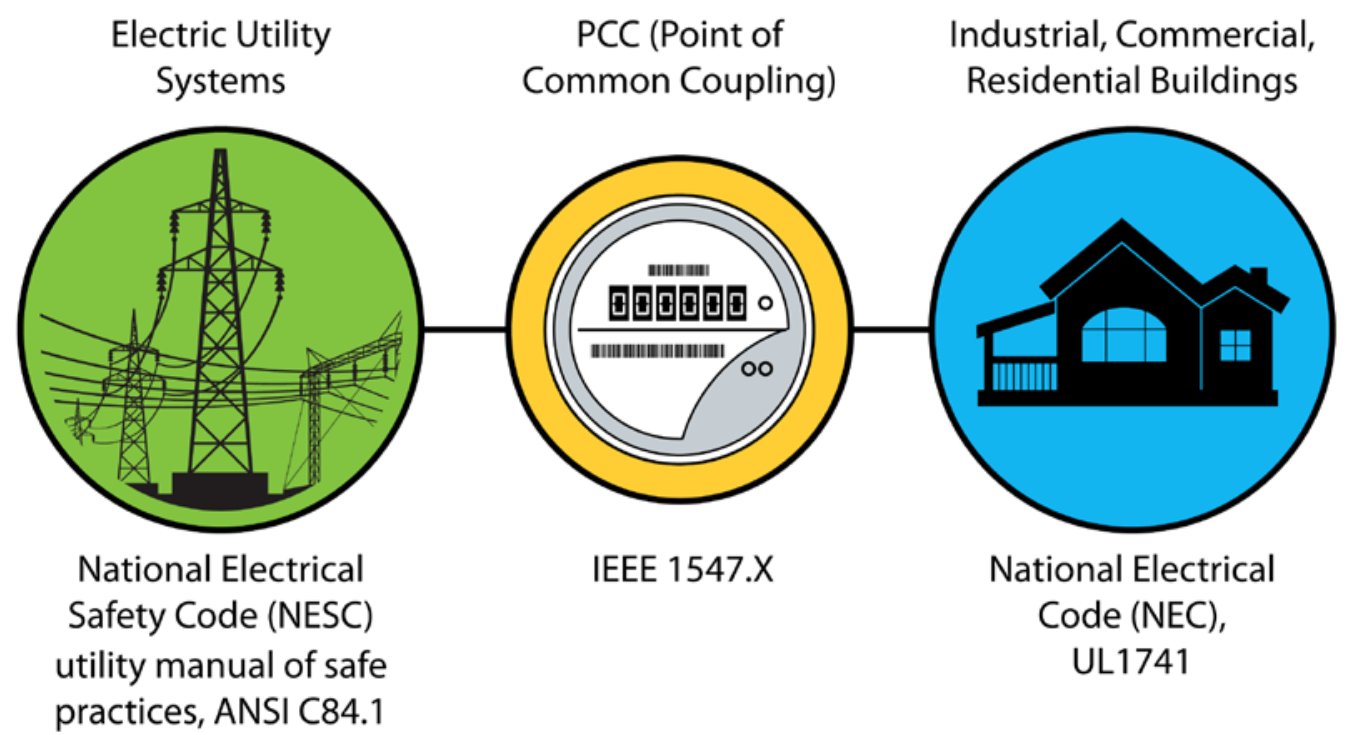

Figure 24. Illustration of the application of the important PV codes and standards

\subsubsection{Institute of Electrical and Electronics Engineers Standard 1547}

The IEEE 1547 Standard for Interconnecting Distributed Resources with Electric Power Systems provides requirements for interconnecting all types of distributed generation systems, including 
PV. ${ }^{19}$ When first approved in 2003, it provided critical standardization for previously diverse interconnection requirements, but it explicitly instructed DERs to disconnect during over/under frequency and voltage events and forbade DERs from actively regulating the voltage ${ }^{20}$ (IEEE 1547 2003). Prompted in part by the large growth in DGPV, the original standard was amended in 2014 to make it possible — but not required - for utilities to work with DERs to require better grid support by regulating voltage and/or riding through grid frequency and voltage disturbances (IEEE 1547a 2014). A full revision of the standard is currently underway and is eventually expected to require configurable and default requirements for DERs to support grid operations including frequency and voltage ride-through requirements that parallel those for transmissionconnected generation, explicit support for advanced inverter functions including voltage control, and provisions to diversify the responses of DERs to avoid adverse system-wide impacts. (See the sidebar below on "Overcoming Germany's 50.2-Hz Problem.") The IEEE 1547 series also includes complementary standards and guidelines, 1547.1-1547.8, for testing, larger systems, microgrids, and other applications. The testing guidelines (1547.1) are also undergoing full revision to complement core standard changes.

\subsubsection{Underwriters Laboratories Standard 1741}

Underwriters Laboratories (UL) Standard 1741 - Standard for Inverters, Converters, Controllers and Interconnection System Equipment for Use with Distributed Energy Resources-is a safety standard for inverters and other equipment used with standalone and grid-connected power systems, including PV systems (Underwriters Laboratory 2010). In most jurisdictions, customerowned-but not utility-owned - inverters must be UL 1741 qualified to interconnect. The standard is harmonized with IEEE 1547 and IEEE 1547.1 and as such is also undergoing a full revision. This update is lagging behind the 1547 amendments, with UL 1741 Supplemental A not likely to be approved until early 2016, two years after IEEE 1547a, to match the provisions in IEEE 1547A and support emerging advanced inverter requirements in California and Hawaii (see also Section 4.4).

\subsubsection{American National Standards Institute Standard C84.1-2011}

The ANSI C84.1-2011 (ANSI 2011) specifies acceptable voltage levels for utility services to customers. It sets the threshold for unacceptable voltage disturbances as described in Section 2.1.

\subsubsection{National Electrical Code/National Fire Protection Association Standard 70}

The National Electrical Code provides safety requirements for all customer electronic wiring and installation. For PV systems, it includes the underlying wire, conduit, and equipment sizing and specifications. Also provided by the National Fire Protection Association is Standard 70, which provides additional specifics aimed directly at preventing fires. Specifically, National Fire Protection Association 70 Article 690 provides PV-specific rules, and a new article is planned to address specific concerns with larger utility-scale PV (691).

\footnotetext{
${ }^{19}$ See IEEE Standards Coordinating Council 21 at http://grouper.ieee.org/groups/scc21/1547/1547 index.html.

${ }^{20}$ Though regulating voltage was not allowed, the original 2003 standard did allow the use of off-nominal power factors, which can help reduce distribution voltage problems from DGPV.
} 


\section{Overcoming Germany's 50.2-Hz Problem}

With more than $40 \mathrm{GW}$ of PV installed, most of which is interconnected to distribution circuits, Germany leads the world in PV system deployment by a significant margin. However, in Germany's race to install massive amounts of PV, some system problems have been identified, and these are informing other countries and regions. One such issue is the "50.2 Hz Problem," which creates the possibility that all PV systems in Germany could drop off the grid simultaneously and create blackouts.

Simply speaking, the German inverters were all originally programmed to drop offline if the grid frequency rose above $50.2 \mathrm{~Hz}$, which could occur when there is more generation (PV, wind, traditional) than load. This could create bigger problems by over-compensating and dropping too much DGP. German PV specialists were required to modify the firmware of most inverters and create what is called a droop function that reduces power output when frequency levels rise above a grid-specific threshold. This retrofit operation for more than 300,000 inverters was estimated to cost up to $€ 175$ million (von Appen et al. 2013).

This experience is informing the discussions around the IEEE 1547 revisions which are expected to include a frequency-droop (frequency/power) function similar to that in the German VDE AR-N 4105 guidelines, but adjusted to the North American 60Hz standard and tailored to the dynamics of the system-level grid interconnect.

\subsection{Advanced Inverters in the United States}

Since 2010, there has been a dramatic upswing in the availability of "advanced" features in PV inverters, largely in response to international requirements (Braun et al. 2011). As discussed in Section 2.1.3, advanced inverters can provide utility-support features such as voltage support, enhanced frequency and voltage ride-through, and a host of autonomous functions and externally controllable functions. As of 2015, most inverters purchased off the shelf in the United States have many advanced (i.e., "smart") functions built in, even though these features are often disabled or hidden in U.S. markets so the units can comply with the older UL 1741-2010 requirements. ${ }^{21}$ In the meantime, these technologies have already been deployed in special situations, and they are increasingly being required in regions with very high penetrations of PV, such as Hawaii (Eber and Corbus 2013) and California (St. John 2013). ${ }^{22}$ Other advanced functions, such as curtailing power output, have been used to ensure no net power production from PV systems in less common and uniquely challenging secondary network distribution systems (Coddington et al. 2011).

\subsection{State Leadership}

As rapid growth in PV outpaces the typically slow and methodical consensus standardsdevelopment process, a growing number of states have established their own requirements for

\footnotetext{
${ }^{21}$ Advanced features have already been required in some international markets (e.g., Germany). As a result, many manufactures have incorporated the capabilities into a standard worldwide device that is configured based on locale within the pre-consumer supply chain.

${ }^{22}$ See California Energy Commission and California Public Utilities Commission pages for information on the Smart Inverter Working Group: http://www.energy.ca.gov/electricity analysis/rule21/.
} 
interconnection. A leader in this effort is California's Smart Inverter Working Group, which has outlined a set of advanced inverter features - ride-through, voltage and reactive power control, and (later) communications - required for interconnection under a revised California Rule 21. However, the updated CA Rule 21 will not take effect until 12 months after still-pending updates to the UL 1741 (California Public Utilities Commission 2014). Citing Rule 21, The State of Hawaii Public Utilities Commission also approved requirements for advanced inverter features, including expanded ride-through during system disturbances, autonomous voltage functions (volt/watt, fixed power factor, and dynamic volt/VAR), assistance in over-frequency, soft-start, remote connection/disconnection, and remote configurability (The Hawaiian Electric Companies 2015). And Hawaii's new rules were the first in the nation to require advanced inverters for distribution interconnections, starting January 1, 2016, after a recent decision to rely on selfcertification until UL 1741 is updated (State of Hawaii Public Utilities Commission 2015). These nation-leading requirements join an already progressive list of Hawaii-specific requirements such as ramp-rate limits.

\subsection{Tariffs and Retail Rates}

Along with procedures and standards, rate structures provide the third key element for DGPV interconnection, particularly as we look toward a future that may have increased participation of distributed resources in system operations. Retail rates influence the interactions of DGPV with distribution system planning and operations in four primary ways ${ }^{23}$ :

1. (Lack of) Incentives for Grid Support from DGPV. Today, rate structures provide disincentives for DGPV to reduce its power output, as may be occasionally required to support the grid: the more electricity produced by DGPV, the more savings (or revenue) a customer receives. Successfully deploying hundreds of gigawatts of DGPV will require DGPV to participate fully in grid operations, and in some situations this will require curtailing real power output either directly to prevent over-generation or to stay within inverter current limits when using reactive power to manage voltage (Turitsyn et al. 2011). Likewise, storage and other complementary technologies that can ease integration of very high penetration DGPV (see Section 6) may only see widespread adoption if economic signals compensate customers based on time- and location-varying grid conditions and market prices. Hence, advanced tariff designs that provide appropriate price signals to customers would provide an economic foundation for effective integration of very high penetrations of DGPV.

2. PV adoption (placement) decisions by end users. Today, rate and incentive structures have a large influence on regional patterns of DGPV adoption. ${ }^{24}$ Looking ahead, local variations in rate structures or incentives could inadvertently or - if carefully designeddeliberately influence the locational adoption of DGPV within a feeder and hence have a strong influence on optimizing DGPV deployment.

\footnotetext{
${ }^{23}$ This section provides an introductory summary of pertinent rate-driven concerns for DGPV. An in-depth discussion of rates, DGPV deployment scenarios, and their economic impacts on utilities can be found in the utility regulatory and business model paper of this On the Path to SunShot series (Barbose et al. 2016).

${ }^{24}$ Economic decisions and rates are only one factor that influences adoption decisions. For more on the drivers of PV adoption, including environmental motivations, see (Borenstein 2015) and (Schelly 2014)
} 
3. Rate consistency and continuity. Decisions to deploy DGPV are based on the economic lifetime of the systems, generally 20 years or more. For customers to make sound investment decisions and potentially provide grid services, it will be important for them to be confident that utilities will not significantly alter retail rates and DGPV compensation mechanisms during the ownership cycle without also offering economically viable options for existing customers.

4. Business model for distribution utilities and their interaction with customers. Increasing adoption of DGPV and other DERs has raised concerns about distribution utilities' ability to continue with business as usual. Some potential alternatives, including more service-oriented utility-customer relations or interactive retail-level markets - such as those proposed in New York's Reforming the Energy Vision (REV)—could fundamentally change distribution system operations and hence impact the integration of very high penetrations of DGPV.

These and other critical economic drivers suggest a need to more fully incorporate technoeconomic approaches into the analysis of PV-grid interactions, even at the distribution level. However, although regulators generally encourage more competition at the retail level and market signals to incentivize optimal DER deployment, an overarching goal is typically to keep rates simple for the vast majority of customers to understand and fair across a wide range of customer types and locations. Modern rate design will have to balance incorporating more appropriate market signals with the need to maintain fairness and avoid overcomplicating the message to customers.

\subsubsection{Retail Rates in the United States}

Retail electricity rates throughout the United States are typically average volumetric rates composed of a generation rate and a delivery rate. The generation rate is an average per-kilowatthour rate for energy, and the delivery rate is an average per-kilowatt-hour rate for the total costs associated with transmission, distribution, and other programs such as industry restructuring, efficiency incentives, and generation subsidies. Residential ratepayers' bills may also include a small fixed component (a per-customer charge) to cover administrative costs, such as billing. These rates generally do not vary by time of day, by wholesale market price, or throughout a customer billing period, and they are uniform for the ratepayers of each rate class throughout the utility service area (i.e., they are location independent). Larger commercial and industrial customers typically have more complex rates that may include charges for peak monthly demand, time-varying rates for volumetric energy consumption, a rate for peak-coincident demand, and/or power-factor adjustment penalties.

\subsubsection{Net Energy Metering}

As of March 2015, 44 states in addition to Washington, D.C., and multiple territories have mandatory NEM for most customer-owned DGPV (North Carolina Clean Energy Technology Center 2015). NEM compensates DGPV customers at the full retail rate for any excess solar production sent into the grid when DGPV output is greater than demand. ${ }^{25}$ That is, the volumetric sales for which customers are charged are computed as $k W h$ net load $=k W h$ load $k W h$ generation during the course of a billing period. If a customer's load is less than or equal to

\footnotetext{
${ }^{25}$ This is primarily of concern in the absence of economic energy storage.
} 
onsite generation, then the customer's bill is effectively zero. In many states, customers cannot have a negative bill (i.e., receive payment for DGPV exports in excess of net load). But customers generally can carry over credit for excess generation that is trued up against annual net load at the end of a year. Hence, a customer can over-generate during summer months when insolation and grid electricity demand are high to compensate for less generation during winter months.

\subsubsection{Beyond Net Energy Metering}

A robust discussion on the characterization of the costs and benefits of NEM for all utility customers is ongoing between regulators, utilities, and DGPV advocates. Utilities in more than a dozen states (North Carolina Clean Energy Technology Center 2015) have raised concerns that NEM does not reflect the true cost/benefit of DGPV, indirectly causing non-PV owners to subsidize the rates of PV owners. Many of the costs and benefits of higher penetrations of DGPV are overlooked using conventional approaches to grid services. In addition, a growing number of states are approaching their NEM caps. ${ }^{26}$ This has prompted active discussion and debate about restructuring tariffs for DGPV and other DERs. Several regions have implemented or proposed NEM alternatives that include monthly fees for PV customers or reduced payment for excess energy produced by PV systems, although other utilities plan to continue to offer NEM even after caps are exceeded (Carlson 2015). Some U.S. jurisdictions are evaluating or piloting "grid modernization" efforts that include altered rate structures and distribution network costallocation methods (Trabish 2015). Key examples include the following:

1. In October 2015, the State of Hawaii Public Utilities Commission discontinued the use of NEM and approved two alternative tariffs: "grid supply" compensates excess generation sold to the utility at the price of avoided generation, and "self supply" prohibits all but small, infrequent injections of power back to the distribution network (State of Hawaii Public Utilities Commission 2015). If they incentivize efficient self-consumption, such tariffs may encourage greater utilization of flexible demand and storage, improving coincidence between PV output and consumption (Fitzgerald et al. 2015).

2. The California Public Utilities Commission announced in December 2015 (California Public Utilities Commission 2015) that it is declining to "impose any demand charges, grid access charges, installed capacity fees, standby fees, or similar fixed charges on NEM residential customers," thereby preserving NEM until better analysis can be conducted on the costs and benefits of DGPV.

3. New York's major Reforming the Energy Vision (REV) distribution reform seeks to transform retail utilities into distribution system operators that offer market-based approaches to remunerate grid owners for power flow no matter the direction of flowi.e., customers who are either buying or selling energy would pay a fee for access to the grid along with a separate charge or credit for the energy bought or sold, respectively. As part of this, the New York Public Service Commission seeks to develop the "LMP+D," a price signal that reflects the wholesale locational marginal price of providing electricity and the "value" of distributed resources to the distribution system. The commission envisions that $\mathrm{LMP}+\mathrm{D}$ captures the full value of DER to the system and will enable

\footnotetext{
${ }^{26}$ An NEM cap is the target level of installed capacity of net-metered PV as a percentage of peak demand.
} 
efficient investment and operational decisions (State of New York Department of Public Service 2015).

\subsection{Research Needs on Interconnection}

Interconnection is a high profile, rapidly evolving area. A number of research efforts could provide timely information and analysis to various stakeholders:

- Expanded tools and methods are needed for streamlined interconnection approvals, including more widespread adoption of methods that incorporate precomputed hosting capacity.

- Continued support is needed for standards development, including technical analysis to inform and validate required/suggested default set points for advanced features such as voltage control, power factor, frequency/voltage ride-through, frequency-watt control, etc.

- Tools and methods are needed for streamlined impact studies, in cases beyond hosting capacity. This could include best practices for system changes to consider when overcoming various types of violations.

- Advanced communications and distribution management systems may ease the integration of high penetrations of DGPV, particularly when distribution systems are reconfigured for maintenance, faults, or load management. Further research is required on how such approaches can impact interconnection, with or without communications connections to DGPV inverters.

- Regular state-by-state reporting, such as in the Database of State Incentives for Renewables and Efficiency (DSIRE), could include tracking of advanced inverter and communications requirements.

- In the context of ongoing discussion about tariff design, rigorous sociotechnical analysis of new tariffs is important since both technical distribution engineering and economic impacts must be considered simultaneously. This including analysis of approaches for incentivizing or monetizing non-energy services including New York's LMP+D and other distribution-level efforts to send the right economic signals to DGPV.

- It is useful to analyze changes in today's business model for utilities that allow either utilities or "new entities" to take responsibility for services, reliability, and possibly other system aspects - also see Barbose et al. (2016) in the On the Path to SunShot series. 


\section{Distribution and Transmission Interactions}

When the SunShot Initiative began in 2011, DGPV deployment in the United States was low enough that its interactions with the transmission system were largely ignored. Today there is increasing recognition that SunShot-level DGPV deployment will require unprecedented awareness and interaction between the historically separate operations of the distribution and transmission systems. Looking forward, improved analysis, technologies (such as communications-enabled inverters), and operating strategies will likely be required to move to a future fully integrated distribution-transmission system that readily supports high penetrations of DGPV at and beyond the SunShot 2030 targets.

Some aspects of distribution-transmission interaction are frequently discussed, such as the ability of DGPV to help relieve congestion - particularly for electrical spurs where geography and land ownership make transmission expansion very difficult ${ }^{27}$ - and the ability of DGPV to reduce system losses by generating closer to loads. Although these concepts are well established, identifying the best practices for analyzing these interactions remains an area of active research as described in Denholm et al. (2014). Further, as described below, a number of more direct techno-economic interactions will become increasing critical as the United States continues on the path toward a future with high penetrations of DGPV, including the following:

1. The importance of DGPV visibility to minimize system operating costs and reserve deployments.

2. Frequency response, transient stability, and inertia with DGPV in the event of large-scale system disturbances.

3. The potential need to provide increased reactive power with large-scale deployment of advanced inverters.

4. A need to develop communications and control architectures that incorporate DGPV into system operations.

\subsection{Visibility for Wholesale Operations}

Today DGPV is largely invisible to bulk system operations, it introduces additional uncertainty into the net demand, and it can, at high enough penetrations, require additional reserve deployments to ensure effective supply-demand balance. Although an increase in reverse power flows from distribution systems into the transmission network may cause issues with equipment wear and tear and potential overvoltages, reverse flows also have the potential to mitigate transmission congestion. To fully realize the benefits and overcome any risks from reverse flow, these new system conditions and contingency limits likely need to be considered in the securityconstrained economic dispatch performed at the transmission level. Looking forward, the effective integration of DGPV at the high SunShot levels for 2020, 2030, and beyond will likely require increased visibility of DGPV in bulk operations to improve forecasting and hence minimize system operating costs and reduce reserve requirements.

\footnotetext{
${ }^{27}$ Two examples of this scenario include the San Francisco peninsula and regions where parks, national forest, or other land use restricts expansion.
} 
To explore these interactions further, we conducted integrated market-transmission-distributionload simulation using NREL's Integrated Grid Modeling System (IGMS) to explore the production cost, reserve, and inadvertent interchange impacts of widespread adoption of DGPV as a function of its visibility to the bulk system operator. IGMS provides comprehensive power system co-simulation by using multiple open-source tools, including FESTIV, MATPOWER, and GridLAB-D (Palmintier 2015; Palmintier, Hale, et al. 2016).

Our test system was loosely based on the Sacramento Municipal Utility District and its neighboring northern California balancing authority areas. As modeled in the IGMS, the system had more than 250 transmission buses, 950 distribution feeders, and more than 1.3 million total electrical nodes. Three different illustrative bounding cases for solar power visibility were considered:

- No visibility for DGPV, with forecasts based solely on load for all time frames: day ahead, hour ahead, and 5 minutes ahead.

- Persistence forecasts, wherein the previous net load values were used to improve realtime dispatch and reserve deployments.

- Perfect forecasts representing complete DGPV visibility and perfect predictions.

As shown in Table 2, our results reveal a clear trend that additional visibility reduces overall production costs. In the $14 \%$ solar penetration (on an annual energy basis) rate scenarios considered here, adding persistence forecasts reduces production costs by $4 \%$ while having full information reduces the costs by $17 \%$. These cost reductions are due to the decreased dispatch costs necessary to deal with the inherent uncertainty of distributed $P V$. In addition, the three reliability and reserve metrics - Critical Performance Standard-2 for inter-balancing area interchange, standard deviation of area control error (ACE), and absolute error of ACE in energy (AACEE) — show considerable improvement with increasing visibility into DGPV.

Table 2. Comparison Among Levels of DGPV Visibility/Forecast for a Test System Loosely Based on the Sacramento Municipal Utility District

\begin{tabular}{|c|c|c|c|c|c|}
\hline $\begin{array}{c}\text { Solar } \\
\text { Penetration } \\
\text { (energy) }\end{array}$ & $\begin{array}{c}\text { Visibility } \\
\text { (Forecast) }\end{array}$ & $\begin{array}{c}\text { Production } \\
\text { Cost } \\
\mathbf{\$ 1 0 0 0 s / d a y}\end{array}$ & $\begin{array}{c}\text { CPS2 } \\
\text { Violations }\end{array}$ & AACEE & $\begin{array}{c}\text { ACE Std. } \\
\text { Dev. }\end{array}$ \\
\hline $14 \%$ & none & 6,833 & - & - & - \\
\hline $14 \%$ & persistence & 6,558 & $-10 \%$ & $-2 \%$ & $-1 \%$ \\
\hline $14 \%$ & perfect & 5,654 & $-22 \%$ & $-23 \%$ & $-13 \%$ \\
\hline
\end{tabular}

Table adapted from Palmintier, Hale, et al. 2016

\subsection{Frequency Response and Transient Stability}

The recent Western Wind and Solar Integration Study-phase 3 (Miller et al. 2014) analyzed the potential impact of DGPV on the frequency stability of the Western Interconnect for various high-renewable futures. It compared the frequency impact of the simultaneous loss of two Palo Verde nuclear units $(2,750 \mathrm{MW})$ - the reference, largest traditional contingency for the Western Electricity Coordinating Council (WECC) - to the loss of the same quantity of distributed 
generation (Figure 25) and found that distributed generation caused a less severe frequency drop (i.e., a higher nadir).

The same study also found that the system could operate reliably with $50 \%$ or more of instantaneous generation from power-electronic-based sources such as DGPV, modern wind turbines, and electric storage. This result is critical because a 50\% instantaneous generation can happen at considerably lower energy penetration levels (e.g., $15 \%$ energy from renewables) during lightly loaded conditions. In these situations, a key concern is low system inertia when fewer traditional synchronous generators are online. This is because the collectively large rotating mass of traditional generators slows the initial rate of frequency drop, allowing time for somewhat slower control systems to respond, but inverter-based technologies do not naturally provide this inertia.

Looking toward a future that might contain very high penetrations of solar and thus further reduce system inertia, it may become necessary to introduce new advanced controls for synthetic inertia. Such controls have already been tested for wind turbines (Clark, Miller, and SanchezGasca 2010), and similar approaches could be used for other power electronic inverters, such as those for DGPV, particularly if small amounts (potentially only a few seconds in duration) of supplemental storage were added to DGPV systems.

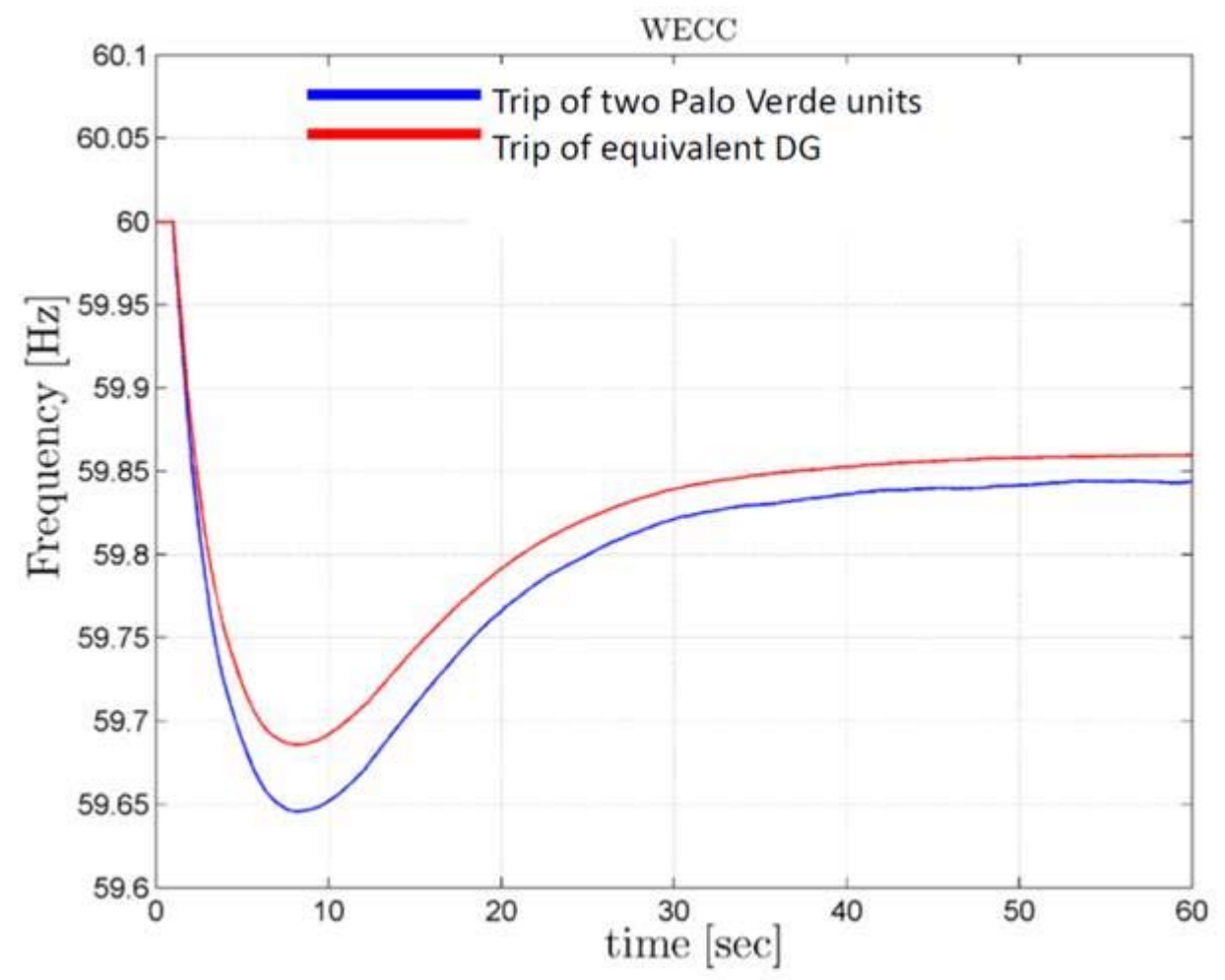

Figure 25. Distributed generation trip resulting in a less severe frequency nadir Image from Miller et al. 2014 


\subsection{Reactive Power and Voltage Control with Advanced Inverters}

The potential widespread adoption of advanced DGPV inverters to manage distributionconnected voltage could introduce a need to provide additional sources of reactive power (VAR). In today's grid, inductive loads - primarily fixed-speed induction motors - represent the main load-side consumer of reactive power. ${ }^{28}$ Reactive power may be produced at the distribution level by substation capacitor banks or onsite power factor correcting capacitors, particularly for larger industrial customers. Still, generators and voltage-support equipment on the transmission system typically supply considerable quantities of reactive power to loads.

As described further in Section 2.1.3, advanced inverters can absorb reactive power to help prevent undesired local voltage rise. At high penetrations of DGPV, this locally helpful effect may impact the system-wide demand for reactive power required. Currently most reactive power demands - largely driven by motor loads - are provide by a combination of transmission resources (e.g., traditional generators, capacitors and synchronous condensers) and distributionlevel or customer-sited capacitors.

To begin exploring these interaction, we used IGMS to study the reactive power demands from widespread adoption of advanced DGPV inverters. In this initial analysis, the IEEE-118 bus test system (Christie 1999) was simulated during the course of 1 day, with DGPV added to the distribution feeders in sufficient quantity to provide $10 \%$ of annual energy demand. Then we compared the transmission-distribution reactive power demand for unity power factor inverters versus advanced inverters with active volt/VAR control using the same reactive power to voltage relation used in Section 3.2.2. Figure 26 illustrates the change in reactive power absorption/injection at each transmission load bus for all simulation periods with and without volt/VAR controlled inverters. Although the median reactive power value is nearly the same for the two cases, there is a slight shift towards an increased demand for reactive power (VAR) from the transmission level with advanced inverters. Because advanced inverter volt/VAR control will typically absorb reactive power to help mitigate local voltage rise, this comparably small increase in reactive power demand shows that a combination of distribution-connected reactive power sources - such as capacitors - and other advanced inverters located in lower-voltage areas - such as far from the substation - can provide the majority of required reactive power. Further research is required to understand if this minimal impact on the transmission system is consistent across other real-world systems. This local provision of reactive power is particularly helpful given the physics-based limitations to transporting reactive power over long distances.

\footnotetext{
${ }^{28}$ Reactive power is also "consumed" by inductive effects in long transmission lines.
} 


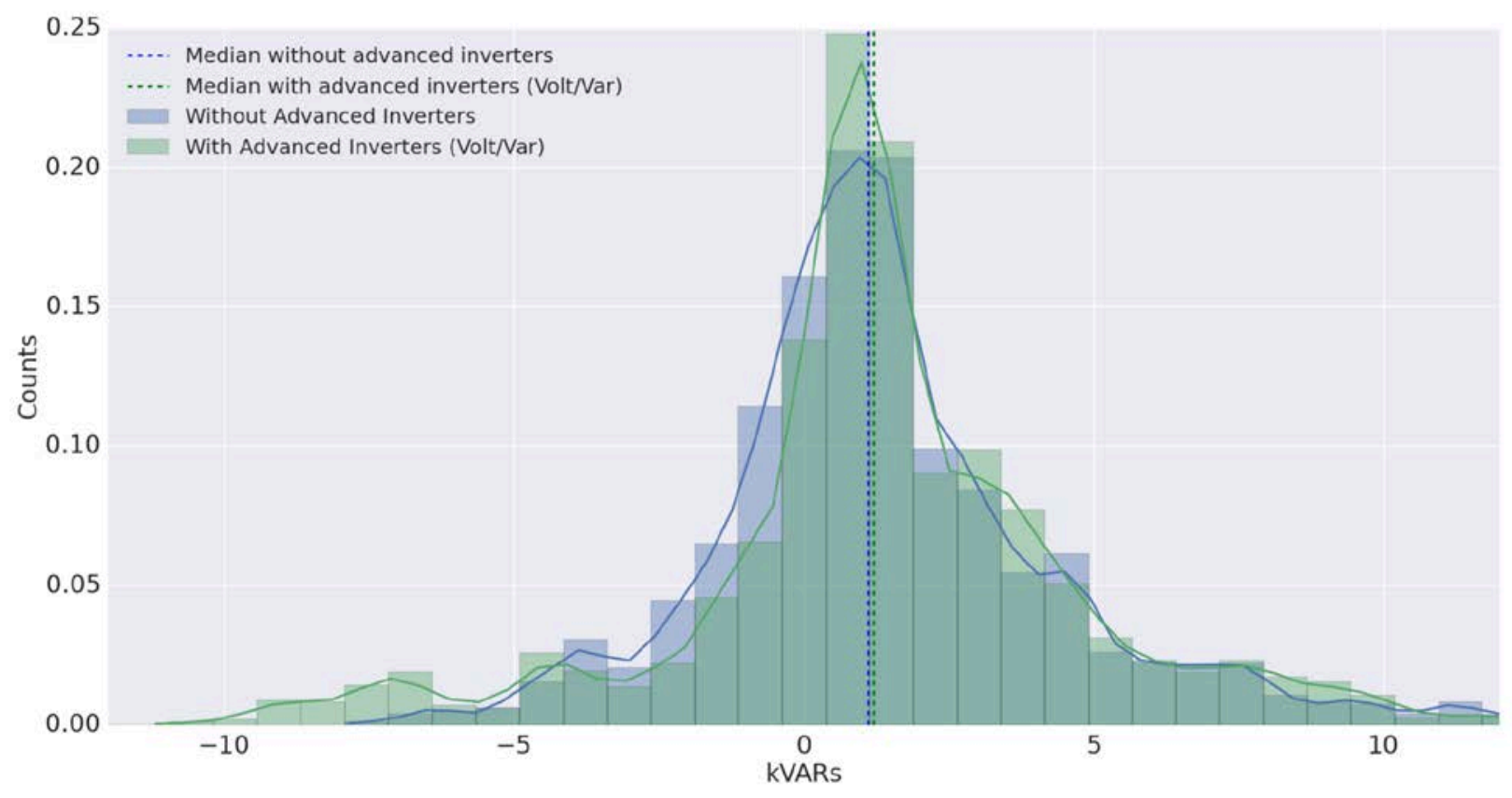

Figure 26. Histograms of transmission load bus reactive power demand (positive) and supply with and without advanced inverter volt/VAR functionality

These results show that the substation-level demand for reactive power from the transmission system may not change much even though advanced inverters typically increase reactive power demand locally to mitigate voltage rise.

Image from Palmintier, Hale, et al. 2016

As is true at the distribution level, transmission voltages are strongly aligned with reactive power. Therefore, to further explore the system-wide impact of advanced inverters, we considered the voltage profile for all transmission nodes for the same scenarios with and without advanced inverters. Figure 27 shows the envelopes of voltage magnitude over time with and without advanced inverters. As shown in the figure, with traditional, real-power-only inverters, there are overvoltages and undervoltages (outside of $\pm 5 \%$ ) on some transmission buses during the morning load increase. In contrast, reactive power absorption by advanced inverters at the distribution level can help eliminate these voltage challenges at the transmission level, even though they are deployed and controlled based on distribution concerns.

Our early results suggest that additional research into distribution-transmission voltage and reactive power interactions is needed to clarify the potential benefits (e.g., transmission voltage regulation) and challenges (e.g., additional reactive power demand) for the widespread adoption of advanced DGPV inverters. 


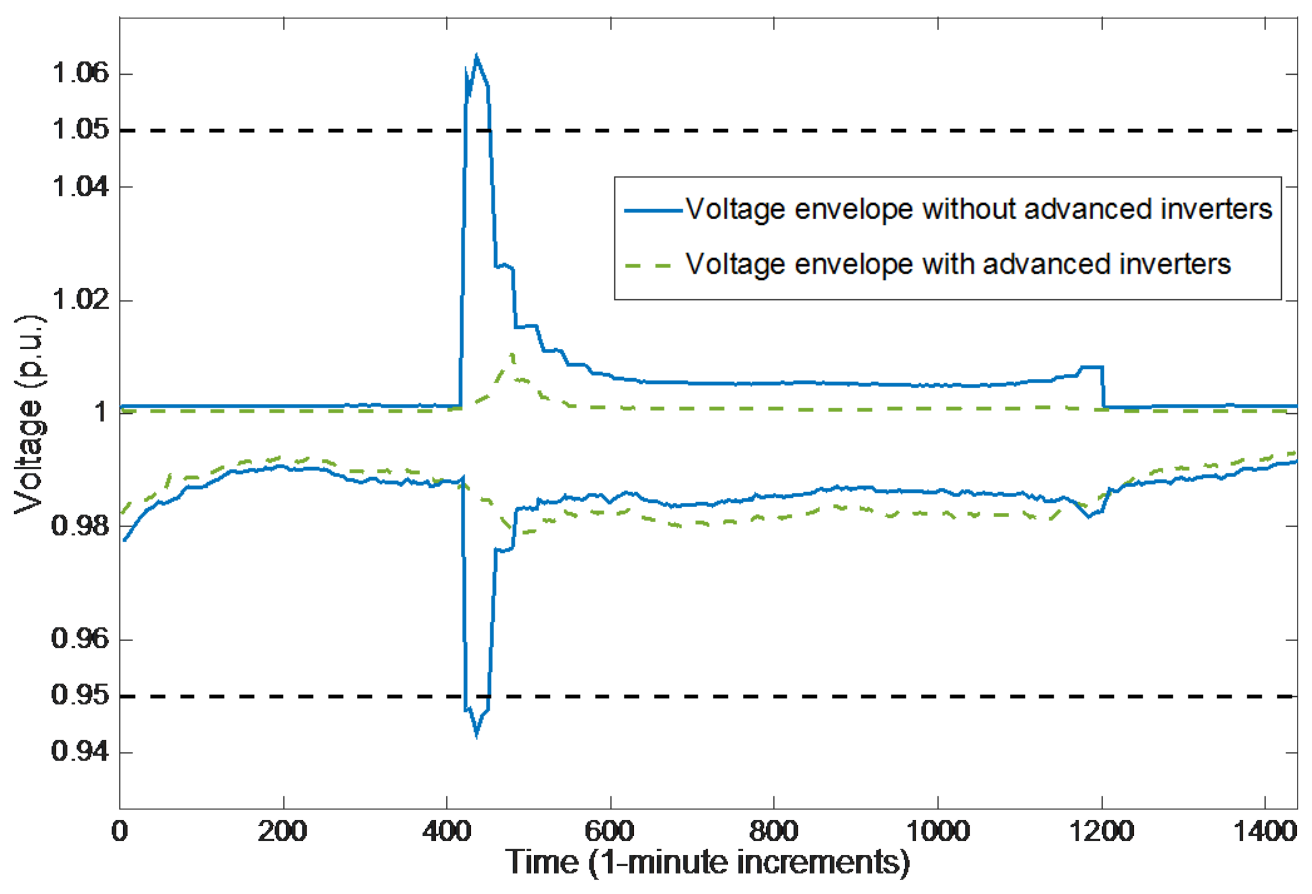

Figure 27. Transmission-level bus voltage magnitudes with and without advanced inverter functionality

Image from Palmintier, Hale, et al. 2016

\subsection{Communications and Control Architectures}

There is increasing interest in having communications pathways to DGPV inverters to better integrate with larger system operations. Communications to inverters is already common for larger systems and for third-party-owned systems; however, historically these communications pathways have been primarily used for asset management and firmware upgrades. Some larger systems have already been forced to have "transfer trip" connections where the substation sends a signal to de-energize the inverter when the larger grid goes out; however, recent interest has shifted to simpler, less expensive, and more pervasive communications to inverters to provide increased visibility of inverter operations (e.g., Yazdanpanahi, Li, and $\mathrm{Xu} 2012$ ) and to provide a pathway for centralized curtailment or set-point changes when required by system-level operations. There are also research and demonstration efforts toward integrating larger DGPV into centrally optimized distribution management system (DMS) based voltage-management schemes (e.g., Palmintier, Ponder, and Gantz 2015).

However, even if there were universal communications to and among DGPV systems, there remains considerable uncertainty around the best architecture(s) for integrating millions of DGPV systems and other DERs into power-system operations. Today there are many competing ideas and a general lack of rigorous analysis or direct comparisons-largely based on limits of existing tools - that can be used to compare alternative DGPV communications and control architectures. For example, Greentech Leadership Group's "More than Smart" framework for increasing the integration of DERs into California's distribution grids (DeMartini 2014) found 
that the value of DER could be increased when hierarchical, distributed control schemes are integrated into grid operations. Other research and development efforts have focused on practical ways to integrate large numbers of DERs into existing centralized utility enterprise control through DER management systems (DERMS) and other distribution automation efforts (Madani et al. 2015; Das et al. 2015). Still other researchers have proposed fully distributed control architectures based on peer-to-peer communications without any centralized controller (e.g., DallAnese et al. 2014). Identifying and deploying the most effective approach or combination to support very high penetrations of DGPV requires a combination of enhanced simulation tools, expanded real-world pilots, and later large-scale deployment and standardization.

\subsection{Research Needs on Transmission-Distribution Interactions}

Because the operations of the distribution and transmission systems historically have been separate, numerous opportunities exist for increasing the understanding of transmissiondistribution interactions in the context of large-scale DGPV deployment:

- The full revision of the IEEE 1547 standard is expected to include provisions — such as voltage and frequency ride-through and over-frequency output reduction- to support system-wide operations during and soon after disturbances. However, although the frameworks have been outlined, there remains considerable debate and little hard analysis to inform the actual set points or ranges within these frameworks. Further integrated distribution and transmission comparative analysis is needed to inform these set points.

- Further characterization of the impacts of solar forecasting and DGPV visibility on bulk system operations, including reserves, is needed to understand interactions on real-world systems to characterize the diversity of these interactions on different systems and under different configurations.

- As introduced in Section 5.3, widespread adoption of advanced DGPV inverters may (or may not) have important impacts on transmission-distribution interactions. Further research is needed to better understand the operational impacts - including reactive power demands - of various advanced inverter modes.

- The interactions between wholesale and retail markets also require further study, leveraging experiences from wholesale market design (e.g., harmonizing physical and market operation) while addressing very significant physical and economic differences between bulk and distribution systems.

- Research into the business model for multi-tier, hierarchical energy ecosystems could include how DGPV assets should be shared and benefits distributed among transmission system operators and distribution system operators.

- An improved understanding of integration methods for incorporating DGPV into distribution and transmission operations through distribution management systems (DMS), energy management systems (EMS), and/or DER management systems (DERMS) and other approaches would be valuable.

- Studies could compare among communications and control architectures for DGPV integration into system operations. 


\section{Storage and Complementary Technologies}

Until recently, the integration of DGPV focused primarily on the integration of solar alone. Today, there is increasing interest in integrating DGPV with energy storage to provide a range of value streams from customer peak charge reduction to resiliency and ramp-rate limits. As a result, there is a near-term need to expand existing DGPV-focused tools and analyses to include storage and to develop and deploy approaches for siting, sizing, and controlling storage both alone and in conjunction with DGPV. Looking forward, DGPV could form the foundation for an integrated suite of DERs that interact to improve grid operations. This could include tightly controlled DER incorporated into microgrids or a looser federation of DERs acting alone, through energy management systems, or aggregator control to provide complementary "virtual storage" that manages household and building energy loads, uses thermal and other indirect energy storage, and/or varies the rate to electric vehicle charging (or discharging) to enable more variable generation.

\subsection{Overview}

Energy storage and other complementary technologies, such as demand response and virtual storage, can have a multitude of benefits, such as load-leveling, contingency and regulating reserves, and peak-shifting, among others (Denholm et al. 2013). In 2013, the California Public Utilities Commission approved a mandate that requires its three largest utilities to have 1,325 MW of energy storage in the grid by 2020 . A mandate in Arizona dictates that energy storage be considered a viable alternative to building or upgrading conventional, fossil-fueled power plants, and, before 2018, Arizona Public Service (APS) plans to solicit competitive bids for energy storage projects worth $10 \mathrm{MWh}$.

However, in contrast to these large-scale energy storage efforts, less than $0.1 \%$ of PV installations in 2014 were coupled with energy storage. Despite this, with the continual reduction of energy storage costs and evolving policies and market rules such as time-of-use retail pricing, the benefit of owning PV and storage systems may increase, and these changes may result in a higher adoption rate for these combined systems. The technological and policy-based advancements can provide services to both end customers and the grid, with GTM Research predicting that combined solar/storage deployments will reach $769 \mathrm{MW}$ by 2020 , with an annual PV plus storage market of \$3.1 billion (GTM Research and SEIA 2015). In Germany, there are also now incentives for PV owners to use storage to increase on-site "self consumption"- and hence limit the amount of power injected back into the distribution system (Stetz et al. 2015)

\subsection{Energy Storage}

Some common examples of energy storage technologies include batteries (lithium-ion, lead-acid, sodium/sulfur, etc.), flywheels, compressed air, capacitors, and pumped hydro storage, among many others. Energy storage projects can range greatly in size, up to the megawatt level for batteries and even in the gigawatts for pumped hydro storage, which constitutes the majority of energy storage capacity in the United States. Depending on the application, the energy capacity, efficiency, charging/discharging rate, and physical size of the storage device can suggest that utilities use certain storage technologies over others. For example, for stationary battery applications, lithium-ion batteries are becoming more cost effective compared to lead-acid 
batteries, which had established a large manufacturing base during the last 100 years and previously dominated the industry (Albright, Edie, and Al-Hallaj I 2015).

Super (or ultra) capacitors, with their small capacities but fast charge/discharge rates, are ideal for balancing short-duration, small fluctuations in the power supply and can also be paired with other battery technologies to provide a wider range of energy and power densities (Dubal et al. 2015). Flow batteries, a technology that resembles both a battery and a fuel cell, can be more appropriate for large-scale energy storage applications, and recent technologies use cheaper and nontoxic organic materials (Lin et al. 2015). Thermal energy storage, a technology that stores thermal energy by heating or cooling a material to be used later for heating/cooling/power generation, has been gaining popularity in recent years in commercial and industrial buildings and campuses. Thermal storage can appear as ice storage or chilled water, as heat from combined heat and power plants, and even as molten salts used to absorb heat energy. Thermal energy storage can be used for balancing renewables, increasing energy efficiency, peak shifting, and performing energy arbitrage, although some applications for thermal storage are more suited to certain applications than other storage technologies. For example, concentrating solar power plants have been found to benefit more from thermal storage than from mechanical or chemical storage technologies (Kuravi et al. 2013).

\subsubsection{Utility-Scale Energy Storage}

Utility-scale energy storage has traditionally targeted transmission-level concerns including large scale grid reliability and resilience, the integration of renewables, enhancement of energy efficiency, provision of grid services, and reduction of generator ramping. However, except for the largest storage units, many of these systems are still distribution-connected, typically as part of the substation, and hence can also be used to help with distribution management as well.

\subsubsection{Community Energy Storage}

Community energy storage (CES) systems can either be one medium-scale storage facility with shared ownership among a community or multiple small battery-based energy storage units connected to the utility transformer's secondary and controlled from a common remote control (American Electric Power (AEP) 2009). Either way, CES systems are connected close enough to customers to provide backup power and to improve electricity service to customers whose circuits are often heavily loaded or might otherwise benefit from the power-conditioning advantages. CES is especially important as an example of a distribution-connected and utility owned and operated distributed energy storage system. It can serve as a robust, fast-responding, and flexible alternative to generation. It can store low-priced energy and provide energy later when the price is high. CES can also provide most types of ancillary services needed to keep the grid stable and reliable.

In 2012, the Sacramento Municipal Utility District piloted both residential energy storage and CES systems with lithium-ion batteries in Anatolia, California (Rawson and Sanchez 2013). In total, 15 residential energy storage and three CES units were installed. Each CES was connected to the pad-mounted transformers on distribution feeders and was sized to work with the group of homes serviced by each transformer. The CES system was about three times larger than the residential energy storage system and could be shared between 5 and 10 homes. These CES systems were used to support existing PV, reduce peak load, regulate voltage, and improve reliability. (See sidebar on "Energy Storage in Sacramento's Anatolia Smart Grid Pilot") 


\section{Energy Storage in Sacramento's Anatolia Smart Grid Pilot}

The Sacramento Municipal Utility District led a multifaceted research project centered on a new housing community on the outskirts of Sacramento that included rooftop PV systems fully integrated with each house in the development (Rawson and Sanchez 2013). These nearly 300 homes resulted in a high-penetration PV integration scenario. The project started by analyzing the impact of the installed PV systems on the distribution level. This analysis included a full validation of the impacts observed using real-time distribution-measurement units located throughout the neighborhood - providing a rich data set for validation. Later in the project, energy storage was added to the circuits in the neighborhood, and a number of use cases for these energy storage assets were undertaken. Energy storage was installed at the customer level and the community level (i.e., at the level of the distribution transformer). Key findings of the project were that although the PV impacts on the circuit were minimal, the distributed energy storage still added value to the Sacramento Municipal Utility District and its customers. Most of this value came from a reduction in peak loading of the neighborhood and the circuit in general. Using the energy storage assets for PV smoothing, although tested in the field multiple times, was not identified as having a large added value.

From 2011 to 2014, Detroit Edison designed, built, and demonstrated CES systems in its service territory, and two of the CES units used secondary-use electric vehicle batteries. In total, 20 separate $25-\mathrm{kW}(50-\mathrm{kWh}) \mathrm{CES}$ units and a $500-\mathrm{kW}$ battery storage device were integrated with a utility-scale PV module.

\subsubsection{Residential Energy Storage}

Residential energy storage, the benefits of which have often been overlooked in favor of gridscale storage, has been receiving more attention in recent years. In April 2015, Elon Musk of Tesla Motors announced the Tesla Powerwall, a lithium-ion battery for residential homes (Debord 2015). SolarCity, headquartered in San Mateo, California, has begun a pilot project in California on 500 residential homes, coordinating energy storage with rooftop PV systems (Canales 2015). At the residential level, multiple goals can be achieved by using energy storage in conjunction with solar energy: backup power during grid outages is provided, excess energy from solar can be used to charge the battery during on-peak hours and subsequently used to supply energy to the household during off-peak hours, and electricity costs and carbon emissions can be reduced.

Energy storage at the residential level can assist DGPV penetration by further helping address potential challenges introduced by DGPV. For example, voltage rises in the distribution grid due to increased PV penetration at peak times can be mitigated using distributed residential energy storage, either by controlling the net power output or through advanced inverter reactive powerbased control. PV + storage systems could also alleviate system-wide challenges by shifting output a few hours to provide electricity during the peak time of the day. Hoff, Perez, and Margolis (2007) find that grid security can be enhanced through PV plus storage systems and that, if consumers were planning on purchasing an uninterruptible power supply already, adding $\mathrm{PV}$ to the system would be a very attractive option. Energy storage devices, in comparison with virtual storage and demand response (discussed below), can provide emergency preparedness and energy when none would otherwise be available. 
With the integration of renewables and balancing of variable generation, the full utility of the battery may not be realized until smarter charging and discharging strategies are adopted (von Appen et al. 2014a). The method in which an energy storage device is best controlled and operated depends on the storage technology. For example, capacitors have a high power density and low energy density, which is suited for fast charging/discharging of small amounts of energy such as might be required to limit ramp rates or provide initial responses to system-wide disturbances; however their characteristics are less useful for storing large amounts of solar energy or performing peak shifting and load leveling. Conventional batteries and the currently cheaper, lower-density flow batteries may be better suited for storing larger amounts of energy and performing these tasks, and they have been gaining popularity in recent years ( $T$. Nguyen and Savinell 2010).

\subsection{Virtual Storage and Demand Response}

Virtual storage through buildings or electric vehicles and techniques such as demand response can improve the use of PV systems without a physical battery or traditional energy storage device. Studies have shown that virtual storage and demand response can supplement the use of energy storage to achieve above a 30\% energy penetration of renewables (Denholm et al. 2010).

\subsubsection{Energy Management Systems}

"Virtual" storage can include techniques such as precooling or preheating a building to perform load shifting and aid in balancing fluctuations in the power supply by renewable energy sources. Instead of turning on expensive, fast-ramping generation to account for spikes in consumption, smart thermostats, for example, could receive a signal to indicate that the peak can be avoided by a reduction in cooling or heating. Home energy management systems and building energy management systems are both examples of control systems that can coordinate devices within a home or a building in response to internal or external factors and signals. While home energy management systems aim to coordinate devices within a home - such as heating, ventilating, and air-conditioning systems; water heaters; rooftop solar; electric vehicles; and other smaller appliances - building energy management systems usually control and measure output from larger mechanical systems, lighting, and building heating, ventilating, and air-conditioning systems. In addition, dynamic demand response along with energy management systems could work together with advanced DGPV inverters to mitigate the intermittency of DGPV due to changing cloud cover.

\subsubsection{Electric Vehicles as Energy Storage}

Electric vehicles (EVs) represent another form of energy storage. If EVs are allowed to discharge, they can act similarly to stationary batteries providing a wide range of distribution and system-wide services, as long as sufficient charge is maintained or replaced for their primary transportation needs. However, most EV manufacturers remain reluctant to allow discharging due to concerns with increased wear and tear associated with the additional cycling. Instead, a more promising near-term role of EVs is the use of smart charging to adjust the rate of charging to help provide grid services in much the same way as other demand response or virtual storage systems. Historically, researchers have focused on the potential for smart charging to provide bulk-level services such as regulation reserves or bulk-level supply-demand balancing (e.g., Lund and Kempton 2008); however opportunities also exist for such smart charging to support 
distribution operations. For example, the power electronics associated with smart charges could also be used to help regulate local voltage in much the same way as advanced inverters.

\subsection{Feeder Hosting Capacity with Energy Storage}

Energy storage with proper placement, sizing, and control can help mitigate potential grid integration challenges from DGPV and thus can increase DGPV hosting capacity. Some assessments of using energy storage to increase DGPV hosting capacity in distribution networks were given in (Canales 2015) and (Etherden 2014). An intelligent control strategy for charging and discharging battery energy storage was proposed by (Alam, Muttaqi, and Sutanto 2012) to mitigate problems in voltage rise caused by rooftop PV. Power quality can be improved by charging and discharging storage to smooth out intermittent renewable generation, and energy losses can be reduced through improved use of distributed PV generation to better match load.

\subsection{Research Needs on Complementary Technologies}

In addition to development of battery and demand response technologies, the following represent research needs for solar complementary technologies:

- Methods must be further developed to optimally place, size, and control traditional storage technologies. These should go beyond past work in this area to incorporate a complete range of configuration, equipment deferral, energy, and service value streams.

- Likewise, additional research into the technical requirements and potential limitations of fully incorporating responsive demand and controllable loads as an alternative to energy storage for balancing the fluctuations of DGPV.

- Research on tariff and retail market structures for solar complementary technologies also requires further exploration to capture the benefits from these resources adequately.

- Moreover, a combination of these research directions for optimal sizing, placement, tariff design, and use of demand response and virtual storage would provide insights into the relative technical strengths and business cases not only for individual technologies but also for synergistic hybrids. 


\section{Conclusions and Research Priorities}

From 2010 through the first half of 2015, the installed capacity of solar photovoltaics (PV) connected to the U.S. distribution system increased sixfold, from approximately $1.8 \mathrm{GW}$ to more than $11 \mathrm{GW}$, and it is expected to quadruple from 2015 to 2020. This represents approximately $50 \%-60 \%$ of total installed PV. Reaching the longer-term 2030 SunShot target of hundreds of gigawatts of solar will require the further adoption of solar at all levels. The distribution system is ready to accommodate such an increase with little or no changes. Our estimates show that the distribution system in the continental United States can accommodate an estimated $170 \mathrm{GW}$ of traditional DGPV with no new equipment and little to no impact on operations, roughly double this amount with advanced inverters, and well beyond these levels with other complementary technologies including storage. However, realizing these penetrations without distribution changes would require siting DGPV based on the hosting capacity of the distribution system. This concern, along with considerable unknowns around interactions of advanced control approaches, transmission-distribution interactions, interaction of DGPV with other DERs, and efficient integration approaches suggest a wide-ranging need for research and development to fully and efficiently achieve these penetration levels.

In the next few years, the distribution interconnection standards (e.g., IEEE 1547) are undergoing active revisions with the intent of better integrating DERs, including DGPV, as core contributors to the power system. However, there remains considerable uncertainty about the optimal set points for advanced inverters and about potential interactions among multiple DER controls and utility equipment. A key research need is helping utilities and other stakeholders identify the best suite of default settings and provide guidance on if or how these settings should be varied at different locations along a feeder and by feeder type, climate, or grid condition. Some of this might leverage the advanced locational and QSTS tools originally developed for hosting capacity analyses.

In addition, further streamlining the review and interconnection process is required to integrate high penetrations of DGPV quickly and inexpensively. This could begin by adapting the promising rapid-approval efforts of using situation-specific alternatives to the $15 \%$ rule of thumb to new regions and scenarios as well as by precomputing hosting capacity. New research is also needed to include advanced inverters and complementary technologies, such as storage, into hosting capacity precomputations and to explore the potential for very rapid, statistics-based approaches to replace full hosting capacity analyses both for prescreening and for utilities that may be unable to invest in and maintain full precomputations. Developing such statistical approaches will require sampling a much larger and more diverse population of distribution feeders to conduct the rigorous validations that have been missing from past clustering and other analyses.

Hosting capacity analysis itself requires further development to robustly include advanced inverters, efficiently incorporate time-series analysis, integrate demographic and trend data into scenarios, include PV and complementary DER technologies, and develop advanced sampling approaches to speed up current brute-force Monte Carlo approaches.

Another critical need by 2020 is developing advanced rate structures and/or markets that provide the right signals, price and otherwise, to consumers and DGPV owners. This includes 
compensating for total energy production and encouraging system-beneficial time and location of (net) production and using DGPV to support grid operations such as local voltage control. Such development will require unprecedented techno-economic analysis tools and algorithms that consider monetary flow and market interactions as integral parts alongside simulations of power flow and technical control systems.

Research during the next five years will be instrumental in laying the foundations that are critical for fully incorporating DGPV into system operations. This includes:

- Providing technical support for on-going revisions to interconnection standards (e.g., IEEE 1547) to identify the best suite of default settings and provide guidance on if or how these settings should be varied at different locations along a feeder and by feeder type, climate, or grid condition.

- Further streamlining the review and interconnection process, potentially including wider use of precomputed, regularly revised hosting capacities or novel, validated statistical alternatives.

- Enhancing hosting capacity methods to incorporate advanced inverters; complementary technologies, such as storage; and advanced analysis techniques into hosting capacity precomputations.

- Developing modeling tools that integrate the transmission system, distribution system, markets, and loads. Initially this will be for analysis/planning and later for operations. These efforts should include quasi-steady-state time-series analysis and faster dynamics, and they should represent markets at a variety of levels, including emerging distributionlevel markets.

- Developing advanced rate structures, tariffs, and/or distribution markets that send effective signals to DGPV for siting, operations, and advanced inverter services while maintaining customer fairness and supporting energy efficiency.

- Integrating DGPV both as modeled dynamics and as a controllable resource into utility distribution management systems.

- Developing and testing synthetic inertia built into inverter controls to fully support periods and regions that have very high penetrations of DGPV.

- Enhancing the representation of DGPV, advanced inverters, and complementary DERs in transmission-scale analyses for steady-state energy, market, and contingency analysis.

- Developing secure, advanced, flexible, and scalable communications systems to effectively coordinate millions of DERs, including DGPV.

- Continuing to advance forecasting techniques and bring these developments to the distribution level. This could also include developing advanced approaches to enhancing the visibility of DGPV by potentially leveraging existing data sources such as advanced metering infrastructure and supervisory control and data acquisition systems.

- Developing approaches and tools to determine the optimal location, sizing, and control of storage — both electrical and virtual — and other complementary technologies. 
It is also important to support these efforts with advanced data analytics in the operational context and to better understand industry trends. This includes tracking system deployments at the distribution and transmission levels and tracking the ever-evolving mix of DGPV ownership.

Beyond 2020, there is a wide range of high-impact research priorities. Many of these can begin today, including the following:

- Exploring advanced control algorithms that leverage emerging distributed control techniques to reduce or avoid central coordination while improving system performance. Such approaches have shown promise in small-scale, limited test simulations, but they require additional research to incorporate the rich array of existing utility devices, handle the diversity of distribution systems, and scale to real-world systems.

- Developing methods to help automate the planning of system upgrades when incorporating PV beyond the current hosting capacity. Early versions of such approaches can be applied to regions already facing very high penetrations of DGPV. Advanced versions of such tools could look beyond individual interconnection requests to consider changes today that might ease future integration of DGPV and other DERs.

- Further enhancing and widespread deployment of near-term research outcomes, including ubiquitous inclusion of DGPV into DMS and system-wide energy management systems, fully integrating distribution-level markets, use of advanced analysis methods and tools in routine operations, and synergistic deployment of advanced DGPV with complementary technologies in real-world electrical systems. 


\section{Glossary}

Advanced Inverter

Alternating Current (AC)

Capacitor

Concentrating Solar Power (CSP)

Direct Current (DC)

Distributed Energy Resource (DER)

Distributed

Generation (DG)

Feeder
An inverter with additional grid-support control features. Such inverters use advanced control systems with existing power electronic circuits to regulate voltage, automatically curtail output based on grid conditions, and to ride-through grid disturbances. Advanced inverters may also support external communication for coordination with system operations. Most modern inverters sold in the U.S. have at least some advanced capabilities that default to being disabled to comply with current U.S. interconnection standards.

Electricity flow that reverses direction multiple times per second in a sinusoidal pattern. In North America, AC power nominally operates at $60 \mathrm{~Hz}$. Most electricity on today's grid is generated, transmitted, and distributed as AC.

A device that stores energy in an electric field. On AC power systems, capacitors are used as a passive source of reactive power.

A type of solar power facility that uses mirrors or lenses to focus solar radiation on a smaller area to produce high temperature thermal energy that can then be converted to electricity. CSP plants are typically largescale facilities that are connected to the transmission system, rather than the distribution system.

Electricity flow that continues steadily in a single direction. Solar PV and batteries are two examples of DC power sources.

Any resource that contributes to power grid operations, but is connected to the distribution system. Typically DERs are smaller in scale, but more numerous, than traditional central power resources. Examples of DERs include distributed generation, including DGPV, microturbines, and backup generators; distribution connected storage; demand response from distribution-connected customers; electric vehicles with controllable charge (and/or discharge); smart buildings; price-responsive loads; and other autonomous or remote-controlled resources. Many DERs are customer-owned.

Any generation source that is connected to the distribution system, such as DGPV.

A portion of the distribution system that connects a number of customers back to a distribution substation. Distribution feeders typically have a radial, or tree-like, topology in operations that can be reconfigured during a fault. A feeder often has hundreds or thousands of small customers, and each distribution substation typically servers a small number (two to five) of feeders. 
Frequency ridethrough

Frequency-droop (frequency/power)

Inverter

Investment Tax Credit (ITC)

Power factor (PF)

Reactive power (VAR, kVAR, MVAR)

Real power (Watt, $\mathrm{kW}, \mathrm{MW})$
The ability of a grid device, such as an advanced DGPV inverter, to temporarily continue to operate during an over- or under-frequency grid disturbance. System-wide frequency disturbances occur during sudden mismatches in supply and demand, such as the unexpected loss of a large generator. The ability of DERs to ride-through such events is critical to reliably integrating high-penetrations of DERs so they don't potentially make a challenging situation worse by tripping off-line. Frequency ride-through capabilities are incorporated in to most advanced inverters and associated requirements are expected to be included in future DER interconnection standards.

Frequency-droop is an advanced inverter control mode that linearly reduces the power generation when frequency gets too high. This provides a gradual reduction in power generation during overgeneration events to avoid sudden changes in power from DERs.

A device that converts DC to AC power, typically using power electronics. Inverters are used to convert DC power from DGPV and storage into the $\mathrm{AC}$ power used by the power grid

A renewable energy incentive that reduces the income tax due by a renewable developer based on the amount of up front capital investment made in renewable energy projects.

The ratio of real power to apparent power - a combination of real and reactive power. Power factors equal to one indicate that voltage and current are in-phase and all current on the system is used to provide useful work. Power factors range from zero to one and can either be absorbing/leading/inductive or injecting/lagging/capacitive. Care is required with signs of power factors since the conventions are not consistently defined. Inverters can be configured to produce other power factors (e.g., 0.95 absorbing) to help manage local voltage rise.

The portion of power flowing on a circuit for which current and voltage are out-of-phase and hence not able to provide useful work to a load. Reactive power roughly corresponds to additional current flowing back and forth through a system. Reactive power can be used to manage voltage challenges with DG since absorbing reactive power can mitigate local voltage rise.

The portion of power flow for which current and voltage are in-phase and able to do real work. Extra real power injection into the grid can raise local voltages. 
Regulator

Tap-changing

Transformer

Volt-Watt control

Volt/VAR control
A type of tap-changing transformer that is used out on a distribution feeder to increase (or decrease) downstream voltage. Regulators have the same nominal voltage on both sides.

A type of electrical transformer that has electromagnetic actuators that can adjust the transformer winding ratios in discrete steps. They may either be load tap changers (LTCs) that are incorporated into the stepdown transformers at a distribution substation, or line regulators located throughout the feeder to make incremental voltage adjustments.

An advanced inverter feature to reduce real power output to help overcome excessively high local voltages.

An advanced inverter feature that absorbs, or injects, reactive power to lower, or raise, the local voltage, respectively

Voltage ride-through The ability of a grid device, such as an advanced DGPV inverter, to temporarily continue to operate during an over- or under-voltage grid disturbance. Voltage disturbances occur during faults, such as shorts, on transmission or distribution lines. At high penetrations of DERs such requirements may be needed to prevent larger grid challenges were large amounts of DERs to suddenly trip off-line. 


\section{References}

Abbey, C., and G. Joos. 2009. "A Stochastic Optimization Approach to Rating of Energy Storage Systems in Wind-Diesel Isolated Grids." IEEE Transactions on Power Systems 24 (1): 418-26. doi:10.1109/TPWRS.2008.2004840.

Advanced Power and Energy Program - University of California, Irvine. 2013. "Development and Analysis of a Progressively Smarter Distribution System.” Final Report - CSI RD\&D Program. Advanced Power and Energy Program.

Akaike, Hirotugu. 1973. "Information Theory and an Extension of the Maximum Likelihood Principle." In Second International Symposium on Information Theory, 267-81. Akademinai Kiado. http://ci.nii.ac.jp/naid/10011153980/.

Alam, M.J.E., K.M. Muttaqi, and D. Sutanto. 2012. "Distributed Energy Storage for Mitigation of Voltage-Rise Impact Caused by Rooftop Solar PV.” In 2012 IEEE Power and Energy Society General Meeting, 1-8. doi:10.1109/PESGM.2012.6345726.

Albright, Greg, Jake Edie, and Said Al-Hallaj I. 2015. "A Comparison of Lead Acid to LithiumIon in Stationary Storage Applications | AltEnergyMag." Accessed November 4. http://www.altenergymag.com/content.php?post_type=1884.

Alyami, S., Yang Wang, Caisheng Wang, Junhui Zhao, and Bo Zhao. 2014. “Adaptive Real Power Capping Method for Fair Overvoltage Regulation of Distribution Networks With High Penetration of PV Systems." IEEE Transactions on Smart Grid 5 (6): 2729-38. doi:10.1109/TSG.2014.2330345.

American Electric Power (AEP). 2009. "Functional Specification For Community Energy Storage (CES) Unit."

ANSI. 2011. "American National Standard For Electric Power Systems and EquipmentVoltage Ratings (60 Hertz)." ANSI C84.1-2011. National Electrical Manufacturers Association.

“APS-Solar Partner Program.” 2015. https://www.aps.com/solarpartner.

Aramizu, J., and J.C.M. Vieira. 2013. "Analysis of PV Generation Impacts on Voltage Imbalance and on Voltage Regulation in Distribution Networks." In 2013 IEEE Power and Energy Society General Meeting (PES), 1-5. doi:10.1109/PESMG.2013.6672822.

Baker, Kyri. 2014. "Coordination of Resources Across Areas for the Integration of Renewable Generation: Operation, Sizing, and Siting of Storage Devices.” Dissertation, Carnegie Mellon University.

Baker, Kyri, Gabriela Hug, and Xin Li. 2014. "Optimal Storage Sizing Using Two-Stage Stochastic Optimization for Intra-Hourly Dispatch.” In North American Power Symposium (NAPS), 2014, 1-6. doi:10.1109/NAPS.2014.6965384. 
Ballanti, A., F. Pilo, A. Navarro-Espinosa, and L.F. Ochoa. 2013. "Assessing the Benefits of PV Var Absorption on the Hosting Capacity of LV Feeders." In Innovative Smart Grid Technologies Europe (ISGT EUROPE), 2013 4th IEEE/PES, 1-5. doi:10.1109/ISGTEurope.2013.6695423.

Barbose, Galen L., and Naïm R. Darghouth. 2015. "Tracking the Sun VIII: The Installed Price of Residential and Non-Residential Photovoltaic Systems in the United States." Edited by Dev Millstein, M. Spears, Ryan H. Wiser, Michael Buckley, Rebecca Widiss, and Nick Grue, August.

Barbose, Galen, John Miller, Ben Sigrin, Emerson Reiter, Karlynn Cory, Joyce McLaren, Joachim Seel, Andrew Mills, Naïm Darghouth, and Andrew Satchwell. 2016. On the Path to SunShot: Utility Regulatory and Business Model Reforms for Addressing the Financial Impacts of Distributed Solar on Utilities. Golden, CO: National Renewable Energy Laboratory. NREL/TP-6A20-65670. http://www.nrel.gov/docs/fy16osti/65670.pdf.

Barbose, Galen L., Samantha Weaver, and Naïm R. Darghouth. 2014. "Tracking the Sun VII: An Historical Summary of the Installed Price of Photovoltaics in the United States from 1998 to 2013.” Technical Report. Berkeley, CA: Lawrence Berkeley National Laboratory.

Bolinger, Mark, and Joachim Seel. 2015. "Utility-Scale Solar 2014: An Empirical Analysis of Project Cost, Performance, and Pricing Trends in the United States." Technical Report LBNL1000917. Berkeley, CA: Lawrence Berkeley National Laboratory.

Borenstein, Severin. 2015. "The Private Net Benefits of Residential Solar PV: The Role of Electricity Tariffs, Tax Incentives and Rebates.” http://www.nber.org/papers/w21342 http://www.nber.org/papers/w21342.pdf.

Braun, Martin, Thomas Stetz, Roland Bründlinger, Christoph Mayr, Kazuhiko Ogimoto, Hiroyuki Hatta, Hiromu Kobayashi, et al. 2011. "Is the Distribution Grid Ready to Accept LargeScale Photovoltaic Deployment? State of the Art, Progress, and Future Prospects." Progress in Photovoltaics: Research and Applications, November. doi:10.1002/pip.1204.

Broderick, Robert, Jimmy Quiroz, Matthew Reno, Abraham Ellis, Jeff Smith, and Roger Dugan. 2013. "Time Series Power Flow Analysis for Distribution Connected PV Generation." Sandia National Laboratories SAND2013-0537.

Broderick, Robert, Matt Reno, Matt Lave, and Jimmy Quiroz. 2015. "Final Technical Report to DOE on Accelerating Cost- Effective Deployment of Solar Generation on the Distribution Grid"." Sandia National Laboratories.

Broderick, Robert, and Joseph Williams. 2013. "Clustering Methodology for Classifying Distribution Feeders.” In 39th IEEE Photovoltaic Specialists Conference. Tampa Bay, FL. http://energy.sandia.gov/wp/wp-content/gallery/uploads/Broderick_SAND20134775C_PVSC391.pdf.

Brown, P.D., J.A. Peas Lopes, and M.A. Matos. 2008. "Optimization of Pumped Storage Capacity in an Isolated Power System With Large Renewable Penetration." IEEE Transactions on Power Systems 23 (2): 523-31. doi:10.1109/TPWRS.2008.919419. 
California Investor-Owned Utilities. 2015. "Distribution Resources Plan (R.14-08-013).” http://www.cpuc.ca.gov/PUC/energy/drp/.

California Public Utilities Commission. 2014. "Decision 14-12-035: Interim Decision Adopting Revisions to Electric Tariff Rule 21 for Pacific Gas and Electric Company, Southern California Edison Company, and San Diego Gas \& Electric Company to Require 'smart' Inverters." http://docs.cpuc.ca.gov/PublishedDocs/Published/G000/M143/K827/143827879.PDF.

—. 2015. "Decision Adopting Successor to Net Energy Metering Tariff."

http://docs.cpuc.ca.gov/PublishedDocs/Efile/G000/M156/K443/156443378.PDF.

Canales, Molly. 2015. "SolarCity Introduces Affordable New Energy Storage Services Across the U.S." SolarCity, April 30. http://www.solarcity.com/newsroom/press/solarcity-introducesaffordable-new-energy-storage-services-across-us.

Carlson, Kristin. 2015. "Green Mountain Power Proposes Strategic Extension of Net Metering for Vermont Homeowners \& Businesses.” Colchester, VT: Green Mountain Power.

Carpenter, B, and A Gelman. 2015. "STAN: A Probabilistic Programming Language.” Journal of Statistical Software.

Carson, Erin, and Eric Davis. 2014. "Utilities Moving Toward Alternative Resource Investments.” Policy Brief. Enerknol.

Chakraborty, S., A. Hoke, and B. Lundstrom. 2015. "Evaluation of Multiple Inverter Volt-VAR Control Interactions with Realistic Grid Impedances." In 2015 IEEE Power Energy Society General Meeting, 1-5. doi:10.1109/PESGM.2015.7285795.

Chakraborty, S., T. Senjyu, H. Toyama, A.Y. Saber, and T. Funabashi. 2009. "Determination Methodology for Optimising the Energy Storage Size for Power System.” IET Generation, Transmission Distribution 3 (11): 987-99. doi:10.1049/iet-gtd.2008.0300.

Chaudhary, S.K., E. Demirok, and R. Teodorescu. 2012. "Distribution System Augmented by DC Links for Increasing the Hosting Capacity of PV Generation.” In 2012 IEEE International Conference on Power Electronics, Drives and Energy Systems (PEDES), 1-5. doi:10.1109/PEDES.2012.6484382.

Christie, Richard. 1999. "Power Systems Test Case Archive." http://www.ee.washington.edu/research/pstca/rts/pg_tcarts.htm.

Chung, Donald, Kelsey Horowitz, and Parthiv Kurup. 2016. On the Path to SunShot: Emerging Opportunities and Challenges in U.S. Solar Manufacturing. Golden, CO: National Renewable Energy Laboratory. NREL/TP-7A40-65788. http://www.nrel.gov/docs/fy16osti/65788.pdf.

Cipcigan, L.M., and P.C. Taylor. 2007. "Investigation of the Reverse Power Flow Requirements of High Penetrations of Small-Scale Embedded Generation." IET Renewable Power Generation 1 (3): 160-66. doi:10.1049/iet-rpg:20070011. 
Clark, K., N.W. Miller, and J.J. Sanchez-Gasca. 2010. "Modeling of GE Wind TurbineGenerators for Grid Studies.” Schenectady, NY: General Electric International, Inc.

Coddington, Michael, Benjamin Kroposki, Thomas Basso, Damian Berger, Kristin Crowell, and John Hayes. 2011. "Performance of a Dynamically Controlled Inverter in a Photovoltaic System Interconnected with a Secondary Network Distribution System." In 2011 37th IEEE Photovoltaic Specialists Conference (PVSC), 001785-89. doi:10.1109/PVSC.2011.6186300.

Coddington, Michael, Benjamin Kroposki, Thomas Basso, Kevin Lynn, Daniel Sammon, Mohammad Vaziri, and Thomas Yohn. 2009. "Photovoltaic Systems Interconnected onto Secondary Network Distribution Systems - Success Stories.” Technical Report NREL/TP-55045061. National Renewable Energy Laboratory (NREL).

Coddington, Michael, Barry Mather, Benjamin Kroposki, Kevin Lynn, Alvin Razon, Abraham Ellis, Roger Hill, Tom Key, Kristen Nicole, and Jeff Smith. 2012. "Updating Interconnection Screens for PV System Integration.” NREL/TP-5500-54063. National Renewable Energy Laboratory (NREL).

Coddington, Michael, and Jeff Smith. 2014. "Current Utility Screening Practices, Technical Tools, Impact Studies, and Mitigation Strategies for Interconnecting PV on the Electric Distribution Systems.” EPRI Report \#3002003277. Palo Alto, CA: EPRI.

Cohen, Michael A., and Duncan S. Callaway. 2015. "Physical Effects of Distributed PV Generation on California's Distribution System." arXiv:1506.06643 [physics], June. http://arxiv.org/abs/1506.06643.

“CSI RD\&D Home Page - Calsolar.” 2015. Accessed November 5. http://www.calsolarresearch.org/.

DallAnese, E., S.V. Dhople, B.B. Johnson, and G.B. Giannakis. 2014. "Decentralized Optimal Dispatch of Photovoltaic Inverters in Residential Distribution Systems." IEEE Transactions on Energy Conversion 29 (4): 957-67. doi:10.1109/TEC.2014.2357997.

Darghouth, Naim, and Ryan Wiser. 2011. "Tracking the Sun IV: An Historical Summary of the Installed Cost of Photovoltaics in the United States from 1998 to 2010.” LBNL-5047E. Ernest Orlando Lawrence Berkeley National Laboratory, Berkeley, CA (US). doi:10.2172/1050985.

Das, R., V. Madani, F. Aminifar, J. McDonald, S.S. Venkata, D. Novosel, A. Bose, and M. Shahidehpour. 2015. "Distribution Automation Strategies: Evolution of Technologies and the Business Case.” IEEE Transactions on Smart Grid 6 (4): 2166-75. doi:10.1109/TSG.2014.2368393.

Debord, Matthew. 2015. "Elon Musk's Big Announcment: It's Called 'Tesla Energy."” Business Insider, May 1. http://www.businessinsider.com/here-comes-teslas-missing-piece-batteryannouncement-2015-4. 
Debruyne, Colin, Jan Desmet, Johan Vanalme, Bart Verhelst, Greet Vanalme, and Lieven Vandevelde. 2010. "Maximum Power Injection Acceptance in a Residential Area." In Proceedings of the International Conference on Renewable Energies and Power Quality.

DeMartini, P. 2014. "More than Smart: A Framework to Make the Distribution Grid More Open, Efficient, and Resilient." Pasadena: Resnick Institute, California Institute of Technology.

Denholm, Paul, Erik Ela, Brendan Kirby, and Michael Milligan. 2010. Role of Energy Storage with Renewable Electricity Generation. Golden, CO: National Renewable Energy Laboratory. NREL/TP-6A2-47187. http://www.nrel.gov/docs/fy10osti/47187.pdf.

Denholm, Paul, Jennie Jorgenson, Marissa Hummon, Thomas Jenkin, and David Palchak. 2013. The Value of Energy Storage for Grid Applications. Golden, CO: National Renewable Energy Laboratory. NREL/TP-6A20-58465. http://www.nrel.gov/docs/fy13osti/58465.pdf.

Denholm, Paul, Kara Clark, and Matt O'Connell. 2016. On the Path to SunShot: Emerging Issues and Challenges in Integrating High Levels of Solar into the Electrical Generation and Transmission System. Golden, CO: National Renewable Energy Laboratory. NREL/TP-6A2065800. http://www.nrel.gov/docs/fy16osti/65800.pdf.

Denholm, Paul, Robert Margolis, Bryan Palmintier, Clayton Barrows, Eduardo Ibanez, Lori Bird, and Jarett Zuboy. 2014. Methods for Analyzing the Benefits and Costs of Distributed Photovoltaic Generation to the U.S. Electric Utility System. Golden, CO: National Renewable Energy Laboratory. NREL/TP-6A20-62447. http://www.nrel.gov/docs/fy14osti/62447.pdf.

Dubal, D. P., O. Ayyad, V. Ruiz, and P. Gómez-Romero. 2015. "Hybrid Energy Storage: The Merging of Battery and Supercapacitor Chemistries." Chemical Society Reviews 44 (7): 177790. doi:10.1039/C4CS00266K.

Dubey, A., S. Santoso, and A. Maitra. 2015. "Understanding Photovoltaic Hosting Capacity of Distribution Circuits.” In 2015 IEEE Power Energy Society General Meeting, 1-5. doi:10.1109/PESGM.2015.7286510.

Eber, Kevin, and David Corbus. 2013. "Hawaii Solar Integration Study: Executive Summary." Technical Report NREL/TP-5500-57215. National Renewable Energy Laboratory (NREL).

EIA. 2015. "Electric Power Annual 2013." http://www.eia.gov/electricity/annual/.

Ellis, Abraham, Carl Lenox, Jimmy Quiroz, and Benjamin Schenkman. 2012. "Initial Operating Experience of the 12MW La Ola Photovoltaic System." In Proceedings of the 2012 38th IEEE Photovoltaic Specialists Conference (PVSC). Austin, TX. doi:10.2172/1031297.

EPRI. 2012a. "Stochastic Analysis to Determine Feeder Hosting Capacity for Distributed Solar PV." 1026640. Palo Alto, CA: Electric Power Research Institute (EPRI).

_. 2012b. "Stochastic Analysis to Determine Feeder Hosting Capacity for Distributed Solar PV." 1026640. Palo Alto, CA: Electric Power Research Institute (EPRI). 
- 2014. "The Integrated Grid: Realizing the Full Value of Central and Distributed Energy Resources." 3002002733.

- 2015a. "Integration of Hosting Capacity Analysis into Distribution Planning Tools." 3002005793. Palo Alto, CA: Electric Power Research Institute (EPRI).

- 2015b. "Alternatives to the 15\% Rule: Modeling and Hosting Capacity Analysis of 16 Feeders." Technical Update 3002005812. Palo Alto, CA: EPRI. http://www.epri.com/abstracts/Pages/ProductAbstract.aspx?productId=000000003002005812.

Etherden, Nicholas. 2014. "Increasing the Hosting Capacity of Distributed Energy Resources Using Storage and Communication.” Disertation, Luleå University of Technology.

Federal Energy Regulatory Commission. 2013. "Standard Interconnection Agreements \& Procedures for Small Generators." http://www.ferc.gov/industries/electric/indus-act/gi/smallgen.asp.

Feldman, David, and Mark Bolinger. 2016. On the Path to SunShot: Emerging Opportunities and Challenges in Financing Solar. Golden, CO: National Renewable Energy Laboratory. NREL/TP-6A20-65638. http://www.nrel.gov/docs/fy16osti/65638.pdf.

Feldman, David, Anna M. Brockway, Elaine Ulrich, and Robert Margolis. 2015. Shared Solar. Current Landscape, Market Potential, and the Impact of Federal Securities Regulation. Golden, CO: National Renewable Energy Laboratory. http://www.nrel.gov/docs/fy15osti/63892.pdf.

Fitzgerald, Garrett, James Mandel, Jesse Morris, and Touati Hervé. 2015. "The Economics of Battery Energy Storage: How Multi-Use, Customer-Sited Batteries Deliver the Most Services and Value to Customers and the Grid.” Rocky Mountain Institute.

http://www.rmi.org/electricity_battery_value.

Fox, Kevin, Sky Stanfield, Laurel Varnado, Culley Thad, Michael Sheehan, and Michael Coddington. 2012. "Updating Small Generator Interconnection Procedures for New Market Conditions.” Technical Report NREL/TP-5500-56790.

Gelman, A, J.B. Carlin, H.S. Stern, and D.B. Rubin. 2014. Bayesian Data Analysis. Vol. 2. London: Chapman \& Hall/CRC.

GTM Research, and SEIA. 2015. "U.S. Solar Market Insight Report: 2015 Q2." https://www.seia.org/research-resources/solar-market-insight-report-2015-q2.

Hambrick, J., and D. Narang. 2012. "High-Penetration PV Deployment in the Arizona Public Service System, Phase 1 Update." In Proceedings of the 2012 38th IEEE Photovoltaic Specialists Conference (PVSC), 000001-000004. Austin, TX. doi:10.1109/PVSC.2012.6317555.

Harlow, J.H. 1996. “Load Tap Changing Control.” Largo, FL: Beckwith Electric Company. 
Hashemi, S., J. Ostergaard, and G. Yang. 2013. "Effect of Reactive Power Management of PV Inverters on Need for Energy Storage.” In Photovoltaic Specialists Conference (PVSC), 2013 IEEE 39th, 2304-8. Tampa Bay, FL. doi:10.1109/PVSC.2013.6744938.

Hoff, T.E., R. Perez, and R.M. Margolis. 2007. "Maximizing the Value of Customer-Sited PV Systems Using Storage and Controls.” Solar Energy 81: 940-45.

Hoke, A., R. Butler, J. Hambrick, and B. Kroposki. 2013. "Steady-State Analysis of Maximum Photovoltaic Penetration Levels on Typical Distribution Feeders." IEEE Transactions on Sustainable Energy 4 (2): 350-57. doi:10.1109/TSTE.2012.2225115.

IEEE 1547. 2003. "IEEE Standard for Interconnecting Distributed Resources with Electric Power Systems.” IEEE Std 1547-2003, July, 1-28. doi:10.1109/IEEESTD.2003.94285.

IEEE 1547a. 2014. "IEEE Standard for Interconnecting Distributed Resources with Electric Power Systems - Amendment 1.” IEEE Std 1547a-2014 (Amendment to IEEE Std 1547-2003), May, 1-16. doi:10.1109/IEEESTD.2014.6818982.

Jauch, E.T. 2005. "Maximizing Automatic Reverse Power Operations with LTC Transformers and Regulators." In 2005 IEEE Power Engineering Society Inaugural Conference and Exposition in Africa, 449-54. doi:10.1109/PESAFR.2005.1611863.

Keller, J., and B. Kroposki. 2010. "Understanding Fault Characteristics of Inverter-Based Distributed Energy Resources.” NREL/TP-5500-46698. NREL.

Kevin P. Schneider, Yousu Chen, David P. Chassin, Robert Pratt, Dave Engel, and Sandra Thompson. 2008. "Modern Grid Initiative Distribution Taxonomy Final Report." Pacific Northwest National Lab.

Kimbis, T., and S. Kann. 2015. "U.S. Solar Market Insight Report: 2014 Year in Review Executive Summary.” http://www.seia.org/sites/default/files/HOlFT6ym3i.pdf.

Kimbis, T, and Shayle Kann. 2013. "U .S. Solar Market Insight Report: 2012 Year in Review Executive Summary." http://www.seia.org/sites/default/files/resources/ZDgLD2dxPGYIR-2012ES.pdf.

Kolenc, Marko, Igor Papič, and Boštjan Blažič. 2015. “Assessment of Maximum Distributed Generation Penetration Levels in Low Voltage Networks Using a Probabilistic Approach." International Journal of Electrical Power \& Energy Systems 64 (January): 505-15. doi:10.1016/j.ijepes.2014.07.063.

Kuravi, Sarada, Jamie Trahan, D. Yogi Goswami, Muhammad M. Rahman, and Elias K. Stefanakos. 2013. "Thermal Energy Storage Technologies and Systems for Concentrating Solar Power Plants." Progress in Energy and Combustion Science 39 (4): 285-319. doi:10.1016/j.pecs.2013.02.001. 
Lave, Matthew, Matthew Reno, and Robert Broderick. 2015. "Characterizing Local HighFrequency Solar Variability and Its Impact to Distribution Studies." Solar Energy 118 (August): 327-37. doi:10.1016/j.solener.2015.05.028.

Lave, Matthew, J Stein, Abraham Ellis, C Hansen, Eichi Nakashima, and Yusuke Miyamoto. 2011. "Ota City: Characterizing Output Variability from 553 Homes with Residential PV Systems on a Distribution Feeder.” SAND2011-9011. Sandia National Laboratories.

Lindl, Tim, Kevin Fox, Abraham Ellis, and Robert Broderick. 2013. "Integrated Distribution Planning Concept Paper, Interstate Renewable Energy Council."

Lin, Kaixiang, Qing Chen, Michael R. Gerhardt, Liuchuan Tong, Sang Bok Kim, Louise Eisenach, Alvaro W. Valle, et al. 2015. "Alkaline Quinone Flow Battery." Science 349 (6255): 1529-32. doi:10.1126/science.aab3033.

Litvak, Nicole. 2015. “U.S. Residential Solar Financing 2015-202.” GTM Research.

Liu, Y., J. Bebic, B. Kroposki, J. de Bedout, and W. Ren. 2008. "Distribution System Voltage Performance Analysis for High-Penetration PV.” In IEEE Energy 2030 Conference, 2008. ENERGY 2008, 1-8. doi:10.1109/ENERGY.2008.4781069.

Lund, Henrik, and Willett Kempton. 2008. "Integration of Renewable Energy into the Transport and Electricity Sectors through V2G." Energy Policy 36 (9): 3578-87.

doi:10.1016/j.enpol.2008.06.007.

Madani, V., R. Das, F. Aminifar, J. McDonald, S.S. Venkata, D. Novosel, A. Bose, and M. Shahidehpour. 2015. "Distribution Automation Strategies Challenges and Opportunities in a Changing Landscape.” IEEE Transactions on Smart Grid 6 (4): 2157-65. doi:10.1109/TSG.2014.2368382.

Mather, B., and A. Gebeheyu. 2015. "Field Demonstration of Using Advanced PV Inverter Functionality to Mitigate the Impacts of High-Penetration PV Grid Integration on the Distribution System." In Proceedings of the 42nd Photovoltaic Specialist Conference (PVSC). New Orleans, LA.

Mather, B., and R. Neal. 2012. "Integrating High Penetrations of PV into Southern California: Year 2 Project Update.” In 2012 38th IEEE Photovoltaic Specialists Conference (PVSC), 000737-41. Austin, TX. doi:10.1109/PVSC.2012.6317711.

McGranaghan, Mark, Thomas Ortmeyer, David Crudele, Thomas Key, Jeff Smith, and Phil Barker. 2008. "Renewable Systems Interconnection Study: Advanced Grid Planning and Operations.” SAND2008-0944. Sandia National Laboratories.

Mehos, Mark, Craig Turchi, Jennie Jorgenson, Paul Denholm, Clifford Ho, and Kenneth Armijo. 2016. On the Path to SunShot: Advancing Concentrating Solar Power Technology, Performance, and Dispatchability. Golden, CO: National Renewable Energy Laboratory. NREL/TP-550065668. http://www.nrel.gov/docs/fy16osti/65668.pdf. 
Menniti, D., M. Merlo, N. Scordino, and F. Zanellini. 2012. "Distribution Network Analysis: A Comparison between Hosting and Loading Capacities." In 2012 International Symposium on Power Electronics, Electrical Drives, Automation and Motion (SPEEDAM), 926-33. doi:10.1109/SPEEDAM.2012.6264635.

Miller, N.W., M. Shao, S. Pajic, and R. D’Aquila. 2014. "Western Wind and Solar Integration Study Phase 3 - Frequency Response and Transient Stability." Subcontract Report NREL/SR5D00-62906. National Renewable Energy Laboratory (NREL).

Mills, A., M. Ahlstrom, M. Brower, A. Ellis, R. George, T. Hoff, B. Kroposki, et al. 2011. "Dark Shadows: Understanding Variability and Uncertainty of Photovoltaics for Integration with the Electric Power System.” IEEE Power and Energy Magazine 9 (3): 33-41.

doi:10.1109/MPE.2011.940575.

Munsell, Mike. 2015a. "US Community Solar Market to Grow Fivefold in 2015, Top 500MW in 2020." Greentech Media, June 23. http://www.greentechmedia.com/articles/read/us-communitysolar-market-to-grow-fivefold-in-2015-top-500-mw-in-2020.

- 2015b. "72\% of US Residential Solar Installed in 2014 Was Third-Party Owned." Greentech Media, July 29. http://www.greentechmedia.com/articles/read/72-of-us-residentialsolar-installed-in-2014-was-third-party-owned.

Narang, David, Raja Ayyanar, Paul Gemin, Murali Baggu, and Devarajan Srinivasan. 2015. "Final Technical Report. Results of Phases 2-5." DOE_APS_EE04679--1. Arizona Public Service Company (APS), Phoenix, AZ (United States).

http://www.osti.gov/scitech/biblio/1171386-final-technical-report-results-phases.

Navarro-Espinosa, A., and L.F. Ochoa. 2015a. "Probabilistic Impact Assessment of Low Carbon Technologies in LV Distribution Systems.” IEEE Transactions on Power Systems PP (99): 1-12. doi:10.1109/TPWRS.2015.2448663.

2015b. "Increasing the PV Hosting Capacity of LV Networks: OLTC-Fitted Transformers vs. Reinforcements.” In Innovative Smart Grid Technologies Conference (ISGT), 2015 IEEE Power Energy Society, 1-5. doi:10.1109/ISGT.2015.7131856.

Navarro-Espinosa, A., L.F. Ochoa, and D. Randles. 2013. "Monte Carlo-Based Assessment of PV Impacts on Real UK Low Voltage Networks.” In 2013 IEEE Power and Energy Society General Meeting (PES), 1-5. doi:10.1109/PESMG.2013.6672620.

Nguyen, Dung, and Jan Kleissl. 2015. "Research on Impacts of Distributed versus Centralized Solar Resource on Distribution Network Using Power System Simulation and Solar NowCasting with Sky Imager.” In Photovoltaic Specialist Conference (PVSC), 2015 IEEE 42nd, 1-3. doi:10.1109/PVSC.2015.7356208.

Nguyen, T., and R.F. Savinell. 2010. “Flow Batteries.” Electrochemical Society Interface. 
North Carolina Clean Energy Technology Center. 2015. "DSIRE: Database of State Incentives for Renewables and Efficiency--Net Metering." http://ncsolarcen-prod.s3.amazonaws.com/wpcontent/uploads/2015/04/Net-Metering-Policies.pdf.

Pacific Gas and Electric. 2015. "Pacific Gas and Electric Company Electric Distribution Resources Plan."

Palmintier, Bryan. 2015. "The Integrated Grid Modeling System (IGMS) for Combined Transmission and Distribution Simulation.” presented at the Power and Energy Society General Meeting, Denver, CO, July 29.

Palmintier, Bryan, Leslie Ponder, and Jesse Gantz. 2015. "Mitigating Adverse Impacts of Distributed Solar PV with Smart Inverters \& Integrated Volt-Var Control." presented at the Alstom North American Users Group, Bellevue, WA, June 3.

Palmintier, Bryan, Elaine Hale, Timothy Hansen, Wesley Jones, David Biagioni, Kyri Baker, Hongyu Wu, Julieta Giraldez, Harry Sorensen, Monte Lunacek, Noel Merket, Jennie Jorgenson, and Bri-Mathias Hodge. 2016. Integrated Distribution-Transmission Analysis for Very High Penetration Solar PV. Golden, CO: National Renewable Energy Laboratory. NREL/TP-5D0065550. http://www.nrel.gov/docs/fy16osti/65550.pdf.

Palmintier, Bryan, Robert Broderick, Barry Mather, Michael Coddington, Kyri Baker, Fei Ding, Matthew Reno, Matthew Lave, and Ashwini Bharatkumar. 2016. On the Path to SunShot:

Emerging Issues and Challenges in Integrating Solar with the Distribution System. Golden, CO: National Renewable Energy Laboratory. NREL/TP-5D00-65331. http://www.nrel.gov/docs/fy16osti/65331.pdf.

Paradis, D., F. Katiraei, and B. Mather. 2013. "Comparative Analysis of Time-Series Studies and Transient Simulations for Impact Assessment of PV Integration on Reduced IEEE 8500 Node Feeder." In 2013 IEEE Power and Energy Society General Meeting (PES), 1-5. doi:10.1109/PESMG.2013.6672951.

Perez, R. 2006. "Integration of PV in Demand Response Programs." NREL subcontract \#AEK5-55057-01 Final Report.

Quiroz, J.E., M.J. Reno, and R.J. Broderick. 2013. "Time Series Simulation of Voltage Regulation Device Control Modes.” In Photovoltaic Specialists Conference (PVSC), 2013 IEEE 39th, 1700-1705. doi:10.1109/PVSC.2013.6744472.

Ravindra, H., M.O. Faruque, P. McLaren, K. Schoder, M. Steurer, and R. Meeker. 2012. "Impact of PV on Distribution Protection System." In North American Power Symposium (NAPS), 2012, 1-6. doi:10.1109/NAPS.2012.6336409.

Rawson, Mark, and Eddie Paul Sanchez. 2013. "Sacramento Municipal Utility District Pv and Smart Grid Pilot at Anatolia." DOE-SMUD-11111-1. Sacramento Municipal Utility District. http://www.osti.gov/scitech/biblio/1162051. 
Reno, Matthew, and Robert Broderick. 2015. "Technical Evaluation of the 15\% of Peak Load PV Interconnection Screen." In Proceedings of the 42nd Photovoltaic Specialists Conference (PVSC). New Orleans, LA. doi:10.1109/PVSC.2015.7356168.

- 2016. "Statistical Analysis of Feeder and Locational PV Hosting Capacity for 216 Feeders." In IEEE PES General Meeting. Boston, MA.

Reno, Matthew, Robert Broderick, and Santiago Grijalva. 2013. "Smart Inverter Capabilities for Mitigating over-Voltage on Distribution Systems with High Penetrations of PV." In Photovoltaic Specialists Conference (PVSC), 2013 IEEE 39th, 3153-58. doi:10.1109/PVSC.2013.6745125.

Reno, Matthew, and K. Coogan. 2013. "Grid Integrated Distributed PV (GridPV).” Sandia Report SAND2013-6733. Sandia National Laboratories Albuquerque, NM; Sandia National Laboratories.

Reno, Matthew, Kyle Coogan, Santiago Grijalva, and Robert Joseph Broderick. 2014. "Locational Dependence of PV Hosting Capacity Correlated with Feeder Load." In IEEE PES Transmission \& Distribution Conference \& Exposition. Chicago, IL. http://www.osti.gov/scitech/biblio/1142288.

Ropp, M.E., M. Begovic, A. Rohatgi, Gregory A. Kern, Sr. R.H. Bonn, and S. Gonzalez. 2000. "Determining the Relative Effectiveness of Islanding Detection Methods Using Phase Criteria and Nondetection Zones." IEEE Transactions on Energy Conversion 15 (3): 290-96. doi:10.1109/60.875495.

Rylander, Matthew. 2015. "Best Practices for Distribution Systems with High PV Penetration." presented at the Presented at UVIG Fall Technical Conference, San Diego CA, October.

Rylander, Matthew, and Jeff Smith. 2012. “Comprehensive Approach for Determining Distribution Network Hosting Capacity for Solar PV." In Proceeding of the 2nd International Workshop on Integration of Solar Power Into Power Systems. Lisbon, Portugal.

Rylander, Matthew, Jeff Smith, Robert Broderick, and Barry Mather. 2015a. "Alternatives to the 15\% Rule: Modeling and Hosting Capacity Analysis of 16 Feeders.” EPRI Report \#3002005812. EPRI.

- 2015b. “Alternatives to the 15\% Rule: Modified Screens and Validation.” EPRI Report \#3002005791. EPRI.

Rylander, Matthew, Jeff Smith, Robert Broderick, Matthew Reno, and Barry Mather. 2015. "Alternatives to the 15\% Rule: Final Project Summary." EPRI Report \#3002006594. EPRI.

Rylander, Matthew, Jeff Smith, Dexter Lewis, and Steve Steffel. 2013. "Voltage Impacts from Distributed Photovoltaics on Two Distribution Feeders." In 2013 IEEE Power and Energy Society General Meeting (PES), 1-5. doi:10.1109/PESMG.2013.6672320. 
Rylander, Matthew, Jeff Smith, and Wes Sunderman. 2015. "Streamlined Method for Determining Distribution System Hosting Capacity." In 2015 IEEE Rural Electric Power Conference (REPC), 3-9. doi:10.1109/REPC.2015.11.

Samadi, A., R. Eriksson, L. Söder, B.G. Rawn, and J.C. Boemer. 2014. "Coordinated Active Power-Dependent Voltage Regulation in Distribution Grids With PV Systems." IEEE Transactions on Power Delivery 29 (3): 1454-64. doi:10.1109/TPWRD.2014.2298614.

San Diego Gas and Electric. 2015. “Application of San Diego Gas \& Electric Company (u 902 E) for Approval of Distribution Resources Plan.”

Schelly, Chelsea. 2014. "Residential Solar Electricity Adoption: What Motivates, and What Matters? A Case Study of Early Adopters." Energy Research \& Social Science 2 (June): 183-91. doi:10.1016/j.erss.2014.01.001.

Seguin, R., J. Woyak, D. Costyk, J. Hambrick, and B. Mather. 2015. "High-Penetration PV Integration Handbook for Distribution Engineers." NREL/TP-5D00-63114. National Renewable Energy Laboratory (NREL).

Sena, S.S., J.E. Quiroz, and R.J. Broderick. 2014. “Analysis of 100 Utility SGIP PV Interconnection Studies." In Photovoltaic Specialist Conference (PVSC), 2014 IEEE 40th, 100510. doi:10.1109/PVSC.2014.6925084.

Seuss, John, Matthew Reno, Robert Broderick, and Santiago Grijalva. 2015. "Improving Distribution Network PV Hosting Capacity via Smart Inverter Reactive Power Support." In Proceedings of the IEEE Power and Energy Society General Meeting. Denver, CO.

Shayani, R.A., and M.A.G. de Oliveira. 2011. "Photovoltaic Generation Penetration Limits in Radial Distribution Systems.” IEEE Transactions on Power Systems 26 (3): 1625-31. doi:10.1109/TPWRS.2010.2077656.

Smith, Jeff, Roger Dugan, Matthew Rylander, and Tom Key. 2012. "Advanced Distribution Planning Tools for High Penetration PV Deployment." In 2012 IEEE Power and Energy Society General Meeting, 1-7. doi:10.1109/PESGM.2012.6345628.

Smith, Jeff, Wes Sunderman, Roger Dugan, and Brenda Seal. 2011. "Smart Inverter Volt/var Control Functions for High Penetration of PV on Distribution Systems." In Proceedings of the IEEE/PES Power Systems Conference and Exposition (PSCE). Phoenix, AZ.

SolarCity. 2015. “Integrated Distribution Planning White Paper.” SolarCity.

Southern California Edison. 2015. "Application of Southern California Edison Company (u 338E) for Approval of Its Distribution Resources Plan.”

Srivastava, A.K., A.A. Kumar, and N.N. Schulz. 2012. "Impact of Distributed Generations with Energy Storage Devices on the Electric Grid.” IEEE Systems Journal 6 (1): 110-17. doi:10.1109/JSYST.2011.2163013. 
State of Hawaii Public Utilities Commission. 2013. "Reliability Standards Working Group Independent Facilitator's Submittal and Final Report." Docket 2011-0206, Attachment 4. PVDG Subgroup Summary of Proposal for Proactive Review Approach.

—. 2015. "Decision 33258: Distributed Energy Resources-Phase 1."

http://www.slideshare.net/civilbeat/phase-1-hawaii-puc-order-der.

State of New York Department of Public Service. 2015. "Staff White Paper on Ratemaking and Utility Business Models."

Steffel, Steve, Amrita Acharya-Menon, and Jason Bank. 2015. "Model-Based Integrated High Penetration Renewables Planning and Control Analysis." presented at the Integrating PV in Distribution Systems: Solutions and Technolgies, NREL, Golden, CO, October 22.

Stetz, T., J. von Appen, F. Niedermeyer, G. Scheibner, R. Sikora, and M. Braun. 2015. "Twilight of the Grids: The Impact of Distributed Solar on Germany?s Energy Transition." IEEE Power and Energy Magazine 13 (2): 50-61. doi:10.1109/MPE.2014.2379971.

Stewart, Emma M, James MacPherson, Slavko Vasilic, Dora Nakafuji, and Thomas Aukai. 2013. "Analysis of High-Penetration Levels of Photovoltaics into the Distribution Grid on Oahu, Hawaii.” NREL/SR-5500-54494. National Renewable Energy Laboratory (NREL), Golden, CO (United States).

St. John, Jeff. 2013. "California Closes in on Smart Solar Inverter Rules." Greentech Media, November 13.

Sullivan, Patrick, Wesley Cole, Nate Blair, Eric Lantz, Venkat Krishnan, Trieu Mai, David Mulcahy, and Gian Porro. 2015. "2015 Standard Scenarios Annual Report: U.S. Electric Sector Scenario Exploration.” NREL/TP-6A20-64072. Golden, CO: National Renewable Energy Laboratory. http://www.osti.gov/servlets/purl/1215209/.

The Hawaiian Electric Companies. 2015. Docket 2014-0192: Proceeding to Investigate Distributed Energy Resource Policies.

Trabish, Herman. 2015. “A Good Rate Design Is Hard to Find: Experts Push Utility-Solar Compromise." http://www.utilitydive.com/news/a-good-rate-design-is-hard-to-find-expertspush-utility-solar-compromise/405894/.

Turitsyn, Konstantin, Petr Šulc, Scott Backhaus, and Michael Chertkov. 2011. "Options for Control of Reactive Power by Distributed Photovoltaic Generators." Proceedings of the IEEE 99 (6): 1063-73. doi:10.1109/JPROC.2011.2116750.

Underwriters Laboratory. 2010. "Standard 1741 - Standard for Inverters, Converters, Controllers and Interconnection System Equipment for Use With Distributed Energy Resources." http://ulstandards.ul.com/standard/?id=1741_2. 
von Appen, J., M. Braun, T. Stetz, K. Diwold, and D. Geibel. 2013. "Time in the Sun: The Challenge of High PV Penetration in the German Electric Grid." IEEE Power and Energy Magazine 11 (2): 55-64. doi:10.1109/MPE.2012.2234407.

von Appen, J., T. Stetz, M. Braun, and A. Schmiegel. 2014a. "Local Voltage Control Strategies for PV Storage Systems in Distribution Grids." IEEE Transactions on Smart Grid 5 (2): 1002-9. doi:10.1109/TSG.2013.2291116.

_. 2014b. "Local Voltage Control Strategies for PV Storage Systems in Distribution Grids.” IEEE Transactions on Smart Grid 5 (2): 1002-9. doi:10.1109/TSG.2013.2291116.

Wang, Yanzhi, Xue Lin, and M. Pedram. 2014. "Adaptive Control for Energy Storage Systems in Households With Photovoltaic Modules.” IEEE Transactions on Smart Grid 5 (2): 992-1001. doi:10.1109/TSG.2013.2292518.

Wang, Zhaoyu, Hao Chen, Jianhui Wang, and M. Begovic. 2014. "Inverter-Less Hybrid Voltage/Var Control for Distribution Circuits With Photovoltaic Generators." IEEE Transactions on Smart Grid 5 (6): 2718-28. doi:10.1109/TSG.2014.2324569.

Whitaker, Chuck, Jeff Newmiller, Michael Ropp, and Ben Norris. 2008. "Renewable Systems Interconnection Study: Distributed Photovoltaic Systems Design and Technology Requirements." SAND2008-0946. Sandia National Laboratories.

Wiser, Ryan, Trieu Mai, Dev Millstein, Jordan Macknick, Alberta Carpenter, Stuart Cohen, Wesley Cole, Bethany Frew, and Garvin A. Heath. 2016. On the Path to SunShot: The Environmental and Public Health Benefits of Achieving High Penetrations of Solar Energy in the United States. Golden, CO: National Renewable Energy Laboratory. NREL/TP-6A20-65628. http://www.nrel.gov/docs/fy16osti/65628.pdf.

Woodhouse, Michael, Rebecca Jones-Albertus, David Feldman, Ran Fu, Kelsey Horowitz, Donald Chung, Dirk Jordan, and Sarah Kurtz. 2016. On the Path to SunShot: The Role of Advancements in Solar Photovoltaic Efficiency, Reliability, and Costs. Golden, CO: National Renewable Energy Laboratory. NREL/TP-6A20-65464.

http://www.nrel.gov/docs/fy16osti/65464.pdf.

Yazdanpanahi, H., Yun Wei Li, and Wilsun Xu. 2012. "A New Control Strategy to Mitigate the Impact of Inverter-Based DGs on Protection System." IEEE Transactions on Smart Grid 3 (3): 1427-36. doi:10.1109/TSG.2012.2184309.

Zinaman, Owen, and Naïm Darghouth. 2015. “A Valuation-Based Framework for Considering Distributed Generation Photovoltaic Tariff Design.” In Proceedings of India Smart Grid Week. Bangalore, India. 


\section{Appendix A: Additional Literature Review}

The impacts of high penetrations of PV in the distribution grid have been studied widely both by actual field experience and through advanced simulations. The high residential PV penetrations in the distribution grids around California, Arizona, Hawaii, and Germany have proved to be perfect grounds for real-time experience on the grid impacts (Mather and Neal 2012; Stewart et al. 2013; EPRI 2014; Ellis et al. 2012; Hambrick and Narang 2012). NREL, in collaboration with Southern California Edison, evaluated the impacts of the high PV penetration on distribution feeders in California (Mather and Neal 2012). The study indicates that, with large-scale PV integration, voltage regulation issues such as potential overvoltage situations and voltage fluctuations with PV variability are more likely to occur. The issues were reported to have been resolved by allowing the PV inverter to operate at a fixed power factor (Mather and Gebeheyu 2015). NREL also studied the repercussions of high PV penetrations in the distribution grid in Hawaii (Stewart et al. 2013). It was recorded that the PV penetration limit was reached when PV systems over-generated, causing reverse power flow into the sub-transmission system. In Germany, the impacts of high PV penetration were recorded to be local overvoltage, loading issues on distribution feeders, risk of mass disconnection of anticipated PV generation, resource variability, generation uncertainty, and the lack of stabilizing inertia that is typical of conventional generators (Braun et al. 2011; von Appen et al. 2013; EPRI 2014; Stetz et al. 2015).

Although critical inferences can be derived from the field study, detailed analyses of the implications of future PV deployments in the grid have been obtained from advanced simulation studies (McGranaghan et al. 2008; Liu et al. 2008; Quiroz, Reno, and Broderick 2013; Rylander et al. 2013; Aramizu and Vieira 2013; Ravindra et al. 2012). Various impacts on the grid due to high PV penetration are brought out in (McGranaghan et al. 2008). One of the important impacts of high PV penetration is related to voltage regulation in the distribution system. The conventional distribution grid is designed for unidirectional power flow with load tap-changing transformers, line regulators, switched voltage regulators, and capacitors to regulate the voltage. However, the bidirectional power flow due to high penetrations of PV in the distribution grid can interfere with the coordination between the existing regulating equipment (Liu et al. 2008; Quiroz, Reno, and Broderick 2013) and can cause voltage-related concern in the grid such as overvoltage, voltage unbalance, and deviation (Rylander et al. 2013; Aramizu and Vieira 2013). Another impact of high PV penetration is on the existing protection system of the grid (Ravindra et al. 2012). DGPV can increase the fault magnitude on the system, and it can change the direction of the fault current flow causing sympathetic tripping of the reclosers (McGranaghan et al. 2008).

The field experiences and analysis suggest there is a limit on the amount of PV that can be integrated into a given distribution circuit without causing any impacts on the grid. The maximum limit on the amount of PV that can be integrated is called the PV hosting capacity of the grid. Many methods have been used to calculate the PV hosting capacity limits of the distribution feeders (Debruyne et al. 2010; Shayani and de Oliveira 2011; Cipcigan and Taylor 2007; Smith et al. 2012; EPRI 2012b; Rylander and Smith 2012; Whitaker et al. 2008; Reno et al. 2014). Some of the methods consider simplified feeder models to calculate the hosting capacity value (Debruyne et al. 2010; Shayani and de Oliveira 2011; Cipcigan and Taylor 2007). However, a widely used method uses an actual feeder model with stochastic framework to 
calculate the hosting capacity of the feeders (Smith et al. 2012; EPRI 2012b; Rylander and Smith 2012).

The PV hosting capacity limit of distribution grids has been debated since 1985. An extensive literature review is presented in (Whitaker et al. 2008), which provides various acceptable PV penetration limits suggested in the literature. Maximum PV capacity limits varying from 5\% to $50 \%$ of the peak load of the feeder have been suggested in the literature (Whitaker et al. 2008). The hosting capacity limits of two feeders of similar voltage class and peak load can range from $3 \%$ to $62.5 \%$ (Rylander et al. 2013). Also, the hosting capacity limits vary with regard to size and placement of PV in the distribution grid (Reno et al. 2014). Therefore, it is speculated that fixing a limit universally on the hosting capacity limit of feeders can over- or underestimate the capacity of a feeder (Rylander et al. 2013).

The maximum PV penetration in a distribution grid is defined when there is violation of any acceptable operating conditions of the distribution grids. Therefore, by way of mitigating the grid concern that may arise due to high PV penetration, the hosting capacity of the grid can be increased (Navarro-Espinosa and Ochoa 2015b; Ballanti et al. 2013; Z. Wang et al. 2014; Reno, Broderick, and Grijalva 2013; Hashemi, Ostergaard, and Yang 2013; von Appen et al. 2014b; Y. Wang, Lin, and Pedram 2014; Srivastava, Kumar, and Schulz 2012; Samadi et al. 2014; Alyami et al. 2014; Chaudhary, Demirok, and Teodorescu 2012). A cost comparison of the on-load tap changing versus line upgrades in increasing the hosting capacity concludes that the large investments in the on-load tap-changing transformer can prove to be cost effective beyond $75 \%$ of PV penetration in the grid (Navarro-Espinosa and Ochoa 2015b). Reactive power support from the PV inverters has been demonstrated to mitigate voltage-related concerns, which are the most important problem that arises due to large PV deployment in the distribution grid (Ballanti et al. 2013; Z. Wang et al. 2014; Reno, Broderick, and Grijalva 2013). The inverter's reactive power support has also been shown to decrease the capacity of storage required in the grid (Hashemi, Ostergaard, and Yang 2013). The advantages of combining DGPV with energy storage have been discussed in (von Appen et al. 2014b; Y. Wang, Lin, and Pedram 2014; Srivastava, Kumar, and Schulz 2012). Further, the curtailment of active power output of PV inverters by a fixed $50 \%$ of nameplate capacity and other adaptive methods to cap the real power output have been reported to reduce the potential for frequency instability due to PV variability (Alyami et al. 2014; Samadi et al. 2014; Ellis et al. 2012). Another method to augment the AC distribution grids with DC links to increase the PV hosting capacity of the grid is proposed in (Chaudhary, Demirok, and Teodorescu 2012).

In the last few years, several studies have been carried out to efficiently quantify the hosting capacity of a particular feeder (Navarro-Espinosa, Ochoa, and Randles 2013; Navarro-Espinosa and Ochoa 2015a; Kolenc, Papič, and Blažič 2015; Hoke et al. 2013; Kevin P. Schneider et al. 2008; Menniti et al. 2012; EPRI 2012b; Sena, Quiroz, and Broderick 2014). Several papers have proposed using Monte Carlo techniques for determining hosting capacity owing to the innate uncertainties present in a distribution system that includes distributed generation (NavarroEspinosa, Ochoa, and Randles 2013; Navarro-Espinosa and Ochoa 2015a; Kolenc, Papič, and Blažič 2015). In (Navarro-Espinosa, Ochoa, and Randles 2013) and (Navarro-Espinosa and Ochoa 2015a), probabilistic impact assessment is used to assess the impact of low-carbon technologies on the low-voltage distribution system. The methodology proposed differs from other approaches that focus on a single scenario (e.g., maximum generation and maximum load) 
and aims to evaluate the system in a statistical manner. In (Navarro-Espinosa, Ochoa, and Randles 2013; Navarro-Espinosa and Ochoa 2015a), Monte Carlo methods are used to randomly select different generation profiles, load profiles, and PV locations on a given feeder to understand the impacts on the feeder. Voltage rise and thermal capacity are used to determine hosting capacity. The percentage of customers with voltage issues (using standards EN50160) and utilization factor of the main feeder (calculated on an hourly basis) are used as the key metrics. In addition to PV, micro combined heat and power $(\mu \mathrm{CHP})$ and electric vehicles are considered in (Navarro-Espinosa and Ochoa 2015a) and evaluated independently. Location, size, and behavior are varied on more than 128 low-voltage feeder models representative of feeders in the U.K. Penetration levels between $0 \%$ and $100 \%$ of low-carbon technologies with a step size of $10 \%$ are investigated using 1-minute residential load profiles and 5-minute time-series profiles for the low-carbon technologies. "Percentage of customers with voltage problems" and "loading levels" (at the feeder head and transformer) are the two metrics used to quantify daily impacts.

In (Kolenc, Papič, and Blažič 2015), a probabilistic approach for network planning with the goal of increasing system utilization is proposed. Distributed generation locations and profiles as well as customer loads were varied using Monte Carlo techniques. An expected distributed generation size for the circuit is given, and distributed generation is added at random nodes until the expected size is reached. The authors suggest that, by applying this methodology in the planning stage, mitigation strategies focusing on increasing hosting capacity can be investigated. Results indicate that, by using actual load profiles (randomly chosen from real recorded profiles) instead of peak profiles, the hosting capacity (in this case defined as the probability that there will be an issue on the line) increases more than $100 \%$ in some cases.

In (Hoke et al. 2013), 16 out of the 24 radial distribution feeder models developed at Pacific Northwest National Laboratories (Kevin P. Schneider et al. 2008) to represent typical distribution feeders in the United States in different climate regions are analyzed under many PV penetration scenarios. Annual load profiles were developed, and PV penetration levels were integrated into the feeder models and increased at a step size of $15 \%$ (starting from $0 \%$ penetration) until an overvoltage or overcurrent situation was detected. Five DGPV scenarios and four single, large PV scenarios were studied for each of the 16 feeders. Results indicate that the maximum tolerable PV penetration for a feeder varies widely among feeders. There was also a wide maximum tolerable PV penetration variation observed with PV location on a single feeder. In most cases, the DGPV systems with 50\% PV penetration resulted in no overvoltage and no overcurrent cases. PV penetration for systems with a smaller distance between feeder source and PV system was generally higher than 50\%. In addition, results indicate that, although the $15 \%$ rule used was conservative in most cases and was never a problem in single PV system cases, issues were observed for approximately 1 in 6 DGPV scenarios.

In (Menniti et al. 2012), hosting capacity and loading capacity, defined as the maximum increase of passive loads, are compared using an AC optimal power flow based mathematical model. The optimal power flow model has the objective of maximizing the rate of generation/load increase on a particular bus that has distributed generation. The model was applied to a four-feeder system composed of 32 nodes and 33 branches and was representative of an actual Italian distribution network. EN 50160 standards were used to determine violations. 
A stochastic approach for analyzing hosting capacity is also proposed by EPRI in (EPRI 2012b). Voltage, thermal, protection, and power-quality thresholds are all used as metrics to determine the maximum PV hosting capacity of a particular feeder. Distribution feeders are modeled using the Open Source Distribution System Simulator (OpenDSS). Maximum recorded feeder loads are used as the four baseload levels for the analysis, and PV penetration on the feeder at random locations is varied between $0 \%$ and $100 \%$ of feeder load. Hosting capacity is reported as minimum and maximum hosting capacity. The minimum hosting capacity represents the PV penetration level where some simulated PV deployments, dependent on location, are acceptable while others are not. The maximum hosting capacity represents the PV penetration level that causes system issues regardless of PV location. The methodology presented in (EPRI 2012b) to determine hosting capacity has been used to evaluate several real feeders, mostly located in California.

In addition to the work described above, more than $\$ 15$ million has been awarded to 16 gridintegration projects by the California Solar Initiative Research, Development, Demonstration, and Deployment program ("CSI RD\&D Home Page - Calsolar" 2015). Funds have been matched by several other organizations for a total of $\$ 30$ million. Projects can be classified into three primary areas: (1) interconnection screens, rules, and standards; (2) modeling and simulation tools and methods; and (3) hardware development and physical testing. Several projects fall into more than one category. Seven of the projects propose new tools and/or improvements to existing tools for evaluating PV interconnection impacts. Four projects have a goal of improving existing interconnection screens, rules, and processes as well as developing essential standards for projects of high penetrations of PV. Finally, five projects summarize and document results and lessons learned from physically installing and testing equipment identified to potentially mitigate adverse $\mathrm{PV}$ impacts and/or to enable high penetrations of $\mathrm{PV}$.

For PV with storage, many recent simulation-based frameworks have been developed to help determine the optimal placement and sizing of storage (Baker 2014); methods to perform peak shifting using optimally sized batteries are shown in (Chakraborty et al. 2009), stochastic methods were developed in (Abbey and Joos 2009) for a wind-diesel isolated grid and in (Brown, Peas Lopes, and Matos 2008) for pumped hydro storage, and the relationship between system marginal price and optimal storage size was used in (Baker, Hug, and Li 2014) to size storage, among many other optimization-based approaches. (Perez 2006) shows an example using three different utilities where all demand in excess of $80 \%$ of peak loading was accounted for using demand response or demand response $+\mathrm{PV}$. Demand response credits as a function of installed PV capacity were explored in (Perez 2006), and the conclusion was that DGPV receiving a substantial portion of demand response credit can be very beneficial to the grid and PV owners. When designing DGPV tariffs, multiple perspectives and objectives must be taken into account, and the key tariff components and possible pricing mechanisms must be identified. For example, time-of-use pricing, distribution locational marginal pricing, and panel orientation incentives are all possible pricing mechanisms for capturing the value of DGPV (Zinaman and Darghouth 2015). 


\section{Appendix B: Additional Details on Statistical Estimates for Nationwide Hosting Capacity}

\section{Multivariate Regression Model}

The national hosting capacity multivariate regression model differs from that described in the sidebar on "Using Statistics to Identify the Key Drivers of Hosting Capacity" because impedance data were not included in the available large-scale feeder descriptive data set. Instead a different model based on readily available descriptive data was developed using:

- Feeder primary voltage $\left(\mathrm{p}=9 \times 10^{-5}\right)$

- Feeder maximum load in MW ( $\mathrm{p}=0.004)$

- Total circuit distance in miles $\left(\mathrm{p}=5 \times 10^{-7}\right)$

- Number of customers $(\mathrm{p}=0.018)$.

This model explains about $60 \%$ (multiple $\mathrm{R}^{2}$ ) of the observed variations in the training data. This model was then applied to available descriptive data for more than 7,000 distribution feeders to produce an estimate of $18,212 \mathrm{MW}$ of hosting capacity across all feeders. This represents about $32 \%$ of the peak demand of the available feeders. Assuming a simultaneity factor of $75 \%{ }^{29}$ to scale the individual feeder peaks to utility-wide peaks, and scaling to the U.S. non-coincident load peak on an interconnection level of 716,236 $\mathrm{MW}^{30}$ (EIA 2015, Table 8.6A) yields an estimated of 171,000 MW of DGPV hosting capacity.

\section{Cross-Checking with California's Distribution Resources Plan}

We cross-checked these results by comparing them to DRP results for more than 3,000 feeders in California. The aggregated hosting capacity estimate using our statistical model compared favorably to a DRP estimate of $8.56 \mathrm{GW}$. The DRP estimate was based on the most restrictive constraint between line segment, feeder, and substation transformer bank-level limits, assuming a $50 \%$ derate for the line segment sum as described in the sidebar on "Determining the Scale of Integration Challenges from DRP Data." The overall range of potential hosting capacities depending on the achieved line section hosting capacity derating is shown in Figure 28. According to the analysis of the DRP integration capacity analysis, the potential hosting capacity of PG\&E's distribution system is 6-9 GW but is more realistically $8-9 \mathrm{GW}$, assuming line section hosting capacity derates smaller than $75 \%$.

\footnotetext{
${ }^{29}$ Our separate analysis of the ratio between the sum of feeder peaks vs. the system-wide peak for a large U.S. utility showed a simultaneity factor of $77 \%$. We rounded this to a slightly more conservative $75 \%$.

${ }^{30}$ This value is an average of the reported summer and winter peaks.
} 


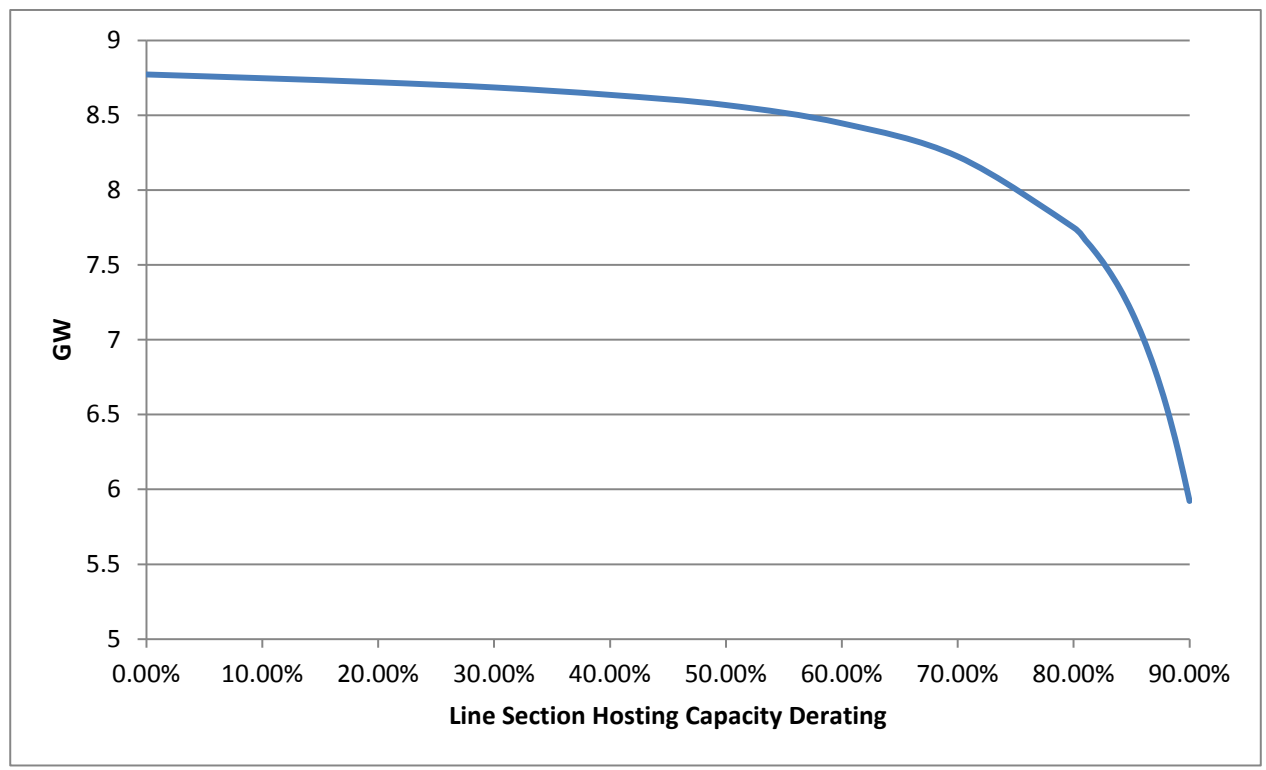

Figure 28. Estimate of PG\&E utility-wide DGPV hosting capacity as a function of line section derating showing that feeder-level hosting capacity limits dominate until the sum of line section hosting capacities are derated more than $60 \%$

Data from Pacific Gas and Electric 2015

\section{Bayesian Estimation of the Error Range}

Bayesian techniques were used to estimate the posterior distribution of possible total hosting capacity given the available data (Figure 29) (Gelman et al. 2014). Posterior sampling was implemented via the STAN probabilistic programming language (Carpenter and Gelman 2015). This resulted in a 90\% credible range of 10,420-45,862 MW for the available feeders, which scales with $75 \%$ simultaneity to $98,000-432,000 \mathrm{MW}$ for the contiguous United States.

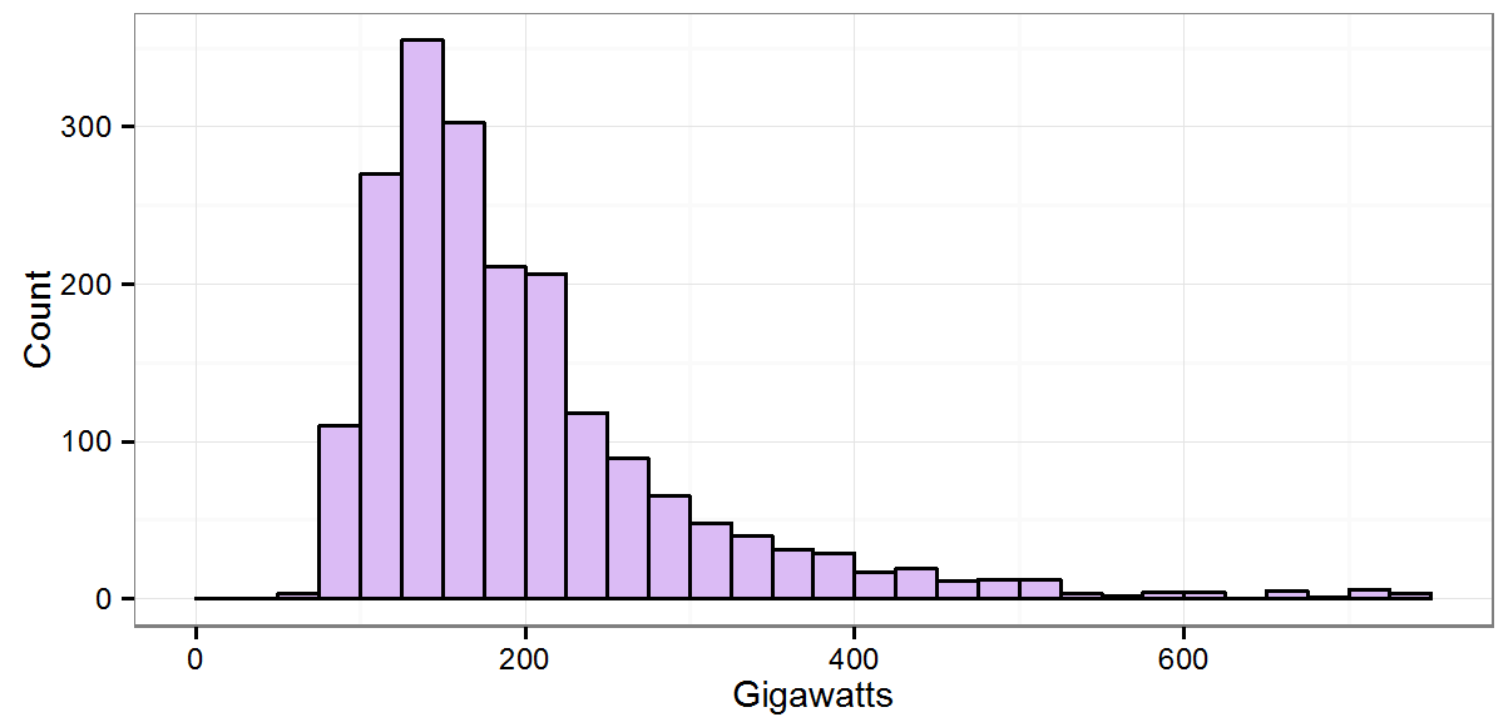

Figure 29. Histogram describing the distribution of aggregated hosting capacity estimates scaled to a national level

Posterior distribution of the aggregated hosting capacity is estimated using Bayesian inference. 


\section{Hosting Capacity Increases with Advanced Inverter Voltage Control}

The estimate of advanced inverters roughly doubling the hosting capacity is based on our analysis of 18 feeders' hosting capacity with and without advanced inverters, which found an average minimum hosting capacity increase of 1.5-3 times. This result was also consistent with the average increase ( 1.98 times) in hosting capacity seen among a partially synthetic population of 216 feeders if all voltage violations are fully corrected by advanced inverters. See Section 3.2.2 for further details. 